UNIVERSIDADE DE SÃO PAULO

FACULDADE DE ECONOMIA, ADMINISTRAÇÃO E CONTABILIDADE DEPARTAMENTO DE ADMINISTRAÇÃO PROGRAMA DE PÓS-GRADUAÇÃO EM ADMINISTRAÇÃo

RAFAEL MORAIS PEREIRA

RELAÇÕES INTERORGANIZACIONAIS E INOVAÇÃO: A IMPORTÂNCIA DOS DIFERENTES PARCEIROS E O FATOR LOCALIZAÇÃO 
Prof. Dr. Marco Antonio Zago

Reitor da Universidade de São Paulo

Prof. Dr. Adalberto Américo Fischmann

Diretor da Faculdade de Economia, Administração e Contabilidade

Prof. Dr. Roberto Sbragia

Chefe do Departamento de Administração

Prof. Dr. Moacir de Miranda Oliveira Júnior Coordenador do Programa de Pós-Graduação em Administração 
RAFAEL MORAIS PEREIRA

\section{RELAÇÕES INTERORGANIZACIONAIS E INOVAÇÃO: A IMPORTÂNCIA DOS DIFERENTES PARCEIROS E O FATOR LOCALIZAÇÃO}

Dissertação apresentada ao Programa de PósGraduação em Administração do Departamento de Administração da Faculdade de Economia, Administração e Contabilidade da Universidade de São Paulo, como requisito parcial para obtenção do título de Mestre em Ciências.

Orientador: Prof. Dr. Felipe Mendes Borini

\section{Versão Corrigida}

(versão original disponível na Biblioteca da Faculdade de Economia, Administração e Contabilidade)

SÃO PAULO 
FICHA CATALOGRÁFICA

Elaborada pela Seção de Processamento Técnico do SBD/FEA/USP

Pereira, Rafael Morais

Relações interorganizacionais e inovação: a importância dos diferentes parceiros e o fator localização / Rafael Morais Pereira. - São Paulo, 2017. $109 \mathrm{p}$.

Dissertação (Mestrado) - Universidade de São Paulo, 2017.

Orientador: Felipe Mendes Borini.

1. Inovação 2. Relações interorganizacionais 3. Evolução tecnológica 4. Cooperação tecnológica I. Universidade de São Paulo. Faculdade de Economia, Administração e Contabilidade. II. Título.

CDD -658.4 


\section{AGRADECIMENTOS}

Agradeço imensamente à minha família. Aos meus pais, Mariana e Carlos, pelo suporte e total confiança. Às minhas irmãs, Raquel, Juliete e Juliana, pelo companheirismo e apoio em todas as horas. A todos, que mesmo com a distância, acreditaram nas minhas escolhas.

Meu imenso agradecimento ao meu orientador professor Felipe Borini, pelas oportunidades, confiança, disponibilidade e amizade ao longo desses anos, que me fizeram amadurecer pessoal e profissionalmente.

Agradeço aos professores Alceu e Henrique pelas contribuições no exame de qualificação e pela participação em banca de defesa final. Agradeço também à professora Simone por ter aceito o convite para participação em minha banca de defesa.

Aos novos amigos da FEA, na nossa querida sala C13, o meu muito obrigado pelo compartilhamento dos desafios, oportunidades e aprendizados. Agradeço aos meus amigos de Boa Esperança e de Viçosa, que mesmo com a distância estiveram sempre comigo.

Obrigado ao PPGA, à FEA e à USP, por toda infraestrutura e qualidade dos profissionais, que permitiram a realização deste trabalho. Agradeço à CAPES pela bolsa de estudos, fundamental para que eu tivesse as condições necessárias para a realização do mestrado.

Quantas pessoas especiais fizeram parte desta conquista! Nos parágrafos que antecederam, ousei destacar algumas delas, mas para além desse esforço, deixo a minha enorme gratidão a todos aqueles que direta e indiretamente contribuíram nesta minha caminhada! 



\section{RESUMO}

O contexto de diferentes possibilidades de relações interorganizacionais com múltiplos parceiros, a visão mais ampla do que se entende por inovação e a necessidade de compreensão de diferentes especificidades dessa interação, como o desenvolvimento de imitação e o fator localização do parceiro, são pressupostos deste estudo. Dado esse cenário, a pergunta de pesquisa que norteou o desenvolvimento do trabalho foi qual a associação entre as relações interorganizacionais com diferentes parceiros e os resultados de inovação? A tese defendida nesta dissertação é que a associação entre as relações interorganizacionais com diferentes parceiros e os resultados de inovação é heterogênea. Ou seja, dado os resultados esperados de inovação, determinadas parcerias são mais importantes do que outras, em função das características particulares da relação. Diante do objetivo geral, de analisar a relação entre a cooperação com diferentes parceiros e o desenvolvimento de inovação, em especial, inovação de processos, esta dissertação foi estruturada em três artigos independentes, mas complementares para atingir aos objetivos propostos. No primeiro artigo realizou-se um levantamento da literatura sobre a associação entre as relações interorganizacionais e os diferentes resultados de inovação, considerando campos de estudo subjacentes, tipos, objetos, parceiros e características das relações. No segundo artigo, foi analisada a relação entre os parceiros de cooperação e o desenvolvimento de imitação de produtos e de processos e, no terceiro artigo, foi analisada a relação entre a localização do parceiro e o desenvolvimento de inovação de processos. A partir de uma revisão sistemática, no primeiro artigo, e da análise em painel dos dados da Pesquisa de Inovação (PINTEC), no segundo e no terceiro artigos, os resultados apresentaram evidências da tese proposta. De modo que foi evidenciado como a associação entre as relações interorganizacionais com diferentes parceiros e os resultados de inovação é heterogênea. Como contribuições, os resultados demonstraram, além do levantamento realizado na revisão sistemática, que o desenvolvimento de imitação de processo tem associação com a cooperação com centros de capacitação, mas não com fornecedores. Enquanto a imitação de produto se beneficia da alta importância dada à cooperação com clientes e não na cooperação com concorrentes. Em relação ao fator localização do parceiro, foi confirmado que o desenvolvimento da inovação de processo nível empresa está associado à cooperação com fornecedores de mesmo estado enquanto o desenvolvimento de inovação de processo nível mundial está associado à cooperação com fornecedores estrangeiros. Ainda, evidenciou-se que a cooperação com concorrentes estrangeiros está associada ao desenvolvimento de inovação de processo para o mercado nacional. Por fim, as evidências demonstraram a relevância da localização próxima dos centros de capacitação profissional e assistência técnica para a inovação de processo em menor grau de novidade assim como a importância das universidades e institutos de pesquisa estrangeiros, sobretudo, desenvolvidos, para o desenvolvimento de inovação com maior grau de inovatividade.

Palavras-chave: Inovação. Relações Interorganizacionais. Evolução Tecnológica. Cooperação Tecnológica. 



\begin{abstract}
The context of different possibilities of interorganizational relations with several partners, the broader view of innovation definition and the need to understand different specificities of this interaction, such as the development of imitation and the partner location factor, are assumptions of this study. Given this scenario, the research question that guided the development of this study refers to what is the association between interorganizational relations with different partners and the innovation outputs. The defended thesis in this dissertation is that the association between the interorganizational relations with different partners and the innovation outputs is heterogeneous. That means, considering the expected innovation outputs, certain partnerships are more important than others, depending on particular characteristics of the interaction among them. Regarding the general aim, wich was to analyze the relationship between cooperation with different partners and the development of innovation, especially process innovation, this dissertation was structured in three independent studies, but complementary to reach the proposed objectives. In the first study, a literature review was developed about the association between interorganizational relations and the different innovation outputs, considering underlying fields of study, types, objects, partners and characteristics of those relations. In the second study, the relationship between the cooperation partners and the development of products and processes imitation was analyzed and, in the third study, the relationship between the partner's location and the development of process innovation was analyzed as well. From a systematic review in the first study, and from a panel analysis of the Innovation Survey data (PINTEC) in the second and third studies, the results presented evidences of the proposed thesis. So, it was evidenced that the association between interorganizational relations with different partners and the innovation outputs is heterogeneous. As contributions the results demonstrated, in addition to the systematic review developed, that the process imitation has association with training centers cooperation, but not with suppliers. Whereas the product imitation is benefited from the high importance given to customers cooperation, not with competitors cooperation. Regarding to the partner location factor, it was confirmed that the development of the innovation at firm level is associated with the suppliers cooperation from the same State, while the development of world-class process innovation is associated with foreign suppliers cooperation. Moreover, it was evidenced that the cooperation with foreign competitors is associated to the development of process innovation for the national market. Finally, the finding showed the relevance of the firm's location to be near to training and technical assistance centers for process innovation to a lower degree, as well as the importance of the foreign universities and research institutes, especially from developed countries, for the development of process innovation with higher degree of innovation.
\end{abstract}

Keywords: Innovation. Interorganizational Relations. Technological Evolution. Technological Cooperation. 



\section{LISTA DE FIGURAS}

Figura 2.1. Termos de busca. 29

Figura 2.2. Visão das Estratégias de Relações Interorganizacionais e os Resultados de Inovação. 32

Figura 2.3. Resultados de Inovação e Parceiros orientados ao Mercado. 34

Figura 2.4. Resultados de Inovação e Parceiros orientados à Ciência. .35

Figura 2.5. Objeto das relações, contexto empírico e resultados de inovação. ....................... 37

Figura 3.1. Dimensões da Atualização Tecnológica. ................................................................ 44

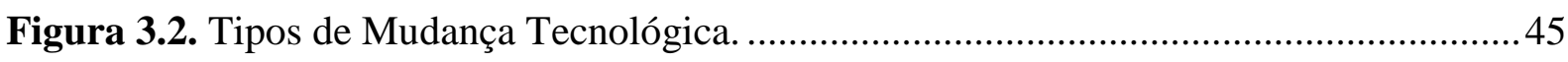

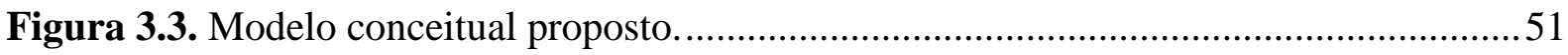

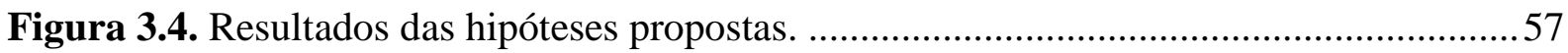

Figura 4.1. Modelo da Dinâmica da Inovação Tecnológica......................................................64

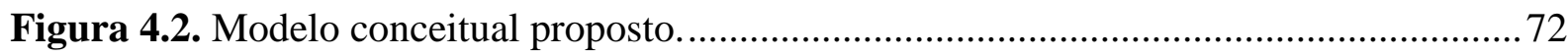

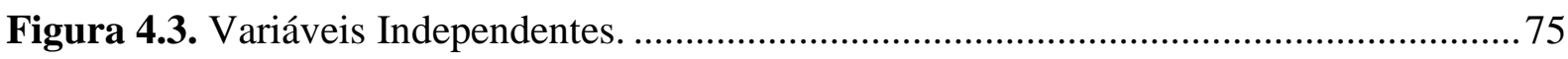

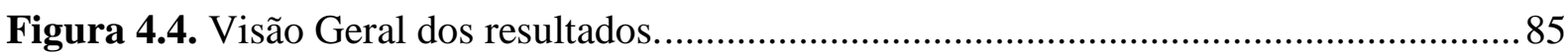





\section{LISTA DE TABELAS}

Tabela 3.1 Matriz de Correlação das variáveis dependentes e independentes 54

Tabela 3.2 Resultados das regressões para a variável dependente Imitação de Produto..........54

Tabela 3.3 Resultados das regressões para a variável dependente Imitação de Processo ........56

Tabela 4.1 Matriz de Correlação das variáveis dependentes e independentes ........................ 78

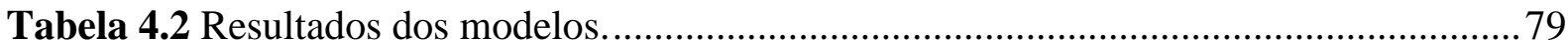

Tabela 4.3 Parceiros estrangeiros de regiões desenvolvidas. .................................................. 83 



\section{SUMÁRIO}

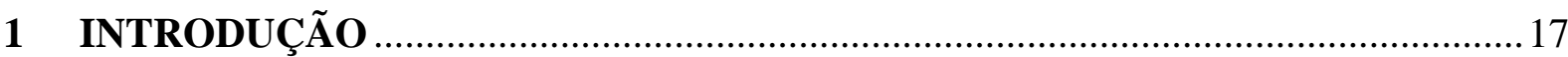

1.1. BREVE CONTEXTO DA INOVAÇÃO E COOPERAÇÃO NO BRASIL .......................... 18

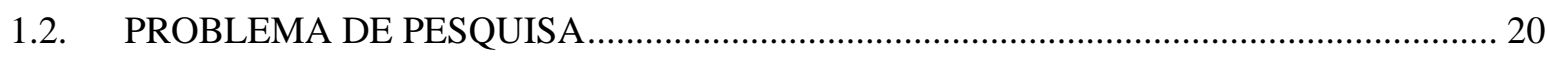

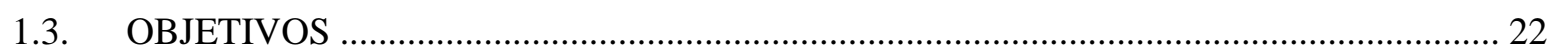

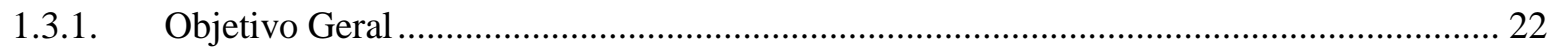

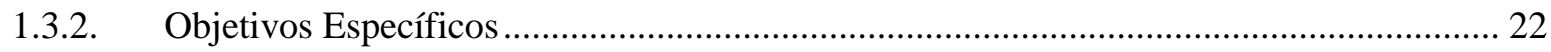

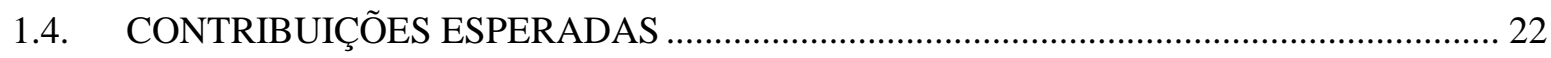

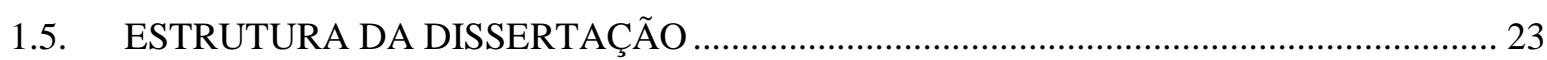

2 ARTIGO I - DINÂMICA DAS RELAÇÕES INTERORGANIZACIONAIS E INOVAÇÃO: UMA REVISÃO SISTEMÁTICA DA LITERATURA ............................ 25

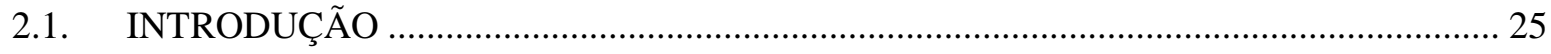

2.2. RELAÇÕES INTERORGANIZACIONAIS NOS ESTUDOS SOBRE INOVAÇÃO ........ 26

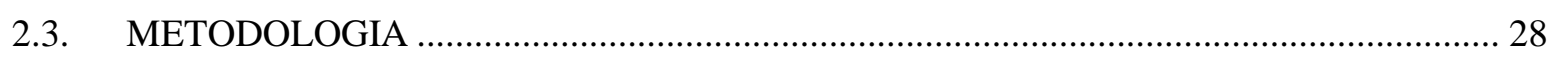

2.3.1. Identificação dos critérios de seleção inicial: termos de busca (Etapa 1) ........................ 29

2.3.2. Agrupamento das Publicações (Etapa 2) e Caracterização dos conjuntos (Etapa 3)......... 29

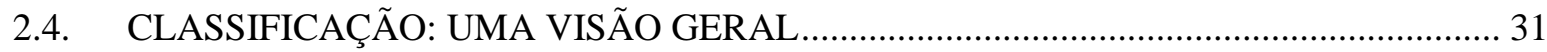

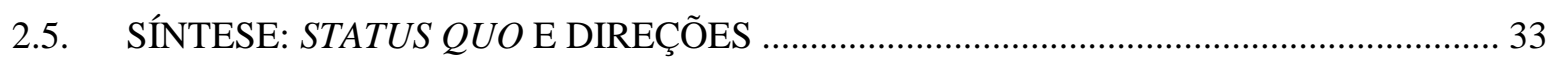

2.5.1. Diferentes Parceiros, Diferentes Resultados de Inovação ............................................... 33

2.5.2. Localização do Parceiro: Estar Próximo ou Distante? ...................................................... 35

2.5.3. Objeto da Relação: P\&D, Pesquisa ou Projeto? ................................................................. 36

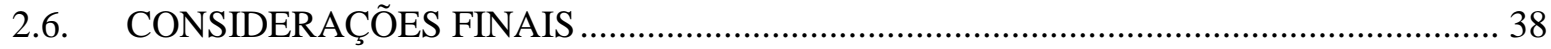

3 ARTIGO II - ATUALIZAÇÃO TECNOLÓGICA EM MERCADOS EMERGENTES: A IMPORTÂNCIA DA COOPERAÇÃO EXTERNA PARA O DESENVOLVIMENTO DE IMITAÇÃO DE PRODUTOS E DE PROCESSOS ............. 41

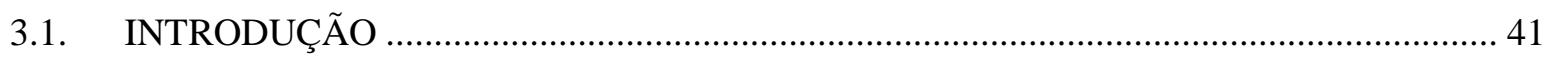

3.2. ATUALIZAÇÃO TECNOLÓGICA E COOPERAÇÃO INTERORGANIZACIONAL ..... 43

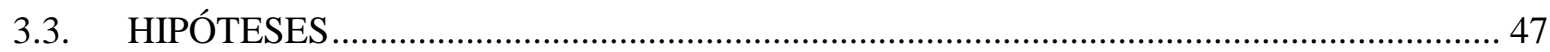

3.3.1. Importância do Modo de inovação doing, using and interacting (DUI) ............................ 47

3.3.2. Importância do Modo de inovação science, technology and innovation (STI) ................. 49

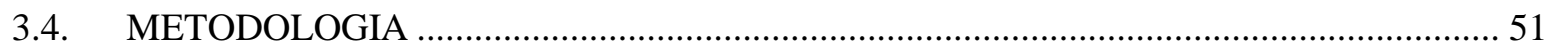

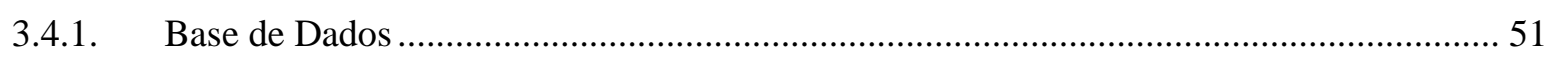

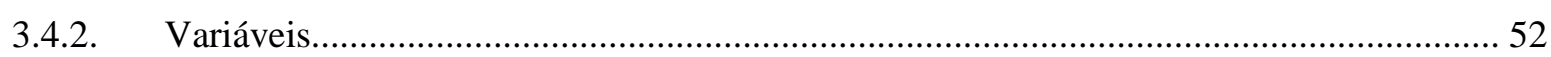

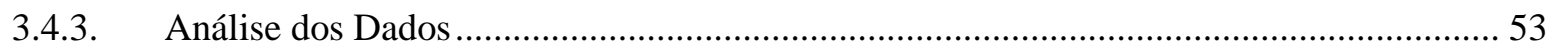

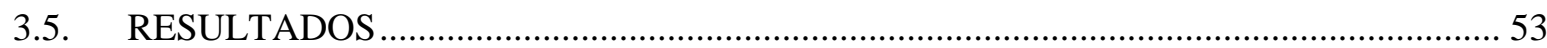

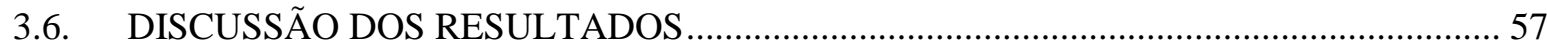

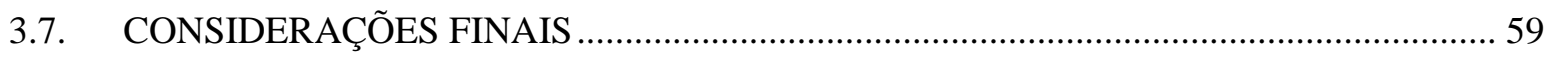


4 ARTIGO III - COOPERAÇÃO INTERORGANIZACIONAL E A INOVAÇÃO DE PROCESSO: A DINÂMICA DA LOCALIZAÇÃO NACIONAL VERSUS

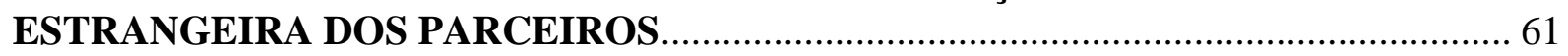

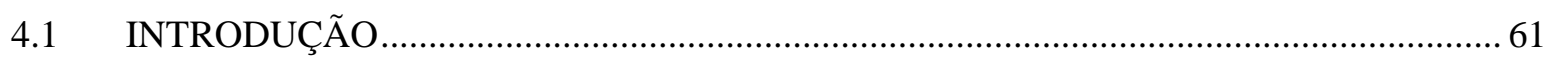

4.2 INOVAÇÃO DE PROCESSOS E A COOPERAÇÃO INTERORGANIZACIONAL ........ 63

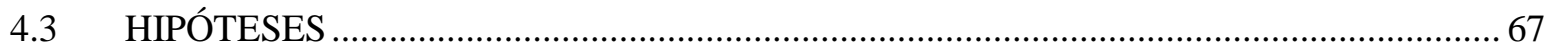

4.3.1 Localização no Modo de inovação doing, using and interacting (DUI) ............................ 67

4.3.2 Localização no Modo de inovação science, technology and innovation (STI)................... 69

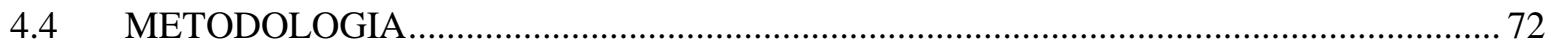

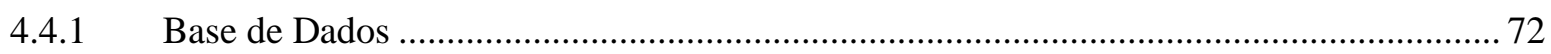

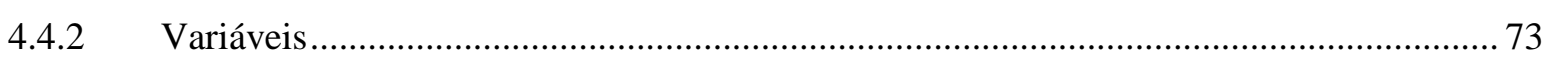

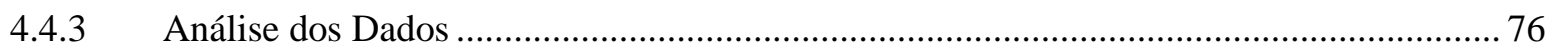

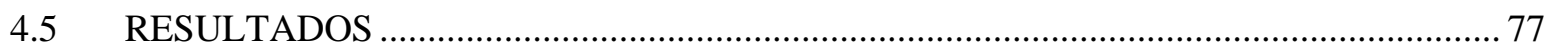

4.5.1 Análise Complementar: Parceiros Estrangeiros oriundos de países Desenvolvidos .......... 82

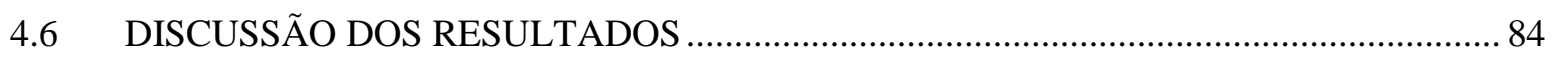

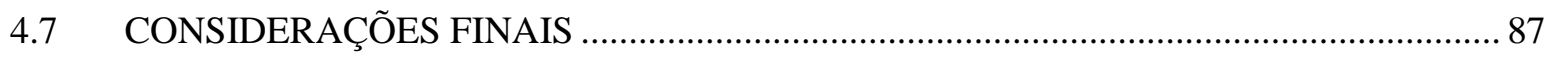

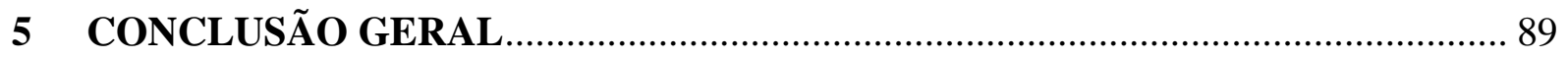

5.1 LIMITAÇÕES E SUGESTÕES PARA FUTURAS PESQUISAS ………………………....90

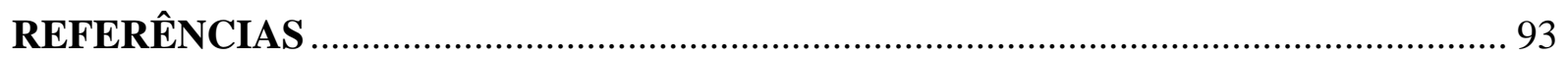

ANEXO A - Setores da Classificação Nacional de Atividades Econômicas..................... 109 


\section{INTRODUÇÃO}

A inovação é vista pelas empresas como uma fonte de competividade, para enfrentar a crescente concorrência de mercado (Fossas-Olalla, Minguela-Rata, López-Sánchez, \& FernándezMenéndez, 2015; Freel \& de Jong, 2009; Pan \& Li, 2016). Embora seja esse o objetivo, ser uma fonte de competitividade, a forma de como as empresas inovam evoluiu de uma perspectiva linear para uma dinâmica mais interativa e sistêmica. Entre as décadas de 1950 e 1990, cinco gerações principais foram identificadas. Na primeira geração, The Technology Push Theory, a tecnologia era "empurrada" para o mercado, enquanto na segunda, The Market Pull Theory, era "puxada" pelo mercado, sendo ambas caracterizadas pela perspectiva linear simples, de que ciência gera tecnologia, a qual satisfaz a necessidade do mercado e vice-versa (Dosi, 1982). Na terceira geração, The Coupling Innovation Process Theory, reconheceu-se uma perspectiva push-pull, na qual o processo é linear, mas não necessariamente sequencial. Já a quarta geração, The Functional Integration Innovation Process Theory, privilegiou o desenvolvimento de um conjunto de atividades paralelas e integração funcional. A quinta geração, The Systems Integration and Networking Innovation Process Theory, preconizou a inovação como um processo contínuo, resultante da ação conjunta de diversos atores (Rothwell, 1994).

No contexto em que as inovações passaram a ser socialmente construídas e não mais realizadas isoladamente (Nielsen, 2010), emergiram teorias específicas da temática, como Sistemas de inovação (SI) (Freeman, 1987; Lundvall, 1988, 1992a; Nelson, 1993), Hélice Tríplice (Etzkowitz \& Leydesdorff, 2000) e Inovação Aberta (Chesbrough, 2003). Dessa forma, o conceito de inovação assumiu uma conotação mais complexa, sendo definida como a produção ou a adoção, assimilação e exploração de uma novidade com valor adicionado nas esferas econômica e social; renovação e ampliação de produtos, serviços e mercados; desenvolvimento de novos modelos de produção; e o estabelecimento de novos sistemas de gestão (Crossan \& Apaydin, 2010).

A inovação tornou-se, portanto, mais dependente de relações interorganizacionais e estruturas institucionais, transcendendo as fronteiras organizacionais empresariais (Jaklič, Damijan, Rojec, \& Kunčič, 2014; Levén, Holmström, \& Mathiassen, 2014; Storbacka \& Nenonen, 2015). As organizações envolvidas nessas relações podem ser públicas, comerciais ou sem fins lucrativos e as relações podem variar de díade, envolvendo apenas duas organizações, à multiplicidade, envolvendo enormes redes de muitas organizações (Cropper, Ebers, Huxham, \& Ring, 2008). Nesse sentido, compreende consórcios, associações, redes, alianças, joint ventures, projetos, cooperação, colaboração, entre outros. Quanto aos atores participantes, também há uma diversidade (Dahlander \& Gann, 2010), como empresas pertencentes ao mesmo 
grupo, fornecedores, clientes, concorrentes, organizações públicas, grupos de interesse, universidades e institutos de pesquisa (Faria, Lima, \& Santos, 2010; Öberg \& Shih, 2014; Schøtt \& Jensen, 2016; Tsai, 2009). Esses parceiros podem ser classificados em dois grupos, que foram adotados nesta pesquisa. O primeiro, parceiros do modo de inovação doing, using and interacting (DUI) ou parceiros de mercado, compreende os clientes, fornecedores $\mathrm{e}$ concorrentes. No segundo grupo, o modo de inovação science, technology and innovation (STI) contempla os parceiros universidades, institutos de pesquisa e centros de capacitação profissional, que também podem ser denominados como parceiros orientados à ciência ou à pesquisa (Jensen, Johnson, Lorenz, \& Lundvall, 2007).

Na subseção seguinte, antes de prosseguir com a problematização da pesquisa, apresenta-se uma breve descrição do ambiente de inovação brasileiro, campo empírico adotado neste estudo.

\subsection{BREVE CONTEXTO DA INOVAÇÃO E COOPERAÇÃO NO BRASIL}

Orientado pelo Manual de Oslo (OECD, 2005), referência internacional dos estudos sobre inovação, o Instituto Brasileiro de Geografia e Estatística (IBGE), com o apoio do Ministério da Ciência, Tecnologia e Inovação e da Financiadora de Estudos e Projetos (Finep), desenvolve a Pesquisa de Inovação (PINTEC) no Brasil. A pesquisa tem como objetivo elaborar um conjunto de indicadores setoriais, nacionais e regionais, das atividades de inovação das empresas brasileiras (IBGE, 2014). Publicada desde 2002, com referência ao triênio (19982000), a sua sexta edição, PINTEC 2014, sistematiza a realidade recente da inovação no país, revelando alguns desafios.

A última edição da pesquisa revelou que, do universo de 132.529 empresas entrevistadas, 47.693 implementaram produtos ou processos novos ou significativamente aprimorados, ou seja, representando uma taxa geral de inovação de 36,0\% (IBGE, 2014). Em relação à edição anterior da Pesquisa, PINTEC 2011, configurou-se uma situação de estabilidade, em função da diferença de apenas 0,3\% acima do verificado anteriormente (35,7\%). Diante desse cenário, de estabilidade da taxa de inovação, inquietações sobre o desempenho do sistema de inovação brasileiro pairam, no sentido de que o mesmo necessita de mais estímulos ou ainda se já não alcançou o seu limite, não sendo capaz de responder aos desafios do mercado e aos estímulos das políticas públicas e das ações promotoras da inovação de modo mais consistente (IEDI, 2016).

Apenas 490 empresas declararam ter introduzido inovações de caráter mundial, o equivalente a $1,2 \%$ de todas as empresas inovadoras. São valores muito semelhantes aos observados na 
PINTEC 2011, quando 483 empresas declararam ter introduzido inovações no nível global. Além disso, $51 \%$ dessas inovações se referem a produtos ou processos completamente novo para a empresa, sendo o restante referente a aprimoramento de um produto ou processo já existente. Com relação a 2011, observou-se uma queda considerável, visto que 58\% dos casos se referiam a produtos ou processos completamente novos na pesquisa anterior. Esses dados revelam que o uso de estratégias baseadas em inovação para conquista de novos mercados ou maior parcela do mercado internacional ainda não está consolidada nas empresas brasileiras (IBGE, 2014).

A cooperação, por sua vez, tornou-se relevante para o desenvolvimento inovação, visto que empresas isoladamente podem ter dificuldades para reunir todas os recursos e competências necessários para implementar inovações (IBGE, 2014). Os indicadores de cooperação da PINTEC são apresentados como o percentual de empresas que cooperaram e que atribuíram importância alta ou média a cada um dos parceiros na cooperação ativa para inovar, no período 2012-2014. A cooperação voltou a decrescer na última edição, atingindo 14,3\% de empresas cooperando com algum tipo de parceiro, no âmbito industrial. Na PINTEC 2011, havia atingido 15,9\%, 5,8 pontos percentuais a mais em relação ao verificado na PINTEC 2008 (10,1\%). Quando se considera o porte das empresas, verifica-se que na indústria, 11,4\% das empresas inovadoras na faixa de 10 a 49 pessoas ocupadas cooperaram, ao passo que no conjunto daquelas com 500 ou mais pessoas ocupadas o valor foi de 44,5\%. Em ambas as faixas, os valores foram inferiores ao observado na PINTEC 2011 (13,1\% e 48,6\%, respectivamente). Os níveis de cooperação mais expressivos estão associados ao setor de eletricidade e gás, 55,0\% do total de empresas inovadoras cooperaram, sendo que, na faixa com 500 ou mais pessoas ocupadas, 95,0\% se envolveu em arranjos cooperativos. Nas empresas do setor de serviços, os percentuais foram maiores do que os percebidos na Indústria, 23,6\% do total de inovadoras em serviços cooperaram (IBGE, 2014).

Em relação à importância dos parceiros na cooperação, no setor industrial, destaca-se a relevância dos fornecedores, pois 76,1\% das empresas inovadoras os apontaram como de relevância alta ou média na cooperação. Na sequência, o segundo parceiro mais relevante foram os clientes ou consumidores, indicados por $70,5 \%$ das empresas inovadoras industriais. No segmento de serviços, os clientes ou consumidores se apresentaram como os principais parceiros $(80,0 \%)$, seguidos pelos fornecedores $(63,7 \%)$. No setor de eletricidade e gás, as universidades ou institutos de pesquisa se destacam (82,2\%), seguidos pelas empresas de consultoria $(63,0 \%)$ e pelos centros de capacitação profissional e assistência técnica $(54,3 \%)$. 
Na edição 2011, os principais parceiros haviam sido as universidades ou institutos de pesquisa (70,4\%) (IBGE, 2014).

\subsection{PROBLEMA DE PESQUISA}

Dado esse contexto (teórico e empírico) de diferentes possibilidades de relações interorganizacionais com múltiplos parceiros e de uma visão mais ampla do que se entende por inovação, a realização deste estudo se sustenta a partir de alguns aspectos principais. $O$ primeiro deles tem como cerne a própria diversidade de relações interorganizacionais existentes (Cropper et al., 2008; Tidd, Bessant, \& Pavitt, 2008). Haja vista que, diante de um domínio complexo com muitas possibilidades de interações, a associação com os distintos resultados de inovação (inovação de produto, de processo, organizacional, marketing, entre outros), também tende a ser diferenciada e o campo de estudos que analisa tais interações é disperso e pouco sistematizado. Estudos têm contemplado análises de setores específicos (Bygballe \& Ingemansson, 2014; Guan \& Liu, 2016) e pesquisas em diferentes regiões do mundo (Alnuaimi, Opsahl, \& George, 2012; Jaklič et al., 2014), enquanto no Brasil, pesquisas sobre cooperação foram realizadas por meio de estudos de casos (Botelho, Oliveira, \& Carrijo, 2013; Calia, Guerrini, \& Moura, 2007; Quandt, 2012). Com o presente estudo pretende-se avançar com o desenvolvimento de um levantamento, que não se esgote em si mesmo, mas que possibilite uma visão ampla das diferentes estratégias de relações interorganizacionais e os diversos resultados de inovação apresentados na literatura.

Um segundo aspecto diz respeito à atualização tecnológica, que pode possibilitar aos países emergentes uma nova oportunidade para desenvolver novas fontes de crescimento econômico (Ernst, 2008). Nesse contexto, como processo inicial, as empresas devem buscar a atualização tecnológica a partir da imitação, visto que esta pode ser considerada como uma estratégia alternativa para desenvolvimento de produtos, processos ou serviços tecnológicos (Jenkins, 2014). Desse modo, um tópico relevante que necessita de mais investigação é a compreensão das interações dinâmicas entre as empresas que se especializam em inovação ou em imitação (Cerqueti, Tramontana, \& Ventura, 2015). E como proposto por Ernst (2008), para ampliar a atualização tecnológica de um conjunto de empresas são necessárias indústrias de apoio fortes e vínculos com universidades, institutos de pesquisa, entre outros parceiros. O contexto externo, portanto, passa a ser relevante nesse processo. Nessa perspectiva, a associação da importância dos diferentes parceiros sobre a inovação com menor grau de novidade, ou seja, imitação, ainda 
carece de constatações mais convergentes. Haja vista que, embora seja sabido que os spillovers de diferentes fontes externas não só estimulam a inovação, mas também induzem a imitação, o último efeito é notadamente negligenciado (Cappelli, Czarnitzki, \& Kraft, 2014). Daí a proposta de associar a cooperação com diferentes parceiros e a imitação de produto e de processo.

Além disso, a inovação de processos, resultado de inovação com destaque adotado nesta dissertação, tem sido negligenciada na literatura, ao ser vista como um resultado secundário (Reichstein \& Salter, 2006; Rosenberg, 1982). Sua relevância compreende o fato de estar associada aos demais tipos inovação, visto que a concepção de um modelo inovativo consistente, pressupõe um processo articulado entre os diferentes esforços de inovação (Wagner \& Bode, 2014) e não tão somente associado ao clássico viés tecnológico da inovação de produto (Robertson, Casali, \& Jacobson, 2012). Ainda, a inovação de processos também se justifica por si só (Ettlie \& Reza, 1992; Reichstein \& Salter, 2006). Entendida como um processo mais interno da empresa, além de promover alterações significativas nas operações do dia-a-dia da organização (Robertson et al., 2012), possibilita reconhecer e adquirir melhores práticas externas e, diante disso, desenvolver novas soluções, alinhando capacidades internas e fontes externas (Un \& Asakawa, 2015). Ademais, considerando o contexto empírico deste trabalho, o Brasil, o que se evidencia é um maior desenvolvimento de inovação de processos quando comparado ao desenvolvimento de inovação de produtos (IBGE, 2014).

Uma última justificativa está atrelada à importância da dimensão localização do parceiro na associação entre as relações interorganizacionais e os resultados de inovação, pois esse aspecto se apresenta inconsistente na literatura. Apesar de vários trabalhos analisarem se a proximidade ou distância geográfica tem influência sobre o estabelecimento de relações com outras organizações (Abramo, D'Angelo, Di Costa, \& Solazzi, 2011; Hewitt-Dundas, 2013; Hoekman, Frenken, \& van Oort, 2009), alguns autores defendem a proximidade geográfica como um facilitador da colaboração, dado o caráter tácito do conhecimento (Owen-Smith \& Powell, 2004). Em contrapartida, essa perspectiva tem sido vista como excessivamente simplificada (Ponds, Van Oort, \& Frenken, 2007), ao não considerar os diferentes tipos de parceiros. Portanto, mesmo que tenha sido considerada como um antecessor da colaboração, os efeitos da localização do parceiro de uma relação já estabelecida sobre os resultados de inovação ainda carece de constatações empíricas, visto que a literatura especializada investiu muito mais esforço empírico na compreensão de relações próximas geograficamente, deixando de lado a análise das relações a longas distâncias (Grabher \& Ibert, 2014). 
Portanto, em função da multiplicidade de relações interorganizacionais estabelecidas com diferentes atores (Cropper et al., 2008), da relevância da concepção de inovação como um fenômeno multifacetado e aberto (Crossan \& Apaydin, 2010) e da necessidade de compreensão de diferentes especificidades dessa interação, como o desenvolvimento de imitação e o fator localização do parceiro, emergiu a seguinte questão de pesquisa: Qual a associação entre as relações interorganizacionais com diferentes parceiros e os resultados de inovação? A tese defendida nesta dissertação é que é heterogênea a associação entre as relações interorganizacionais com diferentes parceiros e os resultados de inovação. Ou seja, dado os resultados esperados de inovação, determinadas parcerias são mais importantes do que outras, em função das características particulares da relação. De modo específico, nos artigos teóricoempíricos, serão consideradas duas características das relações interorganizacionais: a importância dos parceiros para o desenvolvimento de imitação e a localização dos diferentes parceiros.

\subsection{OBJETIVOS}

\subsubsection{Objetivo Geral}

Analisar a relação entre a cooperação com diferentes parceiros e o desenvolvimento de inovação.

\subsubsection{Objetivos Específicos}

- Realizar um levantamento da literatura sobre a associação entre as relações interorganizacionais e os diferentes resultados de inovação, considerando campos de estudo subjacentes, tipos, objetos, parceiros e características das relações.

- Analisar a relação entre os parceiros de cooperação e o desenvolvimento de imitação de produtos e de processos.

- Analisar a relação entre a localização do parceiro e o desenvolvimento de inovação de processos, em seus diferentes graus de inovatividade.

\subsection{CONTRIBUIÇÕES ESPERADAS}

Espera-se contribuir para a literatura, com apresentação de evidências da tese defendida nesta dissertação, de que há uma heterogeneidade na associação entre as relações interorganizacionais com diferentes parceiros e os resultados de inovação. Desse modo, pretende-se evidenciar com os resultados da revisão sistemática empreendida no primeiro artigo e das análises estatísticas 
dos segundo e terceiro artigos que as associações com os parceiros de mercado e de ciência se apresentam de formas distintas com os resultados de inovação, corroborando a tese proposta. Para tanto, destaca-se o fato de adotar a classificação dos parceiros science, technology and innovation (STI) e doing, using and interacting (DUI), individualizando a importância e a localização de cada parceiro (Fitjar \& Rodriguez-Pose, 2013; Gonzalez-Pernia, Parrilli, \& Pena-Legazkue, 2015) e, considerando, ainda como campo empírico um país emergente numa dinâmica longitudinal, diferente de estudos anteriores (Ponds, Oort, \& Frenken, 2010; Su, Tsang, \& Peng, 2009).

\subsection{ESTRUTURA DA DISSERTAÇÃO}

Esta dissertação é formada, além desta introdução, por mais quatro capítulos. No capítulo 2 é apresentado o Artigo I - DINÂMICA DAS RELAÇÕES INTERORGANIZACIONAIS E INOVAÇÃO: UMA REVISÃO SISTEMÁTICA DA LITERATURA. Em seguida é apresentado o Artigo II - ATUALIZAÇÃO TECNOLÓGICA EM MERCADOS EMERGENTES: A IMPORTÂNCIA DA COOPERAÇÃO EXTERNA PARA O DESENVOLVIMENTO DE IMITAÇÃO DE PRODUTOS E DE PROCESSOS. Na sequência, no capítulo 3, é apresentado o Artigo III - COOPERAÇÃO INTERORGANIZACIONAL E A INOVAÇÃO DE PROCESSO: A DINÂMICA DA LOCALIZAÇÃO NACIONAL VERSUS ESTRANGEIRA DOS PARCEIROS. Todos os artigos são independentes, mas complementares, de modo a permitir a consecução do objetivo geral da dissertação. Ao final da dissertação são apresentadas as conclusões gerais e as referências utilizadas. 


\section{ARTIGO I - DINÂMICA DAS RELAÇÕES INTERORGANIZACIONAIS E INOVAÇÃO: UMA REVISÃO SISTEMÁTICA DA LITERATURA}

\subsection{INTRODUÇÃO}

O processo de inovação é um fenômeno aberto e não mais restrito ao ambiente organizacional interno (Kaufmann \& Tödtling, 2001; Tomlinson \& Fai, 2013). Nesse contexto, emerge a possibilidade das empresas se associarem a diferentes parceiros (Chen, Vanhaverbeke, \& Du, 2016), por meio de estratégias de relações interorganizacionais diversas, que incluem redes, alianças, joint ventures, entre outras formas de colaboração (Cropper et al., 2008; Tidd et al., 2008). Contudo, a literatura tem enfatizado mais os antecedentes e as motivações das relações interorganizacionais (Belderbos, Carree, Diederen, Lokshin, \& Veugelers, 2004; Faria et al., 2010; Hagedoorn, Link, \& Vonortas, 2000) do que a influência dessas relações sobre os distintos resultados de inovação.

Indo além, considerando que as empresas estabelecem relações externas a fim de obterem recursos que não dispõem (Bygballe \& Ingemansson, 2014; Gnyawali \& Park, 2011), a seleção dos parceiros deve ser subjacente aos resultados de inovação desejados. Resultados de inovação aqui entendidos como os tipos de inovação, produto, processo, organizacional, de marketing, entre outros (OECD, 2005). Desse modo, propôs-se a seguinte questão de pesquisa: Como a associação entre as relações interorganizacionais e os diferentes resultados de inovação tem sido estudada na literatura? A tese defendida é que, diante de um domínio complexo com muitas possibilidades de interações (Cropper et al., 2008; Dahlander \& Gann, 2010), a associação com os distintos resultados de inovação tem sido evidenciada como diferenciada e o campo de estudos que analisa tais interações é disperso e pouco sistematizado (Pittaway, Robertson, Munir, Denyer, \& Neely, 2004).

Diante disso, o objetivo deste artigo foi realizar um levantamento da literatura sobre a associação entre as estratégias de relações interorganizacionais e os diferentes resultados de inovação. Por meio da revisão sistemática da literatura realizada (Crossan \& Apaydin, 2010; Tranfield, Denyer, \& Smart, 2003), foram selecionados para o estudo 69 artigos, a partir da base ISI Web of Knowledge. Após a análise dos documentos selecionados, os resultados contribuem com uma classificação das diferentes estratégias de relações interorganizacionais com vistas à inovação, considerando campos de estudo subjacentes, tipos, objetos, parceiros e características das relações e resultados de inovação. 
Além disso, diante dos parceiros identificados, o estudo fornece uma visão ampla e dinâmica do processo de inovação oriundo de relações externas, possibilitando ao gestor selecionar os seus parceiros de acordo com os seus objetivos de inovação e ao dirigente público fomentar interações profícuas para a inovação. Por fim, para a academia, a tese defendida de heterogeneidade dos impactos dos diferentes parceiros sobre os resultados de inovação é corroborada. Os resultados evidenciam que as associações com os parceiros de mercado e de ciência se apresentam de formas distintas com os resultados de inovação.

A cooperação com fornecedores, por exemplo, pode ser considerada a mais profícua dentre os parceiros de mercado (Du, Leten, \& Vanhaverbeke, 2014; Fitjar \& Rodriguez-Pose, 2013; Nieto \& Santamaria, 2007; Tomlinson \& Fai, 2013). A cooperação com clientes é associada positivamente somente à inovação de produto em alguns estudos (Gesing, Antons, Piening, Rese, \& Salge, 2015), e, quanto à cooperação com concorrentes, são identificados resultados positivos, negativos e nulos sobre os diferentes resultados de inovação (Bougrain \& Haudeville, 2002; Gonzalez-Pernia et al., 2015; Un \& Asakawa, 2015), evidenciando um campo que ainda necessita de mais constatações empíricas. Por outro lado, o efeito da associação com universidades e institutos de pesquisa sobre os resultados de inovação é mais relevante dentre todos os parceiros identificados (Baba, Shichijo, \& Sedita, 2009; Belderbos, Carree, \& Lokshin, 2006), o que se configura, sobretudo, no suporte em uma literatura própria que tem sido desenvolvida e aprimorada (Geuna \& Muscio, 2009). Nesse intento, pesquisas futuras que analisem os diferentes intervenientes no processo de colaboração universidade e empresa também são bem-vindas (Perkmann \& Walsh, 2007).

\subsection{RELAÇÕES INTERORGANIZACIONAIS NOS ESTUDOS SOBRE INOVAÇÃO}

Os primórdios dos estudos no campo da inovação remontam às descobertas de Schumpeter (1912), principalmente no que diz respeito à relação entre esse fenômeno e o processo de crescimento econômico das nações (Van de Ven, 1986). Daí, ao longo do século XX, diversos estudiosos dedicaram-se a compreender a temática da inovação a partir de diferentes modelos, o que resultou numa evolução conceitual da dinâmica desse campo (Edquist \& Hommen, 1999; OECD, 1997; Rothwell, 1994).

Duas grandes frentes teóricas são definidas por Edquist e Hommen (1999), o modelo linear e o modelo sistêmico da inovação. A perspectiva linear, difundida desde a Segunda Guerra Mundial, preconiza a visão de que ciência gera tecnologia, a qual satisfaz a necessidade do 
mercado. Nesse sentido, supõe um fluxo unidirecional, no qual não há feedback, resultando numa perspectiva simplista de se conceber o fenômeno da inovação. Contrariamente, fundado no final dos anos 1980, o modelo sistêmico do processo de inovação, ou abordagem sistêmica, conduz a uma análise mais completa, ao reconhecer as interdependências complexas e as interações entre os vários elementos do processo de inovação (Edquist \& Hommen, 1999).

Dado que as inovações são socialmente construídas, não devendo, portanto, ocorrer de forma isolada (Nielsen, 2010), emergiu na literatura especializada o quadro conceitual mais dominante para a compreensão dos processos de inovação, os chamados Sistemas de inovação (SI) (Mahroum \& Al-Saleh, 2013). Formulado pela primeira vez na obra de Freeman (1987), os SI foram utilizado para explicar o sucesso econômico do Japão, com foco nos setores de alta tecnologia. Contemporaneamente, a importância da abordagem sistêmica da inovação era revelada por Lundvall (1988), a partir do estudo de interações sociais entre fornecedores e clientes e o seu papel no estímulo a esse processo. Posteriormente, as conceituações iniciais foram aperfeiçoadas e consolidadas por Nelson (1993), Edquist (1997) e OECD (1997), teórica e empiricamente (Buesa, Heijs, Pellitero, \& Baumert, 2006; Martin, 2012).

Em síntese, a concentração de um conjunto de organizações, públicas e privadas, em uma determinada área geográfica e a interação entre esses atores visando à geração, difusão e exploração do conhecimento, caracterizaram os SI (Wonglimpiyarat, 2011). Portanto, a concepção de inovação com um processo coletivo e interativo é a principal mensagem da conceituação dos SI, na perspectiva de Mahroum e Al-Saleh (2013). Nas últimas décadas, houve uma expansão de novos conceitos de SI com foco em outros níveis da economia diferentes do Estado-nação, como os estudos sobre os sistemas tecnológicos, sistemas setoriais de inovação e sistemas regionais de inovação (Tödtling \& Trippl, 2005).

Dada a efervescência dos trabalhos sobre os sistemas de inovação, a partir da década de 1990, estudos sobre redes, colaboração e cooperação interorganizacional e inovação aberta ganharam notoriedade na literatura de inovação. Martin (2012) sintetiza os principais autores. Um dos primeiros a explorar o porquê as empresas colaboraram em seus esforços tecnológicos foi Hagedoorn (1993), enquanto Powell, Koput e Smith-Doerr (1996) descreveram como, em campos caracterizados pelo rápido desenvolvimento tecnológico, o local da inovação é cada vez mais encontrado em redes de aprendizado e não em empresas individuais. Além disso, os autores destacam os trabalhos de Etzkowitz e Leydesdorff (2000) sobre Hélice Tríplice, de Chesbrough (2003) sobre Inovação Aberta e de Von Hippel (2005) sobre a "democratização" da inovação. No bojo da discussão dessas diferentes abordagens, está o "como" as empresas 
cooperam, ou seja, o estudo dos diferentes parceiros envolvidos na cooperação torna-se um fator de interesse relevante.

\subsection{METODOLOGIA}

Diante do objetivo de realizar um levantamento da literatura sobre a associação entre as estratégias de relações interorganizacionais e os diferentes resultados de inovação, o método de revisão sistemática da literatura foi selecionado (Tranfield et al., 2003). O objetivo desse método é a caracterização consistente de um campo fragmentado, a partir de procedimentos sistemáticos de coleta de dados, técnicas de análise de dados descritivas e qualitativas e síntese teoricamente fundamentada (Crossan \& Apaydin, 2010). Para conduzir uma revisão da literatura consistente e com rigor científico e metodológico, o procedimento de três estágios de Tranfield et al. (2003) foi seguido, que consiste em planejamento, execução e relato (apresentação/publicação). O estudo de Crossan e Apaydin (2010), realizado sobre a literatura de inovação, também foi adotado como referência. Durante a etapa de planejamento, foram definidos o objetivo da pesquisa e a fonte de coleta de dados. O objetivo do artigo foi intencionalmente específico, consistindo em realizar um levantamento da literatura sobre a associação entre as estratégias de relações interorganizacionais e os diferentes resultados de inovação. A base de dados do ISI Web of Knowledge foi escolhida como banco de dados de registro, uma vez que é um dos bancos de dados mais abrangentes de revistas científicas. A priori, foram utilizados todos os anos disponíveis na base de dados no momento da pesquisa: de 1900 a 2016 (12 de dezembro).

A segunda etapa do processo de revisão sistemática, a execução, consistiu em cinco etapas (Crossan \& Apaydin, 2010): (1) identificação dos critérios de seleção inicial - termos de busca; (2) agrupamento das publicações; (3) caracterização dos conjuntos de publicações; (4) classificação dos resultados e (5) síntese. As três primeiras etapas dizem respeito aos procedimentos metodológicos de coleta e organização dos dados, portanto são descritas na sequência, e as duas últimas etapas envolvem processamento e análise de dados, portanto são apresentadas nas seções de resultados. 
2.3.1. Identificação dos critérios de seleção inicial: termos de busca (Etapa 1)

A pesquisa inicial na base de dados, a partir do objetivo proposto e da literatura, foi realizada utilizando um comando completo que incluiu as diversas associações (combinações) possíveis entre os itens componentes de três grupos de palavras-chave (Figura 2.1).

\begin{tabular}{|c|c|c|c|c|c|}
\hline Termo Principal & Tipo de Relação & \multicolumn{4}{|c|}{ Parceiro da Relação } \\
\hline \multirow{5}{*}{ Innovation } & \multirow{5}{*}{$\begin{array}{l}\text { Cooperat* } \\
\text { Collaborat" } \\
\text { Network } \\
\text { Partner }\end{array}$} & Market & Consumer & Research Institut* & Test* Institut* \\
\hline & & Research & Supplier & Research Center* & Test* Center ${ }^{*}$ \\
\hline & & Trading & Competitor & Training Institut* & Certification* Institut* \\
\hline & & Knowledge & Consult* & Training Center* & Certification* Center ${ }^{*}$ \\
\hline & & Customer & Universit* & Assistance & Certification* \\
\hline
\end{tabular}

Figura 2.1. Termos de busca.

Fonte: Elaborado pelo Autor. Obs.: o caractere * considera os derivados do termo em questão.

O comando completo foi usado no campo Tópico (título, palavras-chave ou resumo), os tipos de documentos foram "artigo" e "revisão" e não foi considerada nenhuma outra restrição na busca inicial. Foram recuperados em uma amostra inicial um total de 1.101 trabalhos.

\subsubsection{Agrupamento das Publicações (Etapa 2) e Caracterização dos conjuntos (Etapa 3)}

Considerando o roteiro de Crossan e Apaydin (2010), foi adotada uma classificação dos trabalhos em 3 grupos. O primeiro grupo de interesse (Grupo 1) consistiu em revisões e metaanálises. O segundo grupo (Grupo 2) neste estudo foi obtido aplicando-se critérios de seleção baseados no número de citações da amostra inicial. Por fim, considerando os vícios de citações e os atrasos, no Grupo 3, foram isoladas as publicações mais recentes (2011-16), às quais foram aplicados diferentes critérios de seleção, como explicado na sequência.

Grupo 1: Revisões e meta-análises. Para identificar revisões e meta-análises, a pesquisa foi restrita a artigos com o comando completo no tópico (título, palavras-chave ou resumo) e os termos "review" ou "meta" também no tópico do artigo. Esta pesquisa resultou em 52 artigos, mas apenas 8 foram de fato revisões ou meta-análises no sentido analítico adequado, e, dentre esses, 6 artigos eram muito específicos (por exemplo, estudos restritos à pesquisa interdisciplinar, redes escolares, modos de aprendizagem, empresa estendida), portanto foram excluídos. Restaram no Grupo 1, 2 artigos, que de fato corroboram os objetivos do estudo.

Grupo 2: Artigos altamente citados. A partir da amostra inicial de 1.101 artigos, que tiveram o comando completo no tópico, foram identificados 113 documentos de alto impacto, caracterizados por apresentarem uma média de pelo menos cinco citações por ano (até o ano da 
busca - 2016) (Crossan \& Apaydin, 2010), sendo esta uma informação disponível na base. Após a leitura dos resumos e dos textos completos, quando necessário, este grupo foi reduzido a 38 artigos que contribuíram para o desenvolvimento do estudo. Os critérios de exclusão foram considerados de forma conservadora, favorecendo a inclusão em relação à exclusão. Assim, foram excluídos artigos que abordavam campos específicos (química, computação, agricultura, saúde, entre outros) ou não estavam associados ao nível de relações interorganizacionais, ou seja, externas à empresa. Um trabalho, por ser revisão de literatura foi excluído do Grupo 2, pois já estava associado ao Grupo 1, resultando em 37 trabalhos nesse grupo.

Grupo 3: Artigos recentes. Reconhecendo que o método baseado em citações pode discriminar as publicações recentes, um grupo dos artigos mais recentes foi formado. Como os critérios baseados na citação não puderam ser utilizados, um critério de qualidade alternativo foi aplicado para fins de limitação de dados. Com base na premissa de que as principais revistas normalmente publicam trabalhos de alta qualidade, a busca dos documentos mais recentes foi restrita apenas àqueles publicados em top journals, prática já utilizada em revisões no campo da administração (Fastoso \& Whitelock, 2010; Michailova \& Mustaffa, 2012; Rawhouser, Villanueva, \& Newbert, 2016). Para tanto, foi adotado o ranking de top journals associados à área de gestão da tecnologia e inovação desenvolvido por Linton e Thongpapanl (2004) e atualizado por Thongpapanl (2012), que já foi adotado em outros trabalhos (Ratinho, Harms, \& Walsh, 2015; West \& Bogers, 2014). No ranking, os autores discriminam journals generalistas de gestão, que consideram a temática de tecnologia e inovação em suas publicações, e journals especializados na área. Portanto, foram considerados os dez melhores generalistas e os dez melhores especializados para a realização da busca desse grupo.

Além disso, para ratificar e validar a qualidade atual dos journals identificados foi realizada uma consulta a diferentes sistemas de avaliação de periódicos, que confirmaram a qualidade deles. Os sistemas considerados foram: Academic Journal Guide 2015 da Chartered Association of Business Schools, Journal Citation Reports 2015 da Thomson Reuters, SCImago Journal and Country Rank 2015 da Scopus e CWTS Journal Indicators 2015 da Centre for Science and Technology Studies (CWTS) da Universidade de Leiden.

Diante disso, os journals especializados selecionados foram: Research Policy, Journal of Technology Transfer, Technological Forecasting and Social Change, Technovation, Journal of Product Innovation Management, R\&D Management, Research-Technology Management, Industrial and Corporate Change, Journal of Engineering and Technology Management $\mathrm{e}$ IEEE Transactions on Engineering Management. E os journals generalistas foram: Strategic 
Management Journal, Management Science, Harvard Business Review, Organization Science, MIT Sloan Management Review, Academy of Management Journal, Journal of Marketing, Journal of Business Venturing, Academy of Management Review e American Economic Review. Portanto, no Grupo 3 foi considerado o comando completo no tópico, artigos e revisões e os 20 top journals selecionados, resultando em 233 trabalhos. Desse total, 53\% foram publicados a partir de 2011. Assim, o período de 2011 a 2016 foi utilizado como critério de recência, o que resultou em 124 trabalhos. Após a leitura dos resumos e do texto completo, quando necessário, restaram 35 artigos, que contribuíram para o desenvolvimento da pesquisa. Assim como no grupo anterior, a necessidade de exclusão foi realizada de modo cauteloso, ocorrendo somente devido a não aderência do trabalho aos objetivos de pesquisa. Desse modo, as principais justificativas de exclusão foram relacionadas a estudos que analisaram os antecedentes das relações interorganizacionais e não a sua associação com os resultados de inovação, trabalhos com caráter estritamente descritivo do setor científico e tecnológico de determinado país, assim como, estudos que focalizaram a perspectiva de relação entre indivíduos ou na rede interna da empresa. Apesar de serem recentes, 5 artigos neste grupo tiveram uma média de citação superior a cinco por ano, portanto já estavam incluídos no Grupo 2, logo, foram excluídos para evitar a duplicação intergrupo. No Grupo 3 restaram 30 documentos. Ao final, foram obtidos 2 artigos no Grupo 1, 37 artigos no Grupo 2 e 30 artigos no Grupo 3, totalizando um conjunto de 69 artigos para a classificação e síntese dos dados, que são analisados nas seções subsequentes.

\subsection{CLASSIFICAÇÃO: UMA VISÃO GERAL}

Para a classificação e tipologia dos dados, penúltima etapa do processo de revisão (Crossan \& Apaydin, 2010), a literatura identificada foi classificada em dois grupos: estratégias das relações interorganizacionais e os resultados de inovação encontrados no estudos (Figura 2.2). 


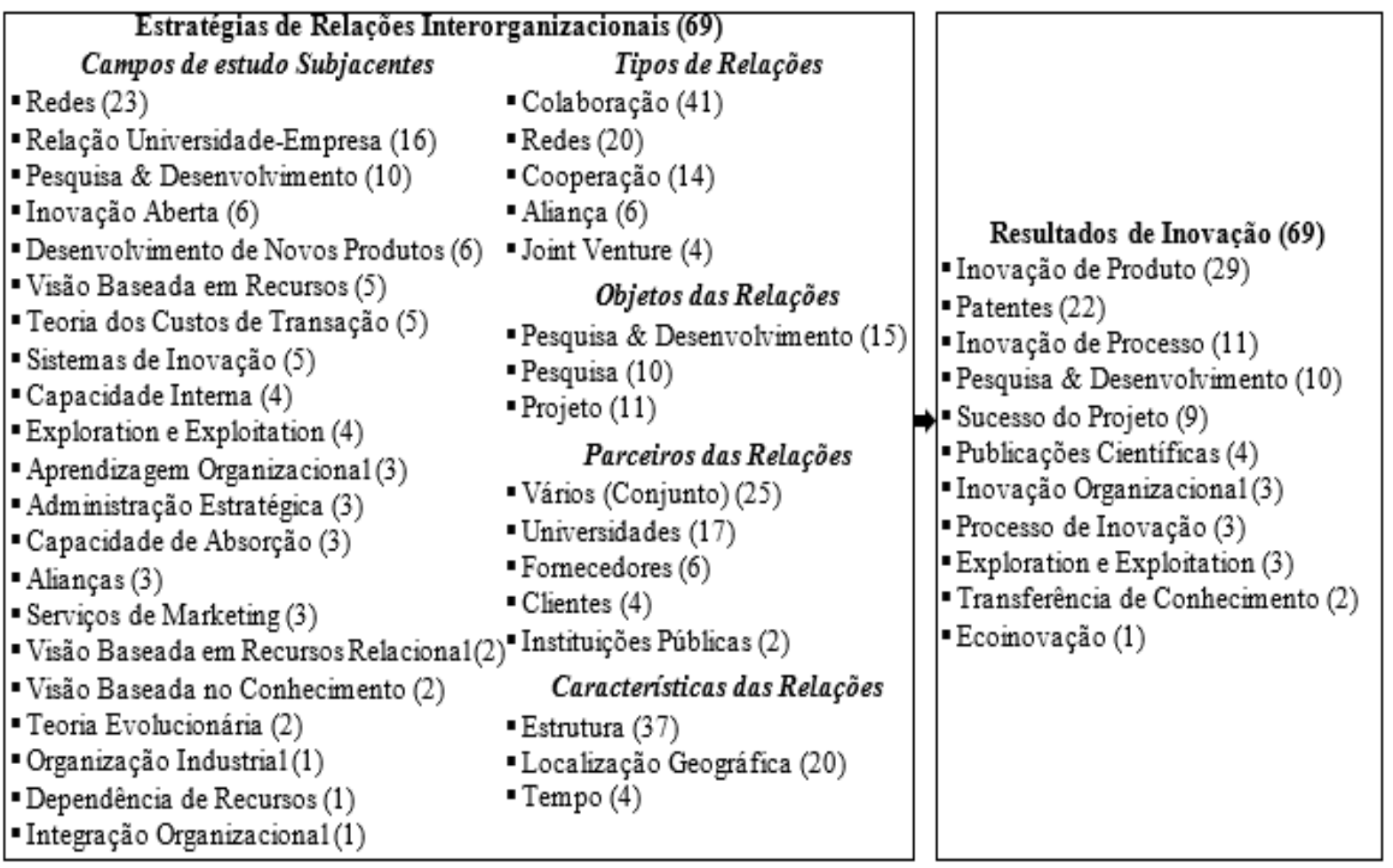

Figura 2.2. Visão das Estratégias de Relações Interorganizacionais e os Resultados de Inovação.

Fonte: Elaborado pelo Autor. Obs.: Entre parênteses são os números de estudos associados ao tópico em questão.

Primeiramente, o que é se evidencia é o uso de um campo teórico diversificado, com temáticas de estudos consolidadas na temática da administração das organizações, que apresentam óticas internas, como a Visão Baseada em Recursos e externas, como Redes. A temática da inovação, apesar de ser um corpo interdisciplinar e multidisciplinar (Crossan \& Apaydin, 2010), tem promovido a ascensão de algumas vertentes teóricas próprias da área, como Inovação Aberta e Sistemas de Inovação. Áreas tradicionais também foram referenciadas, como estratégia, operações e marketing. Em geral, as diferentes estratégias de relações interorganizacionais associadas ao campo da inovação se sustentam em arcabouço teórico vasto, o que tem consequências positivas e negativas. Por um lado, a promoção da inovação como objetivo das organizações se fortalece, haja vista o suporte teórico em diferentes disciplinas. Em contrapartida, a consolidação de um corpo teórico particular, mesmo que diversificado, se distancia diante desse contexto.

A colaboração é o tipo de relação mais recorrente nos estudos, seguida pelas redes e cooperação. Ademais, os tipos se entrelaçam, de modo que são identificadas redes de cooperação, redes de colaboração, alianças cooperativas (Hofman, Halman, \& van Looy, 2016; Zeng, Xie, \& Tam, 
2010). Quanto ao objeto das relações, este por vezes é desconsiderado, visto que dentre os estudos, somente $52 \%$ especificaram de forma clara o objeto da relação estabelecida. No que se refere aos parceiros, a maior parte dos estudos analisa conjuntamente a associação entre os distintos parceiros e os resultados de inovação (Kaufmann \& Tödtling, 2001), por vezes, classificados em dois grupos, como modo de inovação doing, using and interacting (DUI) e science, technology and innovation (STI) (Fitjar \& Rodriguez-Pose, 2013), ou orientados à ciência e orientados ao mercado (Du et al., 2014), ou, ainda, interação vertical e horizontal (Tsai, 2009). Enquanto análise individual dos parceiros, o relacionamento com universidades se destaca, de modo que se constitui como uma literatura particular dentre os diferentes tipos de relações interorganizacionais (Gonzalez-Pernia et al., 2015; Perkmann \& Walsh, 2007).

A estrutura das relações interorganizacionais com vistas à inovação compreende analisar a quantidade de parceiros (Becker \& Dietz, 2004), o modo de governança (Arranz \& de Arroyabe, 2012; Thorgren, Wincent, \& Ortqvist, 2009) e as diferenças hierárquicas, de objetivos e culturais (Ibert \& Muller, 2015). Além disso, a importância de se considerar a localização dos parceiros é um ímpeto, no qual não há um consenso (Ponds et al., 2010), assim como, os efeitos do tempo sobre as relações (Nieto \& Santamaria, 2007).

Em relação aos resultados de inovação, as principais formas de mensurá-los são inovação de produto, patentes, inovação de processo, pesquisa e desenvolvimento e projetos. A inovação de produto se consolida como o principal resultado de inovação e compreende tanto a perspectiva de lançamento de novos produtos (Nieto \& Santamaria, 2007) quanto as vendas oriundas de novos produtos (Belderbos, Carree, \& Lokshin, 2004). Já a patente, seja mensurada pela quantidade, citações ou índices de classes e considerada como um indicador controverso, ainda é muito utilizada (Baba et al., 2009; Huang \& Yu, 2011). Destaca-se também a inovação de processo (Un \& Asakawa, 2015), que por vezes é analisada conjuntamente com a inovação de produto (Robin \& Schubert, 2013; Su et al., 2009).

\subsection{SÍNTESE: STATUS QUO E DIREÇÕES}

\subsubsection{Diferentes Parceiros, Diferentes Resultados de Inovação}

Diante de tantas possibilidades de relações interorganizacionais, a partir dos estudos empíricos com abordagem quantitativa, são apresentados quais os diferentes parceiros de fato estão associados aos diferentes resultados de inovação. Para tanto, foram considerados dois grupos 
de parceiros: orientados ao mercado (ou modo de inovação $D U I$ ), conforme Figura 2.3, e orientados à ciência (modo de inovação STI), conforme Figura 2.4.

\begin{tabular}{|c|c|c|c|}
\hline Inovação & Relação & Parceiro & Estudos \\
\hline \multirow{7}{*}{$\begin{array}{l}\text { Inovação } \\
\text { de } \\
\text { Produto }\end{array}$} & \multirow{3}{*}{ Positiva } & CLI & $\begin{array}{l}\text { (Belderbos et al., 2015; Chen et al., 2016; Fitjar \& Rodriguez-Pose, 2013; Gesing et al., 2015; } \\
\text { Gonzalez-Pernia et al., 2015; Nieto \& Santamaria, 2007; Tomlinson, 2010; Zeng et al., 2010) }\end{array}$ \\
\hline & & FOR & $\begin{array}{l}\text { (Belderbos et al., 2006; Belderbos et al., 2015; Chen et al., 2016; Fitjar \& Rodriguez-Pose, } 2013 \\
\text { González-Pernia et al., 2015; Kaufmann \& Tödtling, 2001b; Nieto \& Santamarí, 2007; Tomlinson } \\
\text { \& Fai, 2013; Zeng et al., 2010) }\end{array}$ \\
\hline & & CONC & (Belderbos et al., 2004, 2006; Belderbos et al., 2015; Gonzalez-Pernia et al., 2015; Zeng et al., 2010) \\
\hline & Negativa & CONC & (Fitjar \& Rodriguez-Pose, 2013; Nieto \& Santamaria, 2007) \\
\hline & \multirow{3}{*}{ Nula } & CLI & (Belderbos et al., 2004, 2006; Kaufmann \& Tödtling, 2001a; Su et al., 2009; Tsai, 2009) \\
\hline & & FOR & (Belderbos et al., 2004; Su et al., 2009; Tsai, 2009) \\
\hline & & CONC & (Chen et al., 2016; Su et al., 2009; Tomlinson \& Fai, 2013; Tsai, 2009) \\
\hline \multirow{5}{*}{$\begin{array}{l}\text { Inovação } \\
\text { de } \\
\text { Processo }\end{array}$} & Positiva & FOR & (Fitjar \& Rodriguez-Pose, 2013; Tomlinson \& Fai, 2013; Un \& Asakawa, 2015) \\
\hline & Negativa & CONC & (Un \& Asakawa, 2015) \\
\hline & \multirow{3}{*}{ Nula } & CLI & (Fitjar \& Rodriguez-Pose, 2013; Su et al., 2009; Tomlinson \& Fai, 2013; Un \& Asakawa, 2015) \\
\hline & & FOR & (Su et al., 2009) \\
\hline & & CONC & (Fitjar \& Rodriguez-Pose, 2013; Su et al., 2009; Tomlinson \& Fai, 2013) \\
\hline \multirow{4}{*}{ Projeto } & \multirow{2}{*}{ Positiva } & CLI & (Du et al., 2014) \\
\hline & & FOR & (Bougrain \& Haudeville, 2002; Du et al., 2014) \\
\hline & \multirow{2}{*}{ Nula } & CLI & (Bougrain \& Haudeville, 2002) \\
\hline & & CONC & (Bougrain \& Haudeville, 2002) \\
\hline
\end{tabular}

Figura 2.3. Resultados de Inovação e Parceiros orientados ao Mercado.

Fonte: Elaborado pelo Autor.

Em relação aos parceiros orientados ao mercado (Figura 2.3), que compreendem clientes/consumidores e fornecedores (relação vertical) e concorrentes (relação horizontal), três conclusões principais são evidenciadas. Primeiramente, uma maior consistência na relevância das relações com fornecedores foi verificada. Elas se apresentam como mais profícuas na associação com a inovação de produtos em relação aos outros parceiros deste grupo (Belderbos, Carree, Lokshin, \& Sastre, 2015), são unanimidade em termos de associação com a inovação de processo e, ainda, se apresentam como significativas nos resultados de inovação de projetos (Bougrain \& Haudeville, 2002; Du et al., 2014). Além disso, ainda que alguns estudos não tenham encontrado relações significativas, a associação com clientes na inovação de produtos foi identificada em alguns estudos. Um terceiro aspecto é o relacionamento com os concorrentes (ou competidores). Mesmo vários estudos explorando tal relação contraditória, os impactos sobre os resultados de inovação não são um consenso, sendo associados a perspectivas positivas (Belderbos, Carree, \& Lokshin, 2004), negativas (Chen et al., 2016) e, até mesmo, indiferentes (Su et al., 2009). Eis aqui uma perspectiva ainda inconclusiva na literatura, portanto uma direção para futuras pesquisas no campo, que considerem outros intervenientes nessa relação.

Os parceiros orientados à ciência são representados, de um lado, pelas universidades e institutos de pesquisa e, de outro, por agências governamentais e instituições intermediárias (Figura 2.4). 


\begin{tabular}{|c|c|c|c|}
\hline Inovação & Relação & Parceiro & Estudos \\
\hline \multirow{4}{*}{$\begin{array}{l}\text { Inovação } \\
\text { de } \\
\text { Produto }\end{array}$} & \multirow{2}{*}{ Positiva } & UNI/ PESQ & $\begin{array}{l}\text { Belderbos et al., 2004; Belderbos et al., 2015; Chen et al., 2016; Fitjar \& Rodriguez-Pose, } \\
\text { 2013; Gesing et al., 2015; Gonzalez-Pernia et al., 2015; Kaufmann \& Tödtling, 2001a; Nietd } \\
\text { \& Santamarí, 2007; Su et al., 2009; Tsai, 2009; Zeng et al., 2010) }\end{array}$ \\
\hline & & GOV/INT & (Chen et al., 2016; Gonzalez-Pernia et al., 2015; Robin \& Schubert, 2013; Zeng et al., 2010) \\
\hline & \multirow{2}{*}{ Nula } & UNI/ PESQ & (Belderbos et al., 2006) \\
\hline & & GOV/INT & (Kaufmann \& Tödtling, 2001a; Zeng et al., 2010) \\
\hline \multirow{3}{*}{$\begin{array}{l}\text { Inovação } \\
\text { de } \\
\text { Processo } \\
\end{array}$} & Positiva & UNI/ PESQ & (Su et al., 2009; Un \& Asakawa, 2015) \\
\hline & \multirow{2}{*}{ Nula } & UNI/ PESQ & (Fitjar \& Rodriguez-Pose, 2013) \\
\hline & & GOV/INT & (Robin \& Schubert, 2013) \\
\hline \multirow{2}{*}{ Projeto } & Positiva & UNI/ PESQ & (Du et al., 2014) \\
\hline & Nula & UNI/ PESQ & (Bougrain \& Haudeville, 2002) \\
\hline \multirow{2}{*}{ Patentes } & Positiva & UNI/ PESQ & (Baba et al., 2009; Huang \& Yu, 2011) \\
\hline & \begin{tabular}{|l|} 
Nula \\
\end{tabular} & UNI/ PESQ & (Schwartz et al., 2012) \\
\hline
\end{tabular}

Figura 2.4. Resultados de Inovação e Parceiros orientados à Ciência.

Fonte: Elaborado pelo Autor.

Nesse âmbito, a principal evidência é o papel das universidades e dos institutos de pesquisa, que apresentam a melhor associação com um tipo de inovação (inovação de produto) dentre todos os parceiros, incluindo os classificados como orientados ao mercado. Ademais, mesmo que em proporção menor em termos de números de estudos comprobatórios, destaca-se que esses atores, também, estão relacionados aos demais resultados da inovação, como patentes e inovação de processo. Essas evidências, fruto da evolução do campo teórico das relações entre empresas e universidades (Gonzalez-Pernia et al., 2015), já trazem benefícios empíricos concretos, por exemplo, na inovação de produto. Ao mesmo tempo, abre um campo futuro para aprofundamento tanto no que se refere aos limites dessas relações em termos de governança (Gesing et al., 2015) quanto no âmbito da associação desse relacionamento com os demais resultados da inovação, como projetos (Bougrain \& Haudeville, 2002), dinâmica pouco explorada.

\subsubsection{Localização do Parceiro: Estar Próximo ou Distante?}

Apesar do ímpeto de estudar o efeito da localização como um antecedente para o estabelecimento de relações interorganizacionais, o debate sobre o efeito da localização geográfica dos parceiros sobre os resultados de inovação ainda permanece inconsistente. De um lado os defensores da proximidade geográfica como fator determinante para a transferência de conhecimento e desenvolvimento de inovação. Do outro lado, tem-se os críticos dessa vertente, que até então vigorava soberana.

Em relação aos favoráveis da localização geográfica próxima dos parceiros, Sorenson, Rivkin e Fleming (2006), considerando diferentes tipos de conhecimento, preconizam que os atores socialmente próximos têm a maior vantagem sobre os atores distantes para o conhecimento da 
complexidade moderada. Nessa mesma linha, a proximidade local é vista como importante ao permitir uma adaptação bem sucedida dos produtos existentes a diferentes requisitos locais, tais como normas técnicas, regulamentações de mercado e preferências dos clientes (van Beers \& Zand, 2014). Além disso, o estudo de Fukugawa (2013) revela que, dentre as pequenas empresas de base tecnológica que colaboram com universidades em pesquisa, aquelas com vínculos locais têm maior vantagem em melhorar a qualidade de seu pessoal de $\mathrm{P} \& \mathrm{D}$ através da aquisição de conhecimentos complementares. Corroborando essa perspectiva, a proximidade geográfica é vista como crucial para avaliar a resolução de problemas se tornando um benefício importante (Bishop, D'Este, \& Neely, 2011).

Já a vertente de estudos contrária à excessiva importância dada à proximidade geográfica dos parceiros, revela que a colaboração com agentes extraregionais é muito mais propícia à inovação do que a colaboração com parceiros locais (Fitjar \& Rodriguez-Pose, 2013). Há constatações empíricas de que a colaboração de pesquisa com um parceiro na mesma região de cluster diminui a produtividade de P\&D tanto em termos de quantidade quanto de qualidade das patentes (Nishimura \& Okamuro, 2011). Ademais, alguns estudos demonstram que não existem efeitos significativos para a proximidade espacial entre os parceiros de cooperação (Schwartz et al., 2012) e outros revelam que a proximidade organizacional (Bruneel, D'Este, \& Salter, 2016) e o envolvimento acadêmico de qualidade (Dornbusch \& Neuhausler, 2015; Ponds et al., 2010) são fatores mais relevantes do que a localização geográfica próxima.

Em suma, a localização dos parceiros com um fator relevante nos estudos de relações interorganizacionais e resultados de inovação é evidente, dado os inúmeros trabalhos que se propuseram a discutir esta temática. Contudo, dada à multiplicidade de relações que podem ser estabelecidas e os distintos resultados de inovação esperados, uma delimitação mais consistente dos fatores que sugerem a proximidade ou não ainda carece de mais estudos empíricos, em diferentes contextos.

\subsubsection{Objeto da Relação: P\&D, Pesquisa ou Projeto?}

Quando se analisa os objetos das relações interorganizacionais com vistas à inovação, a primeira constatação, como já apresentado, é que não é evidenciado de forma explícita em 33 trabalhos (48\%), dentre os analisados, qual é objeto da relação estabelecida. Ademais, dentre aquelas que apresentam tal informação, uma síntese é apresentada na Figura 2.5. 


\begin{tabular}{|c|c|c|c|}
\hline $\begin{array}{c}\text { Objeto da } \\
\text { Relação }\end{array}$ & Estudo & Contexto Empírico & Resultado de Inovação \\
\hline \multirow{13}{*}{ P\&D } & $\begin{array}{c}\text { (Becker \& Dietz, 2004; Belderbos, Carree, \& Lokshin, } \\
\text { 2004) }\end{array}$ & Alemanha & Inovação de Produto \\
\hline & \begin{tabular}{|c|} 
(Fey \& Birkinshaw, 2005) \\
\end{tabular} & Reino Unido e Suécia & Sucesso de P\&D \\
\hline & (Du et al., 2014) & Europa & Sucesso de Projeto \\
\hline & (Belderbos et al., 2006) & Holanda & Inovação de Produto \\
\hline & (Un \& Asakawa, 2015) & Espanha & Inovação de Processo \\
\hline & (Wang \& Li-Ying, 2015) & China & Patente \\
\hline & (Belderbos et al., 2015) & Espanha & Inovação de Produto \\
\hline & (Soh \& Subramanian, 2014) & Setor Biotecnologia & Patente e Publicação Científica \\
\hline & (van Beers \& Zand, 2014) & Holanda & Inovação de Produto \\
\hline & (Barajas, Huergo, \& Moreno, 2012) & Europa & Inovação Organizacional \\
\hline & (Schwartz et al., 2012) & Alemanha & Patente e Publicação Científica \\
\hline & (Huang \& Yu, 2011) & Taiwan & \begin{tabular}{|c|} 
Patente \\
\end{tabular} \\
\hline & (Nishimura \& Okamuro, 2011) & Japão & \begin{tabular}{|c|} 
Patente \\
\end{tabular} \\
\hline \multirow{9}{*}{ Pesquisa } & (Soh \& Subramanian, 2014) & Setor Biotecnologia & Patente e Publicação Científica \\
\hline & (Hoekman et al., 2009) & Europa & Patente e Publicação Científica \\
\hline & (Hall, Link, \& Scott, 2003) & EUA & \begin{tabular}{|l|} 
Sucesso de Projeto \\
\end{tabular} \\
\hline & (Guan, Zuo, Chen, \& Yam, 2016) & Vários Países & Publicação Científica \\
\hline & (Guan \& Liu, 2016) & Setor Nano-energético & Patente \\
\hline & (Sun \& Cao, 2015) & China & Patente \\
\hline & (Fukugawa, 2013) & Japão & Patente \\
\hline & (Okamuro \& Nishimura, 2013) & Japão & Patente e Inovação de Produto \\
\hline & (Robin \& Schubert, 2013) & França e Alemanha & $\begin{array}{l}\text { Inovação de Produto e de } \\
\text { Processo }\end{array}$ \\
\hline \multirow{11}{*}{ Projeto } & (Du et al., 2014) & Europa & Sucesso de Projeto \\
\hline & (Barajas et al., 2012) & Europa & Inovação Organizacional \\
\hline & (Schwartz et al., 2012) & Alemanha & Patente e Publicação Científica \\
\hline & (Nishimura \& Okamuro, 2011) & Japão & \begin{tabular}{|c|} 
Patente \\
\end{tabular} \\
\hline & (Hall et al., 2003) & EUA & Sucesso de Projeto \\
\hline & (Okamuro \& Nishimura, 2013) & Japão & Patente e Inovação de Produto \\
\hline & (Van Echtelt, Wynstra, Van Weele, \& Duysters, 2008) & Alemanha & Sucesso de Projeto \\
\hline & (Bougrain \& Haudeville, 2002) & França & Sucesso de Projeto \\
\hline & (Hoegl \& Wagner, 2005) & Alemanha, Áustria e Suíça & Sucesso de Projeto \\
\hline & (Scandura, 2016) & Reino Unido & Sucesso de P\&D \\
\hline & (Hofman et al., 2016) & EUA & Inovação de Produto \\
\hline
\end{tabular}

Figura 2.5. Objeto das relações, contexto empírico e resultados de inovação.

Fonte: Elaborado pelo Autor.

Diante desse quadro analítico, duas constatações principais: os estudos são realizados principalmente em países (regiões) desenvolvidas e as proxies de resultados de inovação são diversas, mas com poucas referências à inovação de processos. No primeiro aspecto, é evidente a realização de estudos, majoritariamente, nos contextos empírico da Europa, de forma conjunta ou em países isolados, e no Japão, contextos estes que foram vanguarda na concepção de que a inovação está associada ao desenvolvimento tecnológico. Ademais, esta constatação é verificada nos três diferentes tipos de objetos relatados, $\mathrm{P} \& \mathrm{D}$, pesquisa e projetos. Esforços têm sido empreendidos em estudos que adotam economias emergentes como campo empírico, como China (Sun \& Cao, 2015) e Taiwan (Huang \& Yu, 2011), contudo, além de recentes, são minoria, o que abre possibilidades para novas pesquisas que busquem explorar análises desses 
cenários, visando delimitar as diferenças quando se compara os objetos das relações com economias desenvolvidas.

Ao analisar os resultados de inovação considerados nos estudos em questão, verifica-se que as patentes, seguidas pela inovação de produto, sucesso de projeto e publicação científica, são as principais proxies utilizadas, quando se discrimina o objeto das relações. Ressalta-se aqui oportunidades para avanços em futuras pesquisas, considerando a análise dos diferentes objetos de relações externas sobre dois resultados de inovação negligenciados, inovação de processos e inovação organizacional. O segundo apresenta pouco expressividade dada a sua recente institucionalização (OECD, 2005), justificando o fato. Contudo o primeiro, a inovação de processos, mesmo sendo considerado em vários estudos conjuntamente com a inovação de produto (Robin \& Schubert, 2013; Su et al., 2009), ainda merece mais atenção. Somente um trabalho se propôs analisá-la individualmente como resultante da cooperação em P\&D em um país desenvolvido (Espanha) (Un \& Asakawa, 2015), fato que sugere novos estudos que analisem a existência de efeitos distintos em mercados emergentes, quando associados com outros objetos de cooperação, além de P\&D.

\subsection{CONSIDERAÇÕES FINAIS}

O objetivo deste artigo foi realizar um levantamento da literatura sobre a associação entre as estratégias de relações interorganizacionais e os diferentes resultados de inovação. Por meio de uma revisão sistemática da literatura, foram selecionados 69 artigos para o estudo, pois correspondiam aos objetivos propostos. O processo de análise dos resultados foi composto por duas etapas, as quais consistem nas contribuições do estudo. Primeiramente, foi proposto um levantamento geral com as diferentes estratégias de relações interorganizacionais com vistas à inovação, considerando os campos de estudo subjacentes, os tipos, objetos, parceiros e características das relações e os resultados de inovação. A amplitude dessa classificação corrobora a tese defendida, de heterogeneidade entre a cooperação com diferentes parceiros e os resultados de inovação. Contribuindo, dessa forma, com a literatura de estratégias de inovação, pois, ao permitir a identificação de diversos campos de estudo, relações interorganizacionais e características específicas, possibilita ao campo avançar em direção a uma corrente teórica própria, mesmo que diversificada.

Além disso, na segunda etapa, as diferentes associações entre os distintos parceiros identificados nas relações interorganizacionais e os diversos resultados de inovação foram 
analisados. Essa análise, associada à classificação já mencionada, contribui tanto para o contexto gerencial e de políticas públicas quanto academicamente. Para os primeiros, o estudo fornece uma visão ampla e dinâmica do processo de inovação oriundo de relações com outras organizações. Desse modo, possibilita ao gestor selecionar os seus parceiros de acordo com os seus objetivos de inovação e para os dirigentes públicos auxilia em termos de produção de políticas públicas de incentivo à inovação, fomentando relações mais produtivas.

Para a academia, foi evidenciada a complexidade existente na associação entre parceiros orientados ao mercado $(D U I)$ e à ciência $(S T I)$ e os diferentes resultados de inovação. No primeiro grupo, o papel importante dos fornecedores se caracteriza mais consolidado, pois está associado à inovação de produtos, processos e projetos (Du et al., 2014; Fitjar \& RodriguezPose, 2013; Tomlinson \& Fai, 2013). Enquanto isso, o trade off de se associar a concorrentes para a inovação permanece inconsistente, e mesmo sendo considerada uma relação externa de maior risco (Miotti \& Sachwald, 2003), estudos relevam uma associação positiva com os resultados de inovação de produto (Belderbos, Carree, \& Lokshin, 2004; Gonzalez-Pernia et al., 2015). No outro lado, as universidades e institutos de pesquisa se destacam, pois, consolidam uma literatura particular de relações interorganizacionais, interação universidadeempresa (Geuna \& Muscio, 2009; Perkmann \& Walsh, 2007), e ainda se relacionam com diferentes tipos de inovação.

Como limitações da pesquisa, destaca-se a possível omissão de trabalhos relevantes que se dispuseram a compreender as relações de cooperação com diferentes parceiros. Contudo, diante do procedimento metodológico adotado, empreendeu-se em uma proposta que buscou abarcar uma diversidade de fontes, considerando tanto aspectos de recência quanto de qualidade científica. Desse modo, visando ao aprofundamento da proposta aqui desenvolvida, sugere-se futuras pesquisas para a análise tanto dos parceiros de mercado e de ciência consolidados quanto àqueles que ainda apresentam resultados inconsistentes na literatura, de forma a considerar outros aspectos do quadro analítico desenvolvido, como a localização dos parceiros, o grau de inovatividade e o objeto das relações estabelecidas, visto que são aspectos ainda inconclusivos na literatura. 


\section{ARTIGO II - ATUALIZAÇÃO TECNOLÓGICA EM MERCADOS EMERGENTES: A IMPORTÂNCIA DA COOPERAÇÃO EXTERNA PARA O DESENVOLVIMENTO DE IMITAÇÃO DE PRODUTOS E DE PROCESSOS}

\subsection{INTRODUÇÃO}

A atualização tecnológica (technological upgrading) de países emergentes tem sido foco de estudo de diferentes autores (Fu, Pietrobelli, \& Soete, 2011; Giroud, Jindra, \& Marek, 2012; Hobday, 1995; Kim, 1997; Xu \& Li, 2014). Esse conceito pode propiciar aos países, que por anos foram considerados "fábricas globais", uma nova possibilidade para desbloquear novas fontes de crescimento econômico (Ernst, 2008). Além disso, a atualização tecnológica nas economias emergentes deve ser considerada para além da replicação e da importação de tecnologias estrangeiras de países desenvolvidos (Giroud et al., 2012). De fato, é uma forma de complementar a aquisição externa e o desenvolvimento interno de tecnologia, aliados à presença de estruturas institucionais e de governança modernas e sistemas de inovação favoráveis (Drechsler \& Natter, 2012; Fu et al., 2011).

Empresas com um processo de inovação tardio ou incipiente, típico de um mercado emergente, devem buscar a atualização tecnológica a partir da imitação. Ressalta-se que tanto a inovação quanto a imitação podem ser consideradas como estratégias alternativas para desenvolvimento de produtos, processos ou serviços tecnológicos. Como propõe Jenkins (2014), na prática, essas duas alternativas podem ser vistas em um continuиm, de modo que de um lado uma cópia pura da inovação de outra empresa representa uma imitação e de outro tem-se a inovação radical adoção de conceitos novos e distintivos não encontrados em concorrentes existentes representando um polo oposto à imitação (Cappelli et al., 2014; de Brentani, 2001; Laursen \& Salter, 2006; Zhou, 2006).

Desse modo, visto que a inovação bem-sucedida é o motor do crescimento (Schumpeter, 1982), a imitação torna-se inevitável, pois as empresas de sucesso são imitadas por outras que buscam ganhar uma parcela de lucros excedentes. Nessa perspectiva, as empresas que desejam crescer (ou evitar o declínio) não têm outra opção senão imitar (Jenkins, 2014). Quando uma economia está longe da fronteira tecnológica, ela pode crescer imitando. Como a tecnologia já existe, o fluxo de ideias é relativamente menos problemático e a principal tarefa é gerenciar o fluxo de recursos (Cerqueti, Quaranta, \& Ventura, 2016). 
Alguns pesquisadores descobriram que a aprendizagem tecnológica, principalmente a partir da imitação, permitiu que as empresas desenvolvessem produtos e aumentassem suas capacidades tecnológicas (Hobday, 1995; Kim, 1997; Xu \& Li, 2014). Essa atualização tecnológica pode ocorrer no nível da empresa, mas também deve estar associada aos demais estágios da cadeia de valor, sobretudo, para a criação de vínculos no setor e com instituições de apoio, como universidades, institutos de pesquisas, entre outros (Ernst, 2008). Como defende Ernst (2008), para ampliar o conjunto de empresas que são capazes de aprimoramento contínuo no nível micro, são necessárias indústrias de apoio fortes e vínculos com universidades e institutos de pesquisa. De modo que a atualização mútua reforçada, nível empresa e indústria, torna-se um desafio necessário para a criação de um “ciclo virtuoso". O contexto externo, portanto, passa a ser relevante nesse processo. Nesse aspecto, correntes teóricas já revelaram as relações externas como impulsionadoras do fenômeno da inovação nas empresas (Chesbrough, 2003; Etzkowitz \& Leydesdorff, 2000; Nelson, 1993).

Embora seja sabido que os spillovers de diferentes fontes externas não só estimulam a inovação, mas também induzem a imitação, o último efeito é principalmente negligenciado (Cappelli et al., 2014). As exceções são Cappelli et al. (2014) e Nieto e Santamaria (2007) que analisaram a imitação em produto no contexto de países desenvolvidos. Todavia, esses estudos se voltaram exclusivamente para o contexto da inovação de produto e desconsideraram um outro tipo importante de inovação (Reichstein \& Salter, 2006), sobretudo, no âmbito de países emergentes, a inovação de processo. Nesse âmbito, apresenta-se o esforço de Fitjar e Rodriguez-Pose (2013) que analisaram o efeito da colaboração com diferentes parceiros sobre os dois resultados de inovação em graus de novidade distintos, considerando dados de empresas da Noruega, país desenvolvido. Seus achados revelaram que a interação com os fornecedores tende a promover maiores níveis de imitação de produtos e de processos, a interação com os clientes e universidades é particularmente benéfica para a imitação de produtos e a colaboração com concorrentes tem um efeito prejudicial sobre a propensão das empresas inovarem de forma incremental.

Nesse sentido, considerando a dinâmica de desenvolvimento de produtos e de processos de Fitjar e Rodriguez-Pose (2013), o presente estudo avança ao propor uma análise no contexto de um país emergente, diferente dos autores. Isso porque tem-se que os estudos econométricos geralmente explicam um indicador de inovação, como despesas de $\mathrm{P} \& \mathrm{D}$, o número de patentes ou contagens de inovação, mas uma variável de imitação é raramente aplicada, pois essa informação é difícil de encontrar (Cappelli et al., 2014). Diante disso, e considerando a 
relevância dos diferentes parceiros de mercado ou doing, using and interacting (DUI) (clientes, fornecedores e concorrentes) e de pesquisa ou science, technology and innovation (STI) (universidades, institutos de pesquisa e centros de capacitação) com os quais as empresas podem cooperar (Dahlander \& Gann, 2010; Gelsing, 1992; Jensen et al., 2007), a pergunta de pesquisa em avaliar se a cooperação com parceiros de mercado e de pesquisa tem importância para o desenvolvimento de imitação de produto e de processo em um mercado emergente? Como objetivo principal, propomos analisar a importância da cooperação com parceiros de mercado e de pesquisa para o desenvolvimento de imitação de produto e de processo em um mercado emergente.

A tese defendida no artigo é de que ambos, parceiros de mercado e de pesquisa, são importantes para a imitação (inovação incremental), contudo de forma diferenciada. Desse modo, nas hipóteses é proposto que para a imitação de produto a cooperação com clientes e com universidades/institutos de pesquisa é importante ao passo que para a imitação de processo a cooperação com fornecedores e com centros de capacitação é a mais relevante. Para atingir o objetivo proposto, foram utilizados os dados da pesquisa nacional de inovação do IBGE, estratificada por setores da economia brasileira, referentes às coletas dos anos de 2003, 2005, 2008, 2011 e 2014 e a técnica de análise adotada foi a de dados em painel.

A principal contribuição esperada para o âmbito das pesquisas de atualização tecnológica e cooperação para a inovação em mercados emergentes é mostrar qual parceria é a mais adequada para cada tipo de imitação, produto e processo. Esse resultado acrescenta à literatura a importância de se considerar o efeito dos diferentes parceiros para os tipos de inovação com grau de novidade menor, aqui denominados como imitação. Os achados diferem dos resultados de Cappelli et al. (2014) e corrobora Nieto e Santamaria (2007) ao demonstrar, que no contexto de país emergente, os clientes têm importância para a imitação de produto e não os concorrentes. Ainda, diante dos resultados, os impactos positivos da cooperação com fornecedores sobre a imitação de processos, realidade em países desenvolvidos (Fitjar \& Rodriguez-Pose, 2013; Nieto \& Santamaria, 2007), não são verificados no contexto emergente.

\subsection{ATUALIZAÇÃO TECNOLÓGICA E COOPERAÇÃO INTERORGANIZACIONAL}

O processo de imitação é reconhecido como um primeiro passo na dinâmica de atualização tecnológica de empresas em mercados emergentes (Radosevic \& Yoruk, 2016; Wang, Fu, \& Chen, 2013). Portanto, o avanço da literatura sobre inovação aberta e cooperação deve-se se estender para a além da inovação radical, mas também para a compreensão dos efeitos externos 
sobre a imitação, cujos resultados diferem da inovação que até então tem sido o foco principal. Com base em uma revisão da literatura e em um nível muito geral, Radosevic e Yoruk (2016) definiram atualização tecnológica como um processo tridimensional (Figura 3.1).

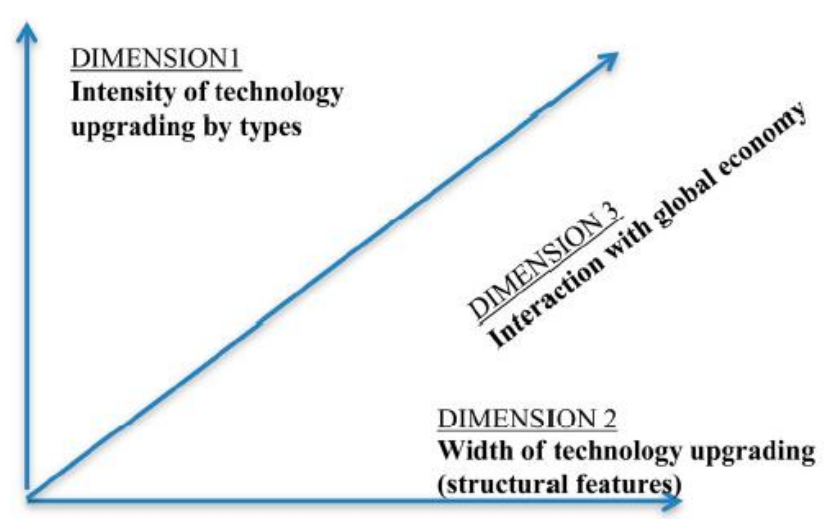

Figura 3.1. Dimensões da Atualização Tecnológica.

Fonte: Radosevic e Yoruk (2016).

A dimensão 1 (eixo vertical) está relacionada à intensidade da atualização tecnológica, exemplificada por diferentes tipos de atividades de inovação. Já a dimensão 2 (eixo horizontal) refere-se à disseminação ou amplitude da tecnologia, como a diversidade do conhecimento tecnológico, os tipos de infraestrutura de apoio e a estrutura das empresas como meios de atualização de tecnologia. Por fim, a dimensão 3 (eixo diagonal) se refere ao fluxo de conhecimento na economia através de uma variedade de canais, como comércio, investimento direto estrangeiro e cadeias de valor globais.

Para além das diferentes dimensões da atualização tecnológica, esse processo pode ser entendido por meio de três diferentes tipos de mudança tecnológica (Wang et al., 2013), quando se considera as perspectivas mercado e tecnologia: incremental, disruptiva e revolucionária (Figura 3.2). 


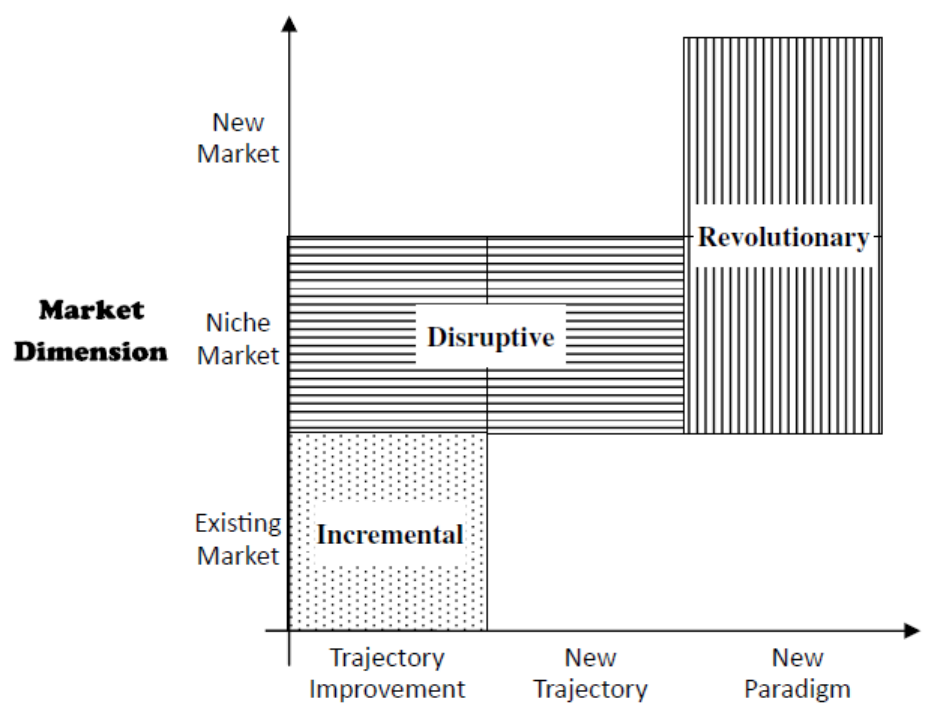

Technology Dimension

Figura 3.2. Tipos de Mudança Tecnológica.

Fonte: Wang et al. (2013).

Cada tipo de mudança tecnológica é definido tanto pela dimensão tecnológica como pela dimensão do mercado (Wang et al., 2013). Uma mudança incremental é definida como melhoria contínua ao longo de uma trajetória tecnológica estabelecida com o objetivo de melhorar o desempenho tecnológico e a participação de mercado em um mercado existente, como ocorre com a maioria dos produtos (Dosi, 1982). Enquanto uma mudança disruptiva é definida como a diversificação tecnológica ou substituição de tecnologia com o objetivo de explorar nichos de mercado, por exemplo o Netbook (Christensen, 1997). Por fim, uma mudança revolucionária (Freeman, 1991) é demonstrada como uma mudança radical para criar um novo paradigma de tecnologia com o objetivo de explorar um novo mercado através de um projeto dominante, por exemplo, o veículo elétrico (Wang et al., 2013).

O processo do desenvolvimento de cada um desses tipos de mudança tecnológica pode ser decomposto em diferentes etapas (Wang et al., 2013). No padrão incremental existem quatro etapas, as quais são imitação simples, imitação criativa, inovação radical e inovação incremental. Já o padrão disruptivo compreende as seguintes etapas: imitação, inovação radical, inovação incremental e inovação revolucionária. Por fim, um padrão revolucionário compreende as seguintes etapas: imitação, inovação revolucionária, inovação radical e inovação incremental.

Mesmo com os diferentes caminhos que padrão tecnológico pode seguir, todos têm como o primeiro passo a imitação. Indo ao encontro de alguns autores que argumentaram em apoio a um caminho incremental para atualização tecnológica, partindo da importação de tecnologia 
até a criação de P\&D original (Hobday, 1995; Kim, 1997). Nesse caminho, o fenômeno da imitação merece destaque ao se considerar os aspectos da atualização tecnológica e do processo de inovação como um todo. O estudo de Jenkins (2014) sugere que as estratégias imitativas podem, por si só, fornecer fontes mais sustentáveis de vantagem competitiva para a empresa. Assim, para o autor tanto a imitação bem-sucedida quanto a mal-sucedida estimula um movimento em direção à inovação como estratégia focal da empresa. Portanto, obter uma melhor compreensão das interações dinâmicas entre as empresas que se especializam em inovação e aquelas que imitam é um tópico importante e definitivamente precisa de investigação adicional (Cerqueti et al., 2015).

A relação entre inovação e imitação tem sido visto como controvérsia dado esse contexto, seja pela questão da legalidade ou do pioneirismo. Por um lado, as imitações (legais e ilegais) têm um efeito positivo da perspectiva da sociedade, mitigando acidentalmente os danos infligidos pelos monopólios e acelerando a difusão da inovação. Por outro lado, um número excessivamente grande de infrações pode matar a atividade de inovação, prejudicando a produção de conhecimento. Além disso, a ausência de inovação por sua vez pode levar à extinção de imitadores, que não têm nada para imitar. Resulta que os inovadores e os imitadores devem coexistir (Cerqueti et al., 2016). Embora a recompensa de um inovador bem-sucedido seja substancial, ser pioneiro em um mercado é inerentemente arriscado e pode absorver muitos recursos. Assim, muitas empresas podem relutar em investir substancialmente no desenvolvimento de produtos inovadores e apresentá-los no mercado antes de seus concorrentes. Em vez disso, elas se voltam para uma estratégia de imitação, copiando os produtos dos outros, na tentativa de aproveitar os esforços dos inovadores (Zhou, 2006).

Assim, a perspectiva micro da inovação (nova para a empresa), entendida aqui como imitação, pode ser aplicada tanto na imitação de produto quanto de processo (Galanakis, 2006; Garcia \& Calantone, 2002). Mais especificamente, o interesse consiste em como as imitações de produto e de processo dependem da cooperação com empresas e instituições da rede de negócio, isso porque as estratégias de cooperação fornecem às empresas acesso a conhecimentos e recursos que de outra forma seriam indisponíveis (Gnyawali \& Park, 2011), embora os recursos internos influenciem significativamente mudanças nas trajetórias empresariais, é a interação com recursos externos, dentro de um grupo de recursos, que normalmente tem maior relevância (Purchase, Olaru, \& Denize, 2014). Ademais, uma única empresa raramente é capaz de gerar difusão bem-sucedida na comercialização de uma inovação, visto que as empresas são vistas como incompletas em termos de não ter todos os recursos necessários para produzir produtos 
ou serviços individuais (Bygballe \& Ingemansson, 2014). Nesse contexto, a cooperação conquistou um papel importante no processo de inovação ao nível da empresa (Öberg \& Shih, 2014), de modo que a alavancagem de redes interfirmas torna-se um recurso estratégico que pode, potencialmente, ser moldado por ação gerencial (Huggins, 2010).

Assim, considera-se as organizações como parte de uma cadeia de valor e dependente de atores externos para gerenciar mudanças em seus ambientes operacionais (Freel \& de Jong, 2009). Os atores externos com os quais as empresas podem estabelecer parcerias para a inovação são diversos (Dahlander \& Gann, 2010), como empresas pertencentes ao mesmo grupo, fornecedores, clientes, concorrentes, organizações públicas, grupos de interesse, universidades e institutos de pesquisa (Faria et al., 2010; Öberg \& Shih, 2014; Schøtt \& Jensen, 2016; Tether, 2002; Tsai, 2009). Com base em Gelsing (1992) e Jensen et al. (2007), se define dois tipos principais de redes - rede de mercado ou comércio e rede de conhecimento ou pesquisa. Os parceiros de mercado (ou de comércio ou modo de inovação $D U I$ ) tem como foco principal a relação comercial, logo contemplam as interações com clientes, fornecedores e concorrentes. Os parceiros de pesquisa (ou de conhecimento ou modo de inovação STI) tem uma relação que se concentra no fluxo de conhecimentos e não na visão comercial, necessariamente, incluindo universidades, instituições de pesquisa, centros de capacitação e instituições de testes e certificações.

\subsection{HIPÓTESES}

As hipóteses a seguir discutem as relações dos parceiros de mercado DUI e de pesquisa $S T I$ com as imitações de produto e de processo.

\subsubsection{Importância do Modo de inovação doing, using and interacting (DUI)}

Estudos internacionais revelam que parceiros empresariais próximos, como fornecedores e clientes, são mais eficazes para o desenvolvimento de atividades de cooperação em inovação (Faria et al., 2010; Soosay, Hyland, \& Ferrer, 2008), relação caracterizada como colaboração vertical (Belderbos, Carree, \& Lokshin, 2004; Tsai, 2009). Ambos desempenham um papel importante no processo de inovação, pois contribuem com informação crucial sobre tecnologias, necessidades dos usuários e mercados (Miotti \& Sachwald, 2003). 
Nessa perspectiva, a relação com clientes tornou-se um componente importante dos esforços de desenvolvimento de muitas organizações e tem ganhado notoriedade (Greer \& Lei, 2012). A atuação com clientes proporciona às empresas não somente benefícios na identificação de oportunidades de mercado para o desenvolvimento de tecnologia, mas também reduz a probabilidade de má concepção nos primeiros estágios de desenvolvimento do produto (Tether, 2002; Tsai, 2009). Desse modo, as empresas, também, estão cada vez mais preocupadas com o estabelecimento de ligações mais estreitas com clientes e usuários (Bygballe \& Ingemansson, 2014). Essas relações permitem as empesas antecipar as novidades do mercado. Dessa forma, é de se esperar que a imitação de produto seja influenciada positivamente pela relação de cooperação com clientes e consumidores.

Os fornecedores, por sua vez, têm geralmente maior experiência e conhecimento mais abrangente sobre as peças e componentes, que podem ser fundamentais para o processo produtivo da empresa (Fossas-Olalla et al., 2015; Tsai, 2009). A colaboração com os fornecedores permite a redução de riscos e de prazos de desenvolvimento de produtos, reforçando simultaneamente a flexibilidade, a qualidade do produto e a adaptabilidade do mercado (Chung \& Kim, 2003), sendo considerada fonte valiosa de informação para desenvolver ou melhorar produtos (Nieto \& Santamaria, 2007). Portanto, as empresas que colaboram tecnologicamente com os fornecedores têm uma maior propensão para a inovação em seus processos (Fossas-Olalla et al., 2015). Como se trata de uma inovação incremental, oriunda dos processos do dia-a-dia e em busca de manter a competitividade da empresa, quanto maior a importância que a empresa concede à parceria com os fornecedores, mais é de se esperar o desenvolvimento de uma imitação de processo (Cappelli et al., 2014; Fitjar \& RodriguezPose, 2013).

Diante disso, clientes e fornecedores podem colaborar para o desenvolvimento de imitação (Nieto \& Santamaria, 2007), porém de maneira diferenciada, se o objetivo é a imitação de produto, cabe à organização conceder maior importância para as relações de cooperação com os clientes. Por outro lado, se o objetivo é a imitação de processo, cabe à organização conceder maior importância para as relações de cooperação com os fornecedores.

Hla: A importância da cooperação com clientes está relacionada ao desenvolvimento de imitação de produtos.

H1b: A importância da cooperação com fornecedores está relacionada ao desenvolvimento de imitação de processos. 
Além da cooperação vertical no âmbito dos parceiros $D U I$, as empresas podem estabelecer relações para inovação com parceiros em uma perspectiva horizontal, como aliando-se a empresas concorrentes. Na atuação junto à concorrência, as empresas envolvidas em um acordo de cooperação podem se beneficiar no compartilhamento de conhecimentos e competências tecnológicas, produzindo um efeito sinérgico na resolução de problemas comuns fora da área de concorrência (Cappelli et al., 2014; Tether, 2002; Tsai, 2009). Miotti e Sachwald (2003) defendem que esse tipo de cooperação é justificável somente em duas situações principalmente: primeiro, quando há um forte interesse comum identificado e, segundo, quando as oportunidades de cooperação para pesquisas têm como foco mercados de atuação diferentes de cada parceiros.

Por outro lado, considerando que o desenvolvimento de inovações pode ser crucial para manter uma vantagem competitiva sobre a concorrência, colaborar com empresas concorrentes é menos comum para produzir inovações, haja vista a trajetória competitiva (Nieto \& Santamaria, 2007; Tether, 2002; Un, Cuervo-Cazurra, \& Asakawa, 2010). Diante disso, corroborando os achados de Fitjar e Rodriguez-Pose (2013), que apresentam que a colaboração com concorrentes tem um efeito prejudicial sobre a propensão das empresas inovarem, defende-se que seja para imitação de produto ou de processo não é dada uma importância alta para a cooperação com esses parceiros.

H1c: A importância da cooperação com concorrentes não está relacionada ao desenvolvimento de imitação de produtos.

Hld: A importância da cooperação com concorrentes não está relacionada ao desenvolvimento de imitação de processos.

\subsubsection{Importância do Modo de inovação science, technology and innovation (STI)}

Além dos parceiros de mercado, os parceiros de pesquisa STI - universidades/instituições de pesquisa e centros capacitação - são importantes para a criação e disseminação de conhecimento científico e tecnológico (Lundvall, 1992b; Nelson, 1993). As empresas que colaboram com universidades e institutos de pesquisa têm maior propensão a inovar (Belderbos, Carree, \& Lokshin, 2004; Cowan \& Zinovyeva, 2013; George, Zahra, \& Wood Jr, 2002). Aliando-se a esses atores, numa perspectiva horizontal, as empresas podem interagir, formal e informalmente, para adquirir novos conhecimentos, beneficiando suas inovações e imitações 
de produto ou de processo (Tsai, 2009). De tal modo que essas parcerias possibilitam a redução do distanciamento entre a descoberta e a aplicação prática, pois as universidades podem colaborar com as empresas desde a ideação até o suporte para outras fases do desenvolvimento de produtos, inclusive na difusão (Berbegal-Mirabent, Sánchez García, \& Ribeiro-Soriano, 2015).

A colaboração com as universidades e institutos de pesquisas tende a ser mais focada em inovações que visam à criação de novos produtos, melhorando a produtividade de vendas (Belderbos, Carree, \& Lokshin, 2004). Instituições públicas de pesquisa não possuem como objetivo principal aplicações comerciais e tendem a se concentrar em uma gama mais genérica do complexo de pesquisa, desenvolvimento e inovação (Miotti \& Sachwald, 2003). Além disso, empresas com interações com centros universitários têm potencial para desenvolver mais patentes e reduzir a despesa de pesquisa e desenvolvimento em uma proporção maior do que empresas que não apresentam esses vínculos (George et al., 2002). Os parceiros de pesquisa, principalmente, universidades, são vistos como úteis para a pesquisa estratégica de inovação de longo prazo (Tether, 2002). Disso desprende-se que, quando a empresa está em busca de imitações de produto, cabe priorizar os laços de cooperação com universidades e institutos de pesquisa (Cappelli et al., 2014).

Por outro lado, o papel dos governos no processo de desenvolvimento e difusão tecnológica é geralmente crucial, mas varia de países e ao longo do tempo (Cerqueti et al., 2016). Desse modo, incentivados pelo poder público, outro importante parceiro para a inovação são os centros de capacitação (Borini, Pereira, \& Rossetto, 2016), como os Centros Japoneses Kosetsushi, os Centros de Tecnologia de Fabricação dos EUA, os Centros de Serviço Real Italiano, as instituições tecnológicas espanholas e os Conselhos de treinamento e empresa do Reino Unido (Barge-Gil, Santamaría, \& Modrego, 2011; Huggins, 1998). No Brasil representados fortemente pelas escolas industriais do sistema S (Sesi e Senai) e mais recentemente pela proliferação dos institutos federais (Manfredi, 2017). Em especial, quanto ao sistema $S$, esses são centros de capacitação suportados pela indústria para a formação de mãode-obra técnica para atuar nas atividades operacionais da indústria. Existe uma associação esperada do aumento da produtividade industrial e essa mão-de-obra especializada, pois ela é formada para trazer o que é de mais novo para a empresa. Essa última, por vezes centrada no seu processo produtivo não tem a possibilidade do acesso ao novo. São os centros de capacitação e seus formados que procuram aproximar as empresas de novas técnicas já existentes no mercado, mas ainda desconhecidas pela empresa. Desse modo é de se esperar uma 
associação da imitação de processo, quando a empresa concede maior importância aos centros de capacitação.

Portanto, propõe-se que os parceiros de pesquisa universidades/institutos de pesquisa apresentam uma associação positiva com a imitação de produto e os centros de capacitação com a imitação de processo.

H2a: A importância da cooperação com universidades/institutos de pesquisa está relacionada ao desenvolvimento de imitação de produtos.

H2b: A importância da cooperação com centros de capacitação está relacionada ao desenvolvimento de imitação de processos.

A Figura 3.3 apresenta o modelo conceitual proposto no artigo.

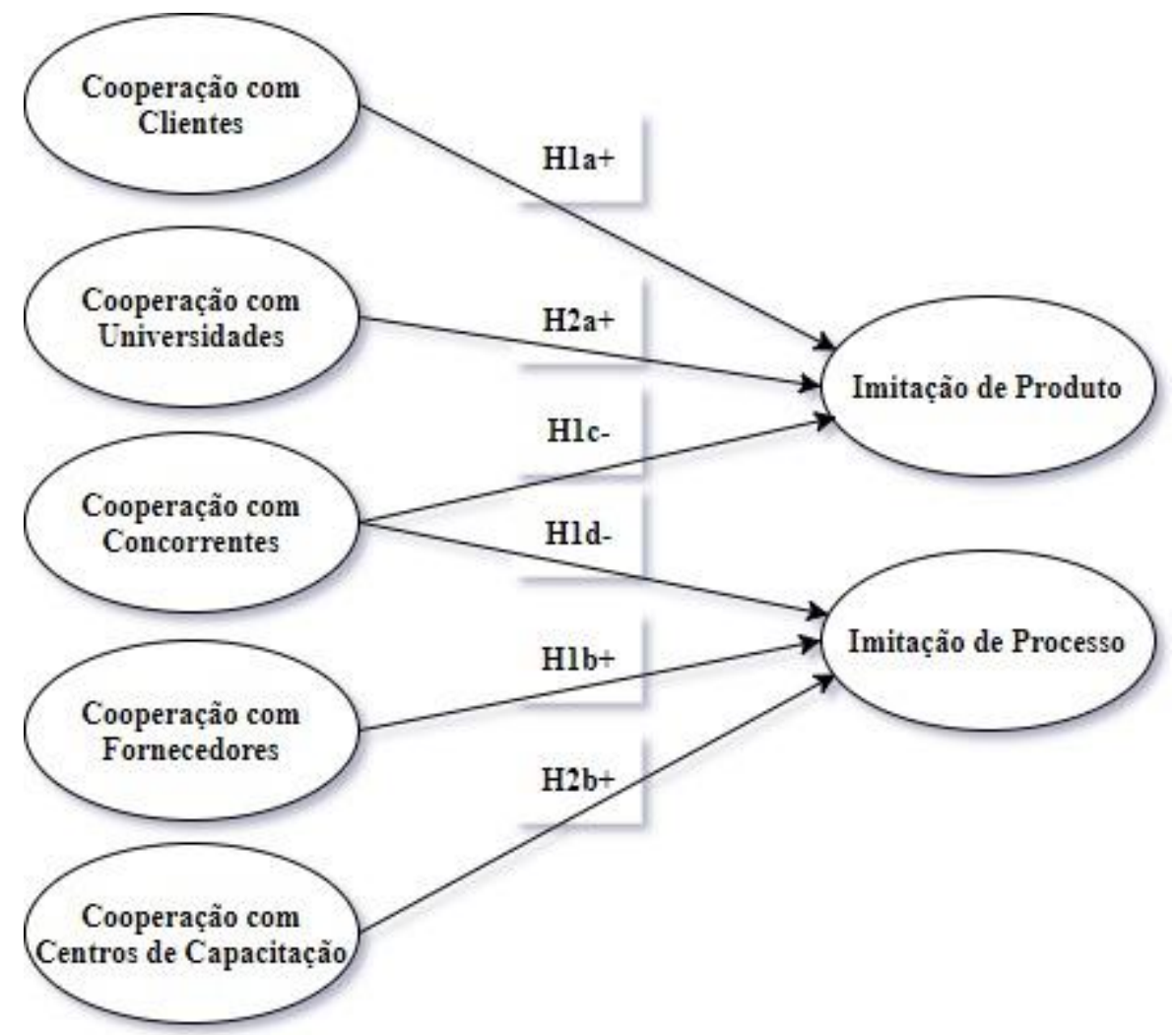

Figura 3.3. Modelo conceitual proposto.

Fonte: Elaborado pelo Autor.

\subsection{METODOLOGIA}

\subsubsection{Base de Dados}

Para o teste das hipóteses foi utilizada uma abordagem quantitativa por meio de dados secundários de empresas localizadas no Brasil. Os dados usados foram coletados por meio de 
acesso secundário aos dados da Pesquisa de Inovação (PINTEC) dos anos de 2003, 2005, 2008, 2011 e 2014, que é conduzida trienalmente pelo Instituto Brasileiro de Geografia e Estatística (IBGE), desde 2000. Esses dados por setor da economia nacional, disponibilizados pelo IBGE para o acesso público, serviram para compor a base. Após exclusões de alguns setores por dados faltantes, foram mantidos o número de vinte e oito setores da economia nacional (Anexo A). Como a amostra abrange cinco edições da pesquisa, isso resulta em 140 casos.

\subsubsection{Variáveis}

As variáveis dependentes avaliam as imitações de produto e de processo, obtida por meio das questões (1) “a empresa introduziu produto novo ou significativamente aperfeiçoado para a empresa, mas já existente no mercado nacional” e (2) “a empresa introduziu processo novo ou significativamente aperfeiçoado para a empresa, mas já existente no mercado nacional”. Isso gerou as duas variáveis dependentes. A primeira, a imitação de produto é resultante da divisão do número total de empresas que declararam realizar inovações de produto novas para a empresa dividido pelo total das empresas daquele setor. A segunda, a imitação de processo, é resultante da divisão do número total de empresas daquele setor que declararam realizar inovações de processos novas para a empresa dividido pelo total das empresas de cada setor. Ambas variáveis foram multiplicadas por cem para obtenção de um valor entre 0 e 100 .

Importante destacar que, acerca das relações de cooperação para inovação, envolvendo as variáveis independentes deste estudo, o IBGE (2014) aponta a cooperação para inovação como a participação ativa da empresa em projetos conjuntos de $\mathrm{P} \& \mathrm{D}$ e outros projetos de inovação com a organização, o que não implica, desnecessariamente, que as partes envolvidas obtenham benefícios comerciais imediatos. Assim, as variáveis independentes captam a importância de cada parceiro para a inovação, sendo elas divididas em dois grupos, o primeiro, "parceiros de Mercado ou DUI', avaliam a importância dos (1) clientes e consumidores, (2) fornecedores e (3) concorrentes, e o segundo, "parceiros de pesquisa ou STI", avaliam a importância das (4) universidades ou institutos de pesquisa e dos (5) centros de capacitação profissional e assistência técnica. Todas estas variáveis apresentavam como opções de resposta como 3=Alta, 2=Média, $1=$ Baixa e $0=$ Não Relevante, de forma que valores mais altos representam maior importância atribuída às parcerias para inovação, valores mais baixos representam menor importância e valor igual a zero indica representatividade nula para a questão. Para a análise foi considerado apenas o número de empresas que considerou Alta a importância do parceiro para a inovação. Com esse número foi obtido o índice de importância que é resultante do número de 
empresas daquele setor que declarou alta a importância da cooperação com o parceiro dividido pelo número total de empresas entrevistadas de cada setor multiplicado por cem para obtenção de um valor entre 0 e 100 .

Foram adotadas quatro variáveis de controle. Três delas representam atividades inovativas desenvolvidas pelas empresas - pesquisa \& desenvolvimento interno, aquisição de máquinas/equipamentos e treinamento. São atividades representativas dos esforços da empresa voltados para a melhoria do seu acervo tecnológico e, consequentemente, para o desenvolvimento e implementação de produtos ou processos novos ou significativamente aperfeiçoados (IBGE, 2014). Essas variáveis foram obtidas por meio do total de empresas que desenvolveram cada atividade inovativa dividido pelo total de empresas entrevistadas de cada setor multiplicado por cem para obtenção de um valor entre 0 e 100.

A Receita Líquida de Vendas (RLV) foi outra variável selecionada como controle, para representar uma variável de produtividade do setor (Su et al., 2009). Essa variável refere-se ao logaritmo natural (ln) da receita líquida de vendas de cada setor dividida pelo total de empresas entrevistadas de cada setor. Por fim, buscando analisar a influência temporal, foram consideradas as variáveis dummies 2005, 2008, 2011 e 2014, referentes às edições da PINTEC.

\subsubsection{Análise dos Dados}

Para análise dos dados, foram adotadas as técnicas estatísticas de regressão linear múltipla e regressão em painel. Desse modo, foram estimadas três regressões para cada variável dependente, Imitação de produto e Imitação de processo, indicando as técnicas (a) Regressão em painel longitudinal (Pooled OLS), (b) Regressão em painel longitudinal com efeitos fixos e (c) Regressão em painel longitudinal com efeitos aleatórios (Fávero, 2015; Gujarati \& Porter, 2011). Para a decisão de qual o melhor modelo de ajuste dos dados, foram considerados dois testes: primeiramente, o Teste de Hausman e, quando necessário, o Teste do multiplicador de Lagrange de Breusch-Pagan (Fávero, 2015; Gujarati \& Porter, 2011).

\subsection{RESULTADOS}

Nesta seção, são apresentados os resultados das regressões propostas. Inicialmente, foi considerada a análise de multicolinearidade, a partir da matriz de correlação e do Variance Inflation Factor (VIF) das variáveis. A matriz de correlação (Tabela 3.1), mesmo apresentando 
todas as correlações como significativas, demonstra valores não muito elevados, afastando indícios de multicolinearidade.

Tabela 3.1 Matriz de Correlação das variáveis dependentes e independentes

\begin{tabular}{|c|c|c|c|c|c|c|c|c|c|c|c|}
\hline Variável & 1 & 2 & 3 & 4 & 5 & 6 & 7 & 8 & 9 & 10 & 11 \\
\hline 1. Imit. de Produto & 1.00 & & & & & & & & & & \\
\hline 2. Imit. de Processo & $0.54 * *$ & 1.00 & & & & & & & & & \\
\hline 3. Clientes & $0.33 * *$ & $0.39 * *$ & 1.00 & & & & & & & & \\
\hline 4. Fornecedores & $0.32 * *$ & $0.35 * *$ & $0.92 * *$ & 1.00 & & & & & & & \\
\hline 5. Concorrentes & $0.22 *$ & $0.38 * *$ & $0.64 * *$ & $0.61 * *$ & 1.00 & & & & & & \\
\hline 6. Universidades & $0.25^{* *}$ & $0.23 * *$ & $0.58 * *$ & $0.54 * *$ & $0.51 * *$ & 1.00 & & & & & \\
\hline 7. C. de Capacitação & $0.26^{* *}$ & $0.48 * *$ & $0.78 * *$ & $0.78 * *$ & $0.78 * *$ & $0.52 * *$ & 1.00 & & & & \\
\hline 8. Receita de Vendas & $0.23 * *$ & $0.20 *$ & $0.62 * *$ & $0.60 * *$ & $0.37 * *$ & $0.57 * *$ & $0.43 * *$ & 1.00 & & & \\
\hline 9. P\&D Interno & $0.45^{* *}$ & $0.28 * *$ & $0.79 * *$ & $0.78 * *$ & $0.51 * *$ & $0.64 * *$ & $0.62 * *$ & $0.65^{* *}$ & 1.00 & & \\
\hline 10. Aq. Máq. e Eq. & $0.57 * *$ & $0.55^{* *}$ & $0.57 * *$ & $0.61 * *$ & $0.38 * *$ & $0.34 * *$ & $0.49 * *$ & $0.48 * *$ & $0.67 * *$ & 1.00 & \\
\hline 11. Treinamento & $0.50 * *$ & $0.40 * *$ & $0.66 * *$ & $0.70 * *$ & $0.40 * *$ & $0.50 * *$ & $0.54 * *$ & $0.61 * *$ & $0.81 * *$ & $0.79 * *$ & 1.00 \\
\hline $\mathbf{N}$ & 140 & 140 & 140 & 140 & 140 & 140 & 140 & 140 & 140 & 140 & 140 \\
\hline Média & 16.54 & 26.60 & 3.33 & 3.84 & 0.67 & 1.82 & 0.87 & 10.26 & 10.75 & 23.89 & 11.51 \\
\hline Desvio Padrão & 7.78 & 10.99 & 4.69 & 6.40 & 1.24 & 2.96 & 1.51 & 1.83 & 12.09 & 8.77 & 8.27 \\
\hline
\end{tabular}

Nota. $* \mathrm{p}<0,05 ; * * \mathrm{p}<0,01$.

Dando continuidade à análise de multicolinearidade, na Tabela 3.2 é verificado que os valores de VIF são inferiores a 10 e o VIF médio igual a 4.18, eximindo problemas de multicolinearidade (Gujarati \& Porter, 2011).

Tabela 3.2 Resultados das regressões para a variável dependente Imitação de Produto

\begin{tabular}{|c|c|c|c|c|c|c|c|c|c|}
\hline \multirow[b]{2}{*}{ Variável } & \multirow[b]{2}{*}{ VIF } & \multicolumn{2}{|c|}{ Modelo 1} & \multicolumn{2}{|c|}{ Modelo 2} & \multicolumn{2}{|c|}{ Modelo 3} & \multicolumn{2}{|c|}{ Modelo 4} \\
\hline & & Coef. & $\begin{array}{c}\text { Erro- } \\
\text { Padrão }\end{array}$ & Coef. & $\begin{array}{c}\text { Erro- } \\
\text { Padrão }\end{array}$ & Coef. & $\begin{array}{c}\text { Erro- } \\
\text { Padrão }\end{array}$ & Coef. & $\begin{array}{c}\text { Erro- } \\
\text { Padrão }\end{array}$ \\
\hline Clientes & 9.52 & & & $0.83 * *$ & 0.22 & & & $0.84 * *$ & 0.22 \\
\hline Fornecedores & 9.06 & & & -0.31 & 0.22 & & & -0.29 & 0.22 \\
\hline Concorrentes & 2.83 & & & $-0.27 * *$ & 0.10 & & & $-0.24 *$ & 0.12 \\
\hline Universidades & 2.29 & & & & & 0.06 & 0.12 & 0.01 & 0.11 \\
\hline C. de Capacitação & 4.53 & & & & & -0.09 & 0.11 & -0.06 & 0.14 \\
\hline Receita de Vendas & 2.10 & 0.57 & 0.41 & 0.48 & 0.39 & 0.60 & 0.41 & 0.49 & 0.39 \\
\hline P\&D Interno & 7.29 & 0.06 & 0.21 & 0.04 & 0.20 & 0.04 & 0.24 & -0.04 & 0.23 \\
\hline Aq. Máq. e Eq. & 2.95 & $0.30 *$ & 0.12 & $0.30 *$ & 0.12 & $0.29 *$ & 0.13 & $0.30 *$ & 0.12 \\
\hline Treinamento & 5.71 & 0.07 & 0.15 & 0.09 & 0.15 & 0.07 & 0.15 & 0.10 & 0.15 \\
\hline Dummy 2005 & 1.65 & $0.69 * *$ & 0.19 & $0.62 * *$ & 0.18 & $0.70 * *$ & 0.19 & $0.62 * *$ & 0.18 \\
\hline Dummy 2008 & 2.09 & $0.69 * *$ & 0.23 & $0.62 * *$ & 0.22 & $0.70 * *$ & 0.24 & $0.62 * *$ & 0.22 \\
\hline Dummy 2011 & 2.07 & 0.24 & 0.22 & 0.07 & 0.22 & 0.26 & 0.24 & 0.08 & 0.23 \\
\hline Dummy 2014 & 2.19 & 0.05 & 0.25 & -0.13 & 0.26 & 0.08 & 0.27 & -0.12 & 0.27 \\
\hline Constante & & $-0.33 *$ & 0.16 & -0.24 & 0.16 & $-0.35^{*}$ & 0.17 & -0.24 & 0.16 \\
\hline $\mathbf{N}$ & & \multicolumn{2}{|c|}{139} & \multicolumn{2}{|c|}{139} & \multicolumn{2}{|c|}{139} & \multicolumn{2}{|c|}{139} \\
\hline $\mathbf{R}^{2}$ & & \multicolumn{2}{|c|}{0.24} & \multicolumn{2}{|c|}{0.23} & \multicolumn{2}{|c|}{0.23} & \multicolumn{2}{|c|}{0.23} \\
\hline $\mathbf{F}$ & & \multicolumn{2}{|c|}{$5.48 * *$} & \multicolumn{2}{|c|}{$5.95 * *$} & \multicolumn{2}{|c|}{$4.40 * *$} & \multicolumn{2}{|c|}{$4.96 * *$} \\
\hline
\end{tabular}

Nota: ${ }^{\dagger} \mathrm{p}<0,10 ; * \mathrm{p}<0,05 ; * * \mathrm{p}<0,01$. 
Para os modelos de regressão, como apresentado, foram estimadas a regressão linear múltipla e outras duas regressões em modelo de painel (efeitos fixos e aleatórios) para cada uma das variáveis dependentes. Para a variável dependente imitação de produto, após inferências por meio do Teste de Hausman (Prob>chi2 $=0.0012$, sig. a $\mathrm{p}<0.05$ ), os resultados demonstraram que o modelo com melhor ajuste para a análise de dados é a regressão de dados em painel com efeitos fixos. Para tanto, são representados na Tabela 3.2 os quatro modelos considerados para a variável Imitação de Produto: somente controle (Modelo 1), controle e parceiros DUI (Modelo 2), controle e parceiros STI (Modelo 3) e completo (Modelo 4).

$\mathrm{Na}$ análise do modelo completo (Modelo 4), constata-se que foi considerado significativo ao nível de $1 \%$ e com um $\mathrm{R}^{2}$ de $23 \%$, ao testar a relação da importância das cooperações de $D U I$ e STI com a imitação de produto. Um coeficiente positivo e significante para os clientes ( $\beta=0.84, p<0.01)$, parceiro $D U I$, suportou H1a. Isso ratifica que quando o objetivo é a imitação de produto, maior é a importância concedida aos clientes e consumidores para a cooperação na atividade de inovação e não aos fornecedores. Ainda, nos parceiros de mercado, a relação entre importância alta dada à cooperação com concorrentes e imitação de produto foi significante e negativa, o que suporta a hipótese H1c. Quanto à hipótese H2a, ou seja, a importância da cooperação com universidades e institutos de pesquisa, parceiros de pesquisa $S T I$, os resultados não apresentam uma associação significativa, logo essa hipótese não foi suportada. De mesmo modo, a importância dos centros de capacitação profissional para a imitação de produto, mesmo não sendo uma hipótese defendida, foi testada e não apresentou uma relação estatisticamente significante.

No que diz respeito às variáveis de controle, a aquisição de máquinas e equipamentos foi considerada positiva e significativa na relação com a imitação de produto $(\beta=0.30, p<0.05$, no Modelo 4). Já em relação à receita de vendas, não foi confirmada sua associação com a imitação de produto. Na perspectiva temporal, uma associação positiva e significativa foi verificada com as variáveis dummies dos anos de 2005 ( $\beta=0.62, p<0.01$, no Modelo 4) e de 2008 ( $\beta=0.62$, $\mathrm{p}<0.01$, no Modelo 4), significativas ao longo dos quatro modelos testados.

Na sequência, na Tabela 3.3 são apresentados os resultados das regressões associadas à segunda variável dependente, imitação de processo. $\mathrm{Na}$ análise de possível multicolinearidade entre as variáveis independentes, os valores de VIF foram aceitáveis, sendo inferiores a 10 (Gujarati \& Porter, 2011), com um VIF médio de 3.98. O modelo adequado para análise dos dados foi o modelo de regressão Pooled OLS, após a realização do Teste de Hausman (Prob>chi2 $=0.8035$, 
não sig. a p <0.05) e do Teste do multiplicador de Lagrange de Breusch-Pagan (Prob>chibar2 $=0.3649$, não sig. a p < 0.05). Na Tabela 3.3 são apresentados os quatro modelos desenvolvidos para a variável Imitação de Processo: somente controle (Modelo 5), controle e parceiros DUI (Modelo 6), controle e parceiros STI (Modelo 7) e completo (Modelo 8).

Tabela 3.3 Resultados das regressões para a variável dependente Imitação de Processo

\begin{tabular}{|c|c|c|c|c|c|c|c|c|c|}
\hline \multirow[b]{2}{*}{ Variável } & \multirow[b]{2}{*}{ VIF } & \multicolumn{2}{|c|}{ Modelo 5} & \multicolumn{2}{|c|}{ Modelo 6} & \multicolumn{2}{|c|}{ Modelo 7} & \multicolumn{2}{|c|}{ Modelo 8} \\
\hline & & Coef. & $\begin{array}{c}\text { Erro- } \\
\text { Padrão }\end{array}$ & Coef. & $\begin{array}{c}\text { Erro- } \\
\text { Padrão }\end{array}$ & Coef. & $\begin{array}{c}\text { Erro- } \\
\text { Padrão }\end{array}$ & Coef. & $\begin{array}{c}\text { Erro- } \\
\text { Padrão }\end{array}$ \\
\hline Clientes & 8.47 & & & $0.26^{\dagger}$ & 0.14 & & & $0.23^{\dagger}$ & 0.13 \\
\hline Fornecedores & 8.12 & & & $-0.25^{\dagger}$ & 0.13 & & & $-0.39 * *$ & 0.13 \\
\hline Concorrentes & 2.81 & & & $0.12^{\dagger}$ & 0.06 & & & -0.03 & 0.08 \\
\hline Universidades & 2.26 & & & & & 0.01 & 0.07 & 0.00 & 0.07 \\
\hline C. de Capacitação & 4.51 & & & & & $0.21 * *$ & 0.07 & $0.32 * *$ & 0.10 \\
\hline Receita de Vendas & 2.10 & $-0.14 *$ & 0.07 & $-0.15^{*}$ & 0.07 & $-0.14 *$ & 0.07 & $-0.12^{\dagger}$ & 0.07 \\
\hline P\&D Interno & 7.12 & 0.07 & 0.10 & -0.04 & 0.12 & -0.06 & 0.11 & -0.05 & 0.12 \\
\hline Aq. Máq. e Eq. & 2.97 & $0.52 * *$ & 0.08 & $0.52 * *$ & 0.08 & $0.51 * *$ & 0.08 & $0.53 * *$ & 0.08 \\
\hline Treinamento & 5.41 & -0.04 & 0.11 & 0.01 & 0.11 & -0.03 & 0.11 & -0.01 & 0.11 \\
\hline Dummy 2005 & 1.65 & $1.48 * *$ & 0.15 & $1.42 * *$ & 0.15 & $1.42 * *$ & 0.15 & $1.41 * *$ & 0.15 \\
\hline Dummy 2008 & 2.07 & $1.50 * *$ & 0.17 & $1.45^{* *}$ & 0.17 & $1.40 * *$ & 0.17 & $1.40 * *$ & 0.17 \\
\hline Dummy 2011 & 2.07 & $1.62 * *$ & 0.16 & $1.48 * *$ & 0.16 & $1.45^{* *}$ & 0.17 & $1.38 * *$ & 0.17 \\
\hline Dummy 2014 & 2.12 & $1.66 * *$ & 0.16 & $1.51 * *$ & 0.17 & $1.49 * *$ & 0.17 & $1.44 * *$ & 0.17 \\
\hline Constante & & $-1.25 * *$ & 0.11 & $-1.17 * *$ & 0.11 & $-1.15 * *$ & 0.11 & $-1.13 * *$ & 0.11 \\
\hline $\mathbf{N}$ & & \multicolumn{2}{|c|}{140} & \multicolumn{2}{|c|}{140} & \multicolumn{2}{|c|}{140} & \multicolumn{2}{|c|}{140} \\
\hline $\mathbf{R}^{2}$ & & \multicolumn{2}{|c|}{0.69} & \multicolumn{2}{|c|}{0.71} & \multicolumn{2}{|c|}{0.69} & \multicolumn{2}{|c|}{0.73} \\
\hline $\mathbf{F}$ & & \multicolumn{2}{|c|}{$35.99 * *$} & \multicolumn{2}{|c|}{$27.98 * *$} & \multicolumn{2}{|c|}{$31.63 * *$} & \multicolumn{2}{|c|}{$26.11 * *$} \\
\hline
\end{tabular}

Nota: ${ }^{\dagger} \mathrm{p}<0,10 ;{ }^{*} \mathrm{p}<0,05 ; * * \mathrm{p}<0,01$

No modelo completo (Modelo 8), significativo ao nível de $1 \%$ e com um $\mathrm{R}^{2}$ de $73 \%$, foi testada a relação da importância das cooperações de mercado $(D U I)$ e de pesquisa $(S T I)$ para a imitação de processo. Em relação aos primeiros, foi constatada uma relação significativa, porém negativa entre a importância dos fornecedores e a imitação de processo $(\beta=-0.39, p<0.01$, no Modelo 8), contrariando a hipótese H1b. Portanto, a importância desse tipo de parceria vertical de mercado não está associada à imitação de processo. Por outro lado, quanto aos clientes, também parceiros de mercado, foi identificada uma associação significativa e positiva com a imitação de processo ( $\beta=0.23, p<0.10$, no Modelo 8$)$, reforçando que tais atores potencializam além da imitação de produto a inovação de processo também. Em relação aos concorrentes, também parceiros $D U I$, não foi verificada uma relação significativa com a imitação de processo. No tocante aos parceiros $S T I$, não foi identificada uma relação significante da importância das universidades e institutos de pesquisa com a imitação de processo, como esperado. Ainda, foi verificada uma associação positiva e significante da importância dos centros de capacitação profissional 
$(\beta=0.32, p<0.01$, no Modelo 8), que sustentou a hipótese H2b. Isto posto, quando o objetivo é a imitação de processo é alta a importância da cooperação com clientes e com centros de capacitação.

$\mathrm{Na}$ análise das variáveis de controle, tanto a aquisição de máquinas e equipamentos $(\beta=0.32$, $\mathrm{p}<0.01$, no Modelo 8) quanto a receita de vendas $(\beta=-0,12, \mathrm{p}<0,10$, no Modelo 8) apresentaram um efeito significativo na relação com a imitação de processo, contudo de modo diferenciado. Afinal, os resultados demonstraram que a empresas que se empenham na realização de atividades de esforço de inovação do tipo aquisição de máquinas e equipamentos estão mais propensos à imitação de processo, ao passo que, aqueles que apresentam maiores faturamentos estão menos propensos a desenvolver esse tipo de imitação. Na dimensão temporal da análise, foi verificada uma associação positiva e significativa com as variáveis dummies de todos os anos considerados para análise, ao nível de significância de $1 \%$.

Na Figura 3.4 esses achados são sintetizados.

\begin{tabular}{|c|c|c|c|}
\hline \multirow{4}{*}{$\begin{array}{c}\text { Parceiros } \\
\text { de } \\
\text { Mercado } \\
\text { DUI }\end{array}$} & Clientes & $\begin{array}{l}\text { Hla: A importância da cooperação com clientes está } \\
\text { relacionada ao desenvolvimento de imitação de produtos. }\end{array}$ & Suportada \\
\hline & Fornecedores & $\begin{array}{l}\text { Hlb: A importância da cooperação com fornecedores está } \\
\text { relacionada ao desenvolvimento de imitação de processos. }\end{array}$ & $\begin{array}{c}\text { Suportada } \\
\text { Negativamente }\end{array}$ \\
\hline & \multirow{2}{*}{ Concorrentes } & $\begin{array}{l}\text { Hlc: A importância da cooperação com concorrentes não está } \\
\text { relacionada ao desenvolvimento de imitação de produtos. }\end{array}$ & Suportada \\
\hline & & $\begin{array}{l}\text { Hld: A importância da cooperação com concorrentes não está } \\
\text { relacionada ao desenvolvimento de imitação de processos. }\end{array}$ & Não Suportada \\
\hline \multirow{2}{*}{$\begin{array}{c}\text { Parceiros } \\
\text { de } \\
\text { Pesquisa } \\
\text { STI }\end{array}$} & $\begin{array}{l}\text { Universidades } \\
\text { e institutos de } \\
\text { pesquisa }\end{array}$ & $\begin{array}{l}\text { H2a: A importância da cooperação com } \\
\text { universidades/institutos de pesquisa está relacionada ao } \\
\text { desenvolvimento de imitação de produtos. }\end{array}$ & Não Suportada \\
\hline & $\begin{array}{l}\text { Centros de } \\
\text { capacitação }\end{array}$ & $\begin{array}{l}\text { H2b: A importância da cooperação com centros de } \\
\text { capacitação está relacionada ao desenvolvimento de imitação } \\
\text { de processos. }\end{array}$ & Suportada \\
\hline
\end{tabular}

Figura 3.4. Resultados das hipóteses propostas.

Fonte: Elaborado pelo Autor.

Os resultados dos nossos modelos de regressão suportaram três das hipóteses propostas (H1a, H1c e H2b). Enquanto, uma hipótese (H1b) foi suportada negativamente e outras duas (H1d e H2a) não foram suportadas. Na sequência, apresentamos as discussões dos resultados.

\subsection{DISCUSSÃO DOS RESULTADOS}

Em relação aos parceiros DUI, que incluem clientes e fornecedores, tidos como os parceiros mais importantes para cooperação em inovação (Belderbos, Carree, \& Lokshin, 2004; Faria et al., 2010; Miotti \& Sachwald, 2003), e concorrentes, foram evidenciados três aspectos principais. O primeiro deles é que a imitação de produto tem associação com a alta importância 
dada à cooperação com clientes (Tsai, 2009), confirmando a hipótese H1a e reforçando estudos da área (Fitjar \& Rodriguez-Pose, 2013). Além disso, a importância dada à cooperação com clientes tem reflexos também na imitação de processo. Nesse sentido, relações estreitas com esses parceiros devem ser exploradas (Bygballe \& Ingemansson, 2014), em função do seu efeito duplo nos dois tipos de imitação considerados. Ademais, como implicações, os spillovers dos clientes podem obtidos para além de acordos formais mas também por meio de transações de mercado (Belderbos, Carree, \& Lokshin, 2004), que podem subsidiar os estágios iniciais da inovação.

No âmbito da análise, foi apontada uma associação significativa da relação dos fornecedores com a imitação de processos, porém negativa, não suportando a hipótese H1b. Tal fato pode ser justificado quando se considera o fornecedor um parceiro estratégico para empresas de países emergentes, no qual a busca de inovação por maior grau de novidade é preferida em detrimento da imitação (Fitjar \& Rodriguez-Pose, 2013), dado o conhecimento especializado deste parceiro (Chung \& Kim, 2003; Fossas-Olalla et al., 2015). Nesse sentido, os fornecedores ajudam a empresa a melhorar seus processos, pois fornecem novos insumos para o fluxo de produção. Logo, potencializam a inovação de processos de maior grau de novidade, e não a imitação, visto que colabora para a aquisição de conhecimento específico da empresa, possibilita o acesso às melhores práticas utilizadas por diferentes empresas da indústria e, ainda, pode construir uma relação mais próxima com a empresa no longo prazo (Un \& Asakawa, 2015).

Por fim, em função da relação controvérsia existente na cooperação com concorrentes pelo risco associado (Miotti \& Sachwald, 2003; Un et al., 2010), uma relação significante e negativa para a imitação de produto e não significativa para a imitação de processo foi verificada, o que demonstra novas evidências desse tipo de cooperação e que ainda carece de novas investigações. Mesmo vários estudos explorando tal relação contraditória, os impactos sobre os resultados de inovação não são um consenso, sendo associados a perspectivas positivas (Belderbos, Carree, \& Lokshin, 2004), negativas (Chen et al., 2016) e, até mesmo, indiferentes (Su et al., 2009).

Em relação aos parceiros $S T I$, os centros de capacitação profissional se destacam como importantes para o tipo de inovação mais incremental no processo produtivo (H2b), ao passo que estão voltados para funções de treinamento ou difusão de conhecimento (Manfredi, 2017) e não na geração de novas tecnologias ou produtos, perspectiva esta que estaria mais alinhada à cooperação com universidades e institutos de pesquisa. Os serviços de treinamento e assistência fornecidos pelos centros tecnológicos (Barge-Gil et al., 2011), atores identificados 
em diferentes países desenvolvidos (Barge-Gil et al., 2011; Huggins, 1998), atuam como fundamentais para a imitação de processo em mercados emergentes, que se caracterizam por oportunidades periódicas de atividades do dia-a-dia (Robertson et al., 2012).

Ainda, os resultados não evidenciaram a importância da cooperação com universidades e institutos de pesquisa para inovações de produto de cunho incremental (H2a), não corroborando estudos da área (Nieto \& Santamaria, 2007). O conhecimento de fronteira científica associado à cooperação com universidades e institutos de pesquisa (Barge-Gil et al., 2011; Geuna \& Muscio, 2009) delineiam, portanto, que esse tipo de interação elucidada na crescente literatura universidade e empresa pode ter associações com graus de inovações em maiores níveis e não no desenvolvimento de imitação.

Além disso, a partir das variáveis de controle, algumas conclusões são destacadas. A variável atividade inovativa, aquisição de máquinas e equipamentos, apresentou-se como relevante para ambos os tipos de imitação, tendo efeito significativo tanto nos modelos intermediários quanto nos modelos completos. Essa variável consiste nos esforços empreendidos pelas empresas na busca pela inovação, desse modo, reflete e fortalece a capacidade absorção das mesmas (Cohen \& Levinthal, 1990; Drechsler \& Natter, 2012; Robertson et al., 2012) e diferente da aquisição de P\&D, típica de empresas de países desenvolvidos. Nesse sentido, enquanto um fator interno da empresa, tal aspecto se torna relevante aliado à cooperação externa, permitindo um maior aproveitamento do spillover externo e promovendo sua atualização tecnológica (Giroud et al., 2012) em países emergentes. Por outro lado, o faturamento em termos de receita de vendas das empresas não se demonstrou relevante para o desenvolvimento de imitação de produto, contudo, apresentou uma relação significativa e negativa com a imitação de processo. Nesse caso, aquelas empresas que apresentam maiores faturamentos desenvolvem menos a imitação de processo. Fica evidente neste âmbito que os investimentos são alocados para inovação com grau de novidade maior e não para a imitação, pressupondo estágios mais avançados de atualização tecnológica (Xu \& Li, 2014; Zhou, 2006).

\subsection{CONSIDERAÇÕES FINAIS}

O presente artigo analisou a importância da cooperação com parceiros de mercado (DUI) e de pesquisa $(S T I)$ para o desenvolvimento de imitação de produto e de processo em um mercado emergente. Tendo como pressuposto a imitação com passo inicial para a atualização tecnológica de empresas em economias emergentes (Kim, 1997), foi evidenciado que os parceiros de 
pesquisa e mercado tem uma importância diferenciada em relação à imitação de produto e de processo. Os resultados mostram que, para os parceiros DUI, a cooperação com os fornecedores se apresentou negativa para a imitação de processo, a importância dos concorrentes teve relação negativa para a imitação de produto e a cooperação com clientes apresentou alta importância para a imitação de produto. Já para os parceiros de STI, a importância dada aos centros de capacitação é evidenciada para a imitação de processo, o que não ocorre para a relação da cooperação com universidade e institutos de pesquisa para a imitação de produto.

Esses resultados evidenciam as principais contribuições do artigo. Primeiro, considerar parceiros de pesquisa e de mercado como algo único (soma dos parceiros DUI e STI) não é o mais adequado para entender as estratégias de cooperação para a inovação e imitação, foco deste estudo. Nesse sentido, diferenciar inovação e imitação leva a prioridades claras, cuja fonte de spillovers afeta o resultado da inovação das empresas (Cappelli et al., 2014). Segundo, dependendo do tipo de imitação, as parcerias com os agentes externos devem se alterar, inclusive dentro das categorias DUI e STI. Consequentemente, esse resultado tem implicações claras para as práticas gerenciais no sentido de apontar qual é o melhor parceiro para cada tipo de imitação, visando à atualização tecnológica (Wang et al., 2013). Por fim, um terceiro aspecto está relacionado ao contexto da imitação em mercados emergentes. Dada a importância do desenvolvimento de imitação nesse cenário, o estudo contribui ao demonstrar que a cooperação com determinados parceiros pode favorecer ou não a imitação desejada. Logo, clientes são relevantes para produtos e processos ao passo que concorrentes para produtos e fornecedores para processos não são os parceiros que impulsionam a imitação, ora, podem estar associadas à níveis de inovação mais elevados.

Como limitação do estudo, destaca-se à delimitação dos tipos de imitação considerados como variáveis dependentes no estudo, que foram a imitação de produto e de processo, desconsiderando imitações relacionadas a inovações de marketing e organizacionais, por exemplo. Contudo, houve um avanço ao considerar a imitação de processo para além da imitação de produto, portanto justificável. Além disso, pesquisas futuras podem prover novas análises contemplando outros parceiros com os quais as empresas cooperam para desenvolver imitação, como consultores, que não foram objeto de análise deste estudo, o que também pode ser considerado como limitações da pesquisa. Por fim, a congruência da literatura sobre atualização tecnológica e o fenômeno da inovação aberta se constitui um campo aberto para novas constatações, com avanços necessários, sobretudo, em diferentes países emergentes para futuras comparações. 


\section{ARTIGO III - COOPERAÇÃO INTERORGANIZACIONAL E A INOVAÇÃO DE PROCESSO: A DINÂMICA DA LOCALIZAÇÃO NACIONAL VERSUS ESTRANGEIRA DOS PARCEIROS}

\subsection{INTRODUÇÃO}

A inovação não é restrita apenas ao nível produto. Além do desenvolvimento e exploração de novos produtos, serviços e mercados, inovar, também, consiste no desenvolvimento de novos modelos de produção (Crossan \& Apaydin, 2010). Em outras palavras, destaca-se a inovação do processo produtivo, denominada daqui em diante como inovação de processo. A inovação de processo não deve ser tão somente uma ação secundária ou de apoio para as tradicionais e superestimadas inovações de produto, mas também vislumbrada a partir de ações coordenadas do dia-a-dia e de caráter estratégico. Todavia, na literatura, o foco notadamente explícito nos determinantes e especificidades da inovação de produto desconsidera e negligencia a importância da inovação de processo, mesmo esta sendo reconhecida como uma função estratégica para as organizações (Tidd et al., 2008; Un \& Asakawa, 2015), em virtude de seu suporte e interação com a inovação de produto (Utterback, 1994). Nessa perspectiva, compreender os determinantes da inovação de processo torna-se relevante ao se considerar os seus impactos positivos, seja em produtividade ou no desempenho superior em relação aos concorrentes (Reichstein \& Salter, 2006; Robertson et al., 2012; Rosenberg, 1982).

Nesse contexto, relações com outras organizações têm sido propostas como relevantes para o acesso a recursos externos (Marxt \& Link, 2002; Pittaway et al., 2004) e, consequente, desenvolvimento de inovações do processo (Un \& Asakawa, 2015). Perspectivas teóricas dos sistemas de inovação (Lundvall, 1988; Nelson, 1993), da inovação aberta (Chesbrough, 2003) e da global value chain (Gereffi, Humphrey, \& Sturgeon, 2005) sustentam a importância do relacionamento com diferentes tipos de parceiros para o desenvolvimento de inovação, inclusive oriundos de diferentes países. Esses parceiros podem ser divididos em dois grupos com os quais as empresas podem cooperar (Jensen et al., 2007). O primeiro, parceiros do modo de inovação doing, using and interacting (DUI) ou parceiros de mercado, contempla os clientes, fornecedores e concorrentes. No segundo grupo, o modo de inovação science, technology and innovation (STI) contempla os parceiros universidades, institutos de pesquisa e centros de capacitação profissional, que também podem ser denominados como parceiros orientados à ciência ou à pesquisa. 
Embora, alguns estudos evidenciam a importância dos parceiros (Faria et al., 2010), a influência da localização do parceiro sobre os resultados de inovação ainda é contraditória na literatura. Muitos estudos discutem a dimensão geográfica, próxima ou distante, como um antecedente de se estabelecer colaborações com outras empresas (Abramo et al., 2011; D'Este, Guy, \& Iammarino, 2013; Ponds et al., 2007; Sorenson et al., 2006). Em função do caráter tácito do conhecimento, autores defendem a proximidade geográfica como um facilitador da colaboração (Owen-Smith \& Powell, 2004). Entretanto, outros estudiosos criticaram este ponto de vista como sendo excessivamente simplificado (Ponds et al., 2007). Ademais, é fato que algumas tentativas associadas a diferentes proxies de resultados de inovação foram empreendidas, como publicações científicas (Ponds et al., 2007), patentes (Baba et al., 2009; Hoekman et al., 2009; Sorenson et al., 2006), produtividade de P\&D (Nishimura \& Okamuro, 2011). Entretanto, a análise individual da localização dos diferentes tipos de parceiros (DUI e STI) e a inovação de processo, ainda consiste em campo aberto de constatações empíricas, desafio esse proposto neste artigo.

Além dessa incongruência do papel da localização dos diferentes tipos de parceiros sobre os resultados de inovação, especificamente na inovação de processo, a literatura especializada investiu muito mais esforço empírico na compreensão de relações de aprendizagem próximas, deixando de lado a análise das relações a longas distâncias (Grabher \& Ibert, 2014). Desse modo, neste artigo é questionado se a localização do parceiro interorganizacional importa para a inovação de processo. $O$ termo localização refere-se a parceiros nacionais ou estrangeiros. Nesse contexto, o objetivo do artigo foi analisar a relação entre a cooperação com parceiros nacionais e estrangeiros e o desenvolvimento de inovação de processo. Defende-se que, a inovação de processo está mais associada à cooperação com fornecedores, clientes, concorrentes (parceiros DUI) e centros de capacitação (parceiros STI) de mesma localidade e menos associada à cooperação com universidades e institutos de pesquisa (modo de inovação $S T I)$ de mesma localidade.

Para testar as hipóteses foi utilizada a técnica de regressão com dados em painel, considerando 28 setores empresariais brasileiros, entre os anos de 2003 e 2014, compreendidos na Pesquisa de Inovação (PINTEC) desenvolvida pelo Instituto Brasileiro de Geografia e Estatística (IBGE), o que representa um total de 107.854 empresas (IBGE, 2014). Considerando um campo empírico de um país emergente numa perspectiva longitudinal ampliando aspectos de estudos anteriores (Ponds et al., 2010; Su et al., 2009), espera-se contribuir para a discussão do papel da localização (nacional versus estrangeira) dos parceiros sobre os resultados de inovação das 
empresas envolvidas nesses arranjos (Fitjar \& Rodriguez-Pose, 2013; Gonzalez-Pernia et al., 2015), demonstrando que nem sempre a localização distante (ou próxima) é benéfica, mas é dependente do tipo de parceiro, inclusive dentro dos grupos DUI e STI (Barge-Gil et al., 2011; Gonzalez-Pernia et al., 2015). Por fim, em termos de contribuições para o contexto gerencial e de políticas públicas, apresenta-se uma visão ampla de como diferentes parceiros (nacionais e estrangeiros) estão associados aos resultados de inovação de processo, possibilitando ao gestor selecionar os seus parceiros de acordo com os objetivos de inovação e aos dirigentes públicos auxiliar e fortalecer o contexto institucional do sistema nacional de inovação, provendo políticas públicas de incentivo à inovação que fomentem relações mais produtivas e mais seguras.

O artigo compreende, além desta introdução, a seguinte estrutura: o referencial teórico contempla os aspectos principais sobre a inovação de processo e a cooperação interorganizacional. As hipóteses destacam a diferenciação dos efeitos da cooperação com parceiros nacionais e estrangeiros do modo de inovação science, technology and innovation (STI) e do modo doing, using and interacting (DUI). Nos procedimentos metodológicos a base de dados utilizada e a descrição das variáveis dependentes e independentes são apresentadas. Os resultados testam as hipóteses por meio de regressão de dados em painel longitudinal (Pooled OLS, efeitos fixos e efeitos aleatórios). Na sequência, segue a discussão dos resultados com importantes reflexões sobre os resultados achados. Por fim, nas considerações finais destaca-se as principais contribuições do artigo, limitações e sugestões para futuras pesquisas.

\subsection{INOVAÇÃO DE PROCESSOS E A COOPERAÇÃO INTERORGANIZACIONAL}

No âmbito da discussão dos tipos de inovação, sobretudo produto e processo, os desdobramentos, sejam sociais e econômicos dessas inovações, são diferentes entre si, visto que o desenvolvimento de um novo produto tem um efeito mais externo, por exemplo, na economia e no nível de emprego, enquanto as inovações de processo produtivo objetivam otimizações e reduções de custo, notadamente um viés mais interno às organizações (Fagerberg, Mowery, \& Nelson, 2004). Segundo o Manual de Oslo (OECD, 2005), a inovação de processo é definida como a implementação de um método de produção ou distribuição novo ou significativamente melhorado, incluindo mudanças significativas em técnicas, equipamentos e/ou softwares (OECD, 2005). Em síntese consiste na introdução de um novo método de produção (Un \& Asakawa, 2015), compreende atividades como instalação de uma tecnologia de fabricação nova ou melhorada, utilização de equipamentos computadorizados para o 
controle da qualidade da produção, introdução de rotinas novas ou melhoradas para sistemas de compra, contabilidade ou manutenção, aquisição de novas ferramentas de softwares desenhadas para melhorar os fluxos de oferta, entre outras (OECD, 2005).

Demonstrando as distintas fases das inovações de produto e de processo conjuntamente, Utterback e Abernathy $(1975,1994)$ propuseram um modelo de evolução tecnológica. Os autores determinaram que esses dois tipos de inovação variam de acordo com as taxas de inovação e estágios de desenvolvimento, configurando três fases distintas na dinâmica da inovação tecnológica (Figura 4.1):

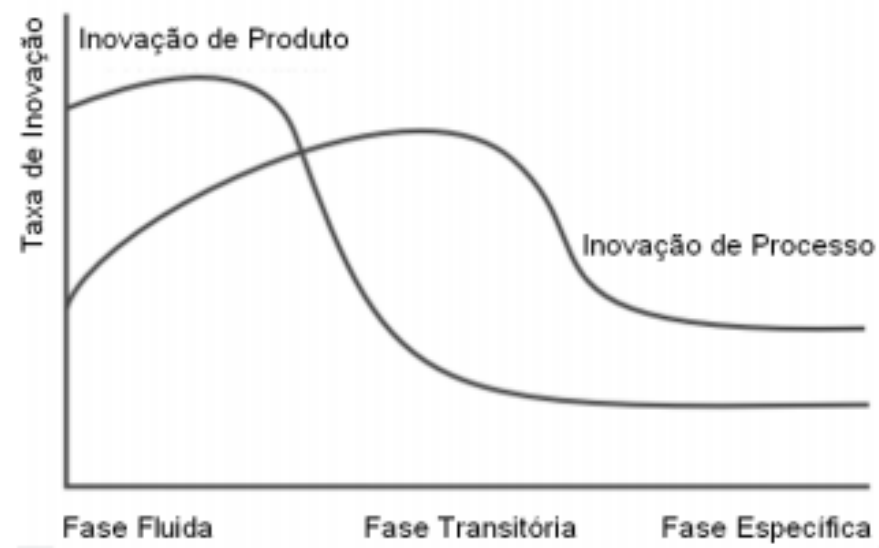

Figura 4.1. Modelo da Dinâmica da Inovação Tecnológica.

Fonte: Utterback e Abernathy $(1975,1994)$.

Na fase fluida o objetivo consiste no desenvolvimento de produtos novos ou melhores, a partir de máquinas e equipamentos já existentes. Essa fase é caracterizada por um alto grau de incertezas (tecnológicas e de mercado) e de mudanças no produto para seu aperfeiçoamento. Em síntese, considerada uma fase de formação, a ênfase é dada no produto, mais especificamente na melhoria do desempenho do produto a partir de um grande volume de experiência, e não nos processos de produção com a preocupação de reduzir custos. Neste período, as empresas investem em inovação radical de produtos ao invés de inovar em processos. As empresas acreditam que, considerando as necessidades dos clientes, pode ajudálos a se tornarem jogadores dominantes no mercado, consequentemente, a inovação de produtos ocorre com mais frequência do que a inovação de processos (Abernathy \& Utterback, 1978; Utterback \& Abernathy, 1975).

Na sequência da dinâmica de evolução, a ênfase do investimento na fase transitória muda da inovação radical de produtos para processos. Diante disso, as inovações de processo chegam ao 
ápice e há uma diminuição considerável nas inovações de produto, visto que o objetivo é desenvolver o melhor processo tecnológico, tendo um produto de menor custo e de qualidade. Esta fase se caracteriza, portanto, pelo aperfeiçoamento do processo produtivo, uma vez que a grande quantidade de projetos da fase anterior é substituída por projetos padronizados. Logo, há uma busca por eficiência e produtividade, para obtenção de economias de escala (Utterback, 1994).

Por fim, na fase específica, a inovação do processo é comum, mas a inovação do produto é rara (Yeo, Kim, Park, \& Kang, 2015), de modo que as inovações de produtos são principalmente de cunho incremental, enquanto há mais inovações direcionadas para o processo produtivo. Dada a necessidade constante de administração dos riscos associados a novos investimentos, as empresas passam a se concentrar na gestão de custo, volume, capacidade de produção e qualidade. A padronização e maturidade do produto marca esta fase e, portanto, novos investimentos em inovações importantes ou radicais podem levar a um novo estágio ou fase fluida de evolução tecnológica (Utterback \& Abernathy, 1975).

É fato que, mesmo sendo revelada há algum tempo a necessidade de complementariedade entre inovação de produto e de processo, a inovação de processo ainda é considerada o lado "sujo e pedante" do processo de inovação (Rosenberg, 1982), quando comparada à inovação de produtos (Cefis \& Marsili, 2012; Reichstein \& Salter, 2006). Além disso, Reichstein e Salter (2006) enfatizam que a inovação de processos tem sido frequentemente considerada uma atividade inovadora de segunda ordem. No entanto, a inovação de processo, também, consiste num elemento importante na competitividade da empresa (Un \& Asakawa, 2015). Corroborando essa perspectiva, Robertson et al. (2012) assevera que todas as organizações em todos os setores - serviços, agricultura, mineração, construção, bens de manufatura - empregam algum processo de produção novo que contribui diretamente para a sua competitividade. No âmbito de produtos homogêneos, por exemplo, o preço baixo torna-se uma variável estratégica central, resultante de estruturas de custos mais baixas baseadas em processos mais eficientes (Robertson et al., 2012). Além disso, as oportunidades potenciais para a inovação de processos podem surgir periodicamente como resultado das atividades do dia-a-dia. Eventuais alterações que, por si só, não justificam a substituição de equipamentos relativamente novos podem tornarse viáveis quando os equipamentos mais antigos devem ser reparados ou substituídos em consequência de desgaste natural. Sendo essas alterações pequenas mudanças ou atualizações que potencializam melhorias na produtividade (Robertson et al., 2012). 
Nessa mesma ótica, Reichstein e Salter (2006) postulam que a inovação de processos continua a ser um elemento central nas principais teorias da inovação e do desenvolvimento econômico. A inovação de processo é importante por pelo menos três razões. Em primeiro lugar, as inovações de processo são uma importante fonte de aumento da produtividade. Em segundo lugar, a inovação de processo pode permitir que as empresas obtenham vantagem competitiva. Em terceiro lugar, a inovação de processos é um elemento importante na política governamental de inovação (Reichstein \& Salter, 2006). Portanto, a inovação de processo pode ser caracterizada por novos elementos introduzidos nas operações de produção ou de serviço de uma organização - materiais de entrada, especificações de tarefas, mecanismos de fluxo de trabalho e informação e equipamentos usados para produzir um produto ou prestar um serviço - com o objetivo de reduzir custos e/ou garantir maior qualidade do produto (OECD, 2005; Un \& Asakawa, 2015).

Ademais, propõe-se associar a inovação de processo como o novo imperativo dos estudos da inovação, mais precisamente, no que diz respeito à concepção aberta para relações com o ambiente e outras organizações. Para além da concepção linear da inovação, portanto, há uma necessidade de acesso a recursos externos por meio de relações interorganizacionais, que são preconizadas nas vertentes teóricas dos sistemas de inovação (Lundvall, 1988; Nelson, 1993) e inovação aberta (Chesbrough, 2003). O foco diz respeito à associação entre a cooperação com diferentes parceiros e os resultados de inovação. Basicamente, os parceiros de cooperação podem ser clientes, fornecedores, concorrentes, prestadores de serviços específicos, universidades, institutos de pesquisa privados ou públicos, centros de capacitação, empresas de consultoria, outras empresas de um grupo empresarial ou instituições governamentais (Belderbos, Carree, \& Lokshin, 2004; Schwartz et al., 2012; Tsai, 2009). Em geral, a análise dos diferentes parceiros tem sido realizada por vezes de forma agrupada em algumas classificações, sendo a que prevalece o modo de inovação science, technology and innovation (STI) e doing, using and interacting (DUI) (Fitjar \& Rodriguez-Pose, 2013; Gonzalez-Pernia et al., 2015; Jensen et al., 2007; Sun \& Cao, 2015).

Dentre os estudos que se propuseram associar esses diferentes parceiros à inovação, majoritariamente, foram dedicados a analisar a associação dessas parcerias exclusivamente com a inovação de produto, tida como o principal tipo de inovação (Belderbos et al., 2015; Gesing et al., 2015; Koufteros, Vickery, \& Dröge, 2012; Roberts \& Candi, 2014; Zeng et al., 2010). Em alguns poucos casos foram analisados os efeitos sobre as inovações de produto e de processo (Fitjar \& Rodriguez-Pose, 2013; Gonzalez-Pernia et al., 2015; Robin \& Schubert, 
2013; Su et al., 2009; Tomlinson \& Fai, 2013; Wagner \& Bode, 2014) e poucos estudos se despuseram a enfatizar tão somente a inovação de processo (Ettlie \& Reza, 1992; Un \& Asakawa, 2015), como é proposto neste artigo. Esta proposta se diferencia do primeiro (Ettlie \& Reza, 1992) que teve ênfase, sobretudo, na relação da inovação de processo com a mudança interna da organização. E, em relação ao segundo (Un \& Asakawa, 2015), há um avanço ao considerar o efeito da localização individual de cada parceiro no contexto de um país emergente, diferente dos autores.

Haja vista a busca por maior eficiência nas operações, um pressuposto é que a cooperação externa potencializa o desenvolvimento de inovação de processo na empresa (Un \& Asakawa, 2015). Tipo de inovação que assume um papel estratégico nas organizações como fonte de vantagens competitivas, tanto por promover o desenvolvimento de algo que os concorrentes não conseguem ou por fazê-lo de forma melhor (Tidd et al., 2008). Assim, na seção de desenvolvimento das hipóteses do estudo, é acrescentado à discussão das relações entre os diferentes parceiros de cooperação e a inovação de processo o fator localização do parceiro, no que diz respeito à importância da localização geográfica próxima ou distante.

\subsection{HIPÓTESES}

Nessa seção, seguindo a perspectiva de Fitjar e Rodriguez-Pose (2013) de que as interações nos modos de inovação DUI e STI podem ter dimensões geográficas muito diferentes, discute-se na sequência como a localização de cada um desses dois grupos de parceiros está associada ao desenvolvimento de inovação de processo.

\subsubsection{Localização no Modo de inovação doing, using and interacting (DUI)}

A cooperação vertical com os parceiros da cadeia de valor (isto é, fornecedores e clientes) é o tipo mais comum de parceria (Hewitt-Dundas, 2013; Kaufmann \& Tödtling, 2001; van Beers \& Zand, 2014). Quando existem fortes e estreitos laços de cooperação, as empresas são mais propensas a se envolverem ações conjuntas no desenvolvimento tecnológico, melhorando coletivamente a apropriabilidade das inovações ao longo da cadeia de valor (Tomlinson \& Fai, 2013). Fornecedores são uma fonte importante de ideias para melhorar a produção e, assim, desempenhar um papel fundamental nas inovações de processo (Un \& Asakawa, 2015). As empresas muitas vezes precisam trabalhar em estreita colaboração com seus fornecedores a fim de entender e utilizar todo o potencial das novas tecnologias e materiais (Su et al., 2009; Wagner 
\& Bode, 2014). Quanto aos clientes, alguns estudos não evidenciam associações significativas entre as colaborações com clientes e a inovação de processo (Tomlinson \& Fai, 2013; Un \& Asakawa, 2015). Nesse contexto, mesmo a relação com clientes seja potencialmente mais benéfica para a inovação de produto (Belderbos et al., 2015; Gesing et al., 2015), em casos específicos ela pode ser vantajosa para processos. Un e Asakawa (2015) destacam, por exemplo, que uma empresa pode melhorar seus processos quando seus clientes líderes têm potencial para criar os seus próprios processos de geração de inovações, satisfazendo as necessidades de ambos os atores. Em síntese, a busca ativa por feedback de fornecedores e clientes pode ser uma boa estratégia para melhorar o processo de produção, gerando assim inovações nos processos (Robin \& Schubert, 2013).

Por outro lado, a cooperação com parceiros fora da cadeia de valor, como os concorrentes é tida como mais arriscada (Giovannetti \& Piga, 2017), pois, embora exista colaboração entre concorrentes, permitindo que seus concorrentes observem alguns de seus processos de projeto e fabricação, aqueles que colaboram dependem da ideia de que os concorrentes ainda não terão conhecimento total sobre como os processos funcionam juntos, como um sistema produzindo a eficiência e a qualidade da produção (Un \& Asakawa, 2015). Nesse sentido, a fim de evitar o comportamento oportunista, fortes e estreitas relações cooperativas agem como um mecanismo de governança (entre empresas parceiras), o que pode amenizar tal comportamento. Isso geralmente é conseguido por meio de firmas parceiras que promovem normas sociais e legitimidade para códigos de conduta (implícitos), o que reduz os custos de monitoramento entre empresas. Ademais, visto que os concorrentes pertencem à mesma indústria, as melhores práticas desenvolvidas e mantidas pelos concorrentes podem ser relevantes e potencialmente úteis para a empresa (Fitjar \& Rodriguez-Pose, 2013; Un \& Asakawa, 2015).

Dada a identificação da relevância da cooperação tanto com fornecedores e clientes quanto com concorrentes, a proposta é que a localização geográfica próxima desses parceiros é mais relevante para o desenvolvimento de inovação de processo. O modo de inovação $D U I$ requer cooperação com parceiros que partilham os mesmos problemas e experiências práticas, o que significa que o conhecimento transferido nessa perspectiva tende, como regra geral, a ser mais tácito, que depende da compreensão local e do contexto cultural (Un \& Asakawa, 2015). Mesmo com a possibilidade de interação à distância com os clientes e fornecedores, dada à sua caraterística de falta de proximidade geográfica, organizacional e, provavelmente, social e institucional, a interação próxima é mais relevante, assim como, com os concorrentes. Afinal, o contexto de interação DUI de inovação tende a confiar nos conhecimentos de "know-how", 
que são tipos de conhecimento obtidos através de interações repetidas, principalmente informais (Gonzalez-Pernia et al., 2015). Isto representa necessariamente contatos face a face e proximidade geográfica para poder colher os efeitos indiretos e os conhecimentos tácitos gerados a partir do ambiente local (Fitjar \& Rodriguez-Pose, 2013; Romijn \& Albaladejo, 2002). Nesse sentido, considerando diferentes níveis de localização dos parceiros (mesmo estado, outros estados, mesmo país e estrangeiro) são enunciadas a seguir as hipóteses relacionadas aos parceiros $D U I$.

H1: A cooperação com parceiros da cadeia de valor (clientes e fornecedores) da mesma localidade está mais associada ao desenvolvimento de inovação de processo, quando comparada à cooperação com parceiros de outras localidades.

H2: A cooperação com parceiros concorrentes da mesma localidade está mais associada ao desenvolvimento de inovação de processo, quando comparada à cooperação com parceiros de outras localidades.

\subsubsection{Localização no Modo de inovação science, technology and innovation (STI)}

As parcerias do modo de inovação $S T I$ têm como objetivo gerar o conhecimento codificado e explícito que pode ser utilizado para produzir novas inovações. A capacidade de gerar e adotar inovações, também dependerá, em grande parte, do capital humano disponível na empresa e do nível de treinamento. Por conseguinte, além dos investimentos em P\&D, o nível de educação da força de trabalho e a cooperação com centros de pesquisa e de capacitação são indicadores chave para a análise da inovação e os resultados econômicos ligados à inovação (Fitjar \& Rodriguez-Pose, 2013). Dentre os diversos parceiros STI, estão inclusos acordos de pesquisa de empresas com universidades, institutos de pesquisa, centros de tecnologia, centros de capacitação profissional, assistência técnica, entre outros (Barge-Gil et al., 2011; Du et al., 2014; Fitjar \& Rodriguez-Pose, 2013; Gonzalez-Pernia et al., 2015).

Desse modo, em relação aos parceiros STI, pode-se distingui-los em dois grupos: um grupo formado pelas universidades e institutos de pesquisa e um segundo compreendendo centros de tecnologia e de capacitação profissional, serviços de consultoria, laboratórios de desenvolvimento de pesquisa, associações públicas, entre outros (Cohen \& Levinthal, 1990; Gonzalez-Pernia et al., 2015; Romijn \& Albaladejo, 2002). A lógica por trás desta distinção é que a pesquisa básica tende a ser uma tarefa empreendida por parcerias entre empresa e 
universidade ou institutos de pesquisa, na busca por inovações mais radicais, enquanto a pesquisa aplicada, assim como serviços de treinamento e assistência, é tipicamente uma atividade mais delineada na ação junto aos parceiros STI do segundo grupo (Barge-Gil et al., 2011).

Estudos indicam que as colaborações com universidades e institutos de pesquisa têm um impacto positivo em diferentes proxies de inovação, como na inovação de produtos (Du et al., 2014; Nieto \& Santamaria, 2007), em projetos (Du et al., 2014), em patentes (Baba et al., 2009) e, inclusive, na inovação de processo (Su et al., 2009; Un \& Asakawa, 2015). Essa colaboração orientada à ciência, permite à empresa questionar como os processos são realizados e reanalisar todo o processo do início ao fim, buscando alcançar maior eficiência (Un \& Asakawa, 2015). Isso resulta na possibilidade, por exemplo, da empresa encontrar novos métodos para gerenciar o fluxo de materiais dentro da organização ou novos conceitos para uma melhor organização do manuseio de materiais (Un \& Asakawa, 2015). Nessa perspectiva, Gonzalez-Pernia et al. (2015) enfatizam que a inovação de processos segue também uma abordagem mais experiencial para atualizar os métodos e tecnologias de operação que normalmente são testados com o apoio de alguns agentes do STI, como centros de tecnologia e de capacitação, consultores privados e laboratórios, pois essas atividades de otimização de custos correspondem melhor à fase de exploração e aprimoramento do conhecimento existente.

Os atores do segundo grupo, mesmo não tendo o prestígio das universidades na literatura sobre cooperação e inovação (Geuna \& Muscio, 2009; Perkmann \& Walsh, 2007), assumem diferentes nomenclaturas e estão presentes em diferentes países desenvolvidos, como os Centros Japoneses Kosetsushi, os Centros de Tecnologia de Fabricação dos EUA, os Centros de Serviço Real Italiano, as instituições tecnológicas espanholas e os Conselhos de treinamento e empresa do Reino Unido (Barge-Gil et al., 2011; Huggins, 1998). No Brasil, esses atores podem ser representados pelo Sistema S, que conta com uma rede de escolas, laboratórios e centros tecnológicos espalhados por todo o território nacional, voltada para o treinamento profissional, assistência social, consultoria, pesquisa e assistência técnica, qualificando e promovendo o bem-estar social e disponibilizando educação profissional (Brasil, 2015).

Ademais, considerando esses dois grupos de parceiros $S T I$ e a distinção entre eles, o efeito da localização desses parceiros é decorrente, sobretudo, de dois fatores - formalidade da interação e qualidade do parceiro. Numa corrente relacionada aos centros de capacitação, as diferenças de estrutura de incentivos e de contextos institucionais existentes na relação empresa e instituições de ciência e/ou pesquisa dão origem a arranjos complexos. Isto torna geralmente 
impossível codificar todas as contingências em um contrato e, consequentemente, essas colaborações têm de se apoiar, pelo menos parcialmente, em instituições menos formais, reduzindo assim o risco de oportunismo (Ponds et al., 2007). Portanto, nessa perspectiva a proximidade geográfica importa, pois pode ajudar a superar esses problemas, por causa de um interesse comum na troca de trabalho, no acesso a fundos locais e na confiança mútua induzida por contatos e interações informais (Bishop et al., 2011; Ponds et al., 2007). Nessa linha de pensamento, parceiros STI impulsionados por agências governamentais, sobretudo, em países emergentes, assumem um papel que necessita da proximidade geográfica. Afinal, atuam com um papel de suporte na implementação de técnicas (Barge-Gil et al., 2011; Gonzalez-Pernia et al., 2015) ao passo que capacita o capital humano das empresas em ações cotidianas (Fitjar \& Rodriguez-Pose, 2013). Desse modo,

H3: A cooperação com parceiros centros de capacitação e assistência técnica da mesma localidade está mais associada ao desenvolvimento de inovação de processo, quando comparada à cooperação com parceiros de outras localidades.

Por outro lado, o tipo de conhecimento característico das relações STI com universidades e institutos de pesquisa sugerem uma outra visão. O conhecimento é caracterizado por mais codificado, sendo assumido como universal, que pode ser compartilhado por meio de contextos culturais e distância geográfica (Fitjar \& Rodriguez-Pose, 2013). Aliado a esse ponto, acrescenta-se o aspecto qualidade do parceiro, no que diz respeito à excelência reconhecida e reputação. Para além da proximidade geográfica e de relações informais locais, as empresas preferem colaborar com universidades (e outros parceiros da fronteira da ciência) de alta qualidade e reconhecimento notável que podem se localizar a uma longa distância comparada a universidades próximas de baixa qualidade (Laursen, Reichstein, \& Salter, 2011; Nishimura \& Okamuro, 2011), em especial se tratando de empresas localizadas em países emergentes ou não desenvolvidos. Nesse sentido, é provável que essas colaborações STI sejam desencadeadas pela reputação baseada em conhecimento dos parceiros de alta qualidade e a proximidade geográfica seja de menor relevância (Dornbusch \& Neuhausler, 2015), possibilitando interações em escalas espaciais múltiplas nacionais e internacionais (Ponds et al., 2010; Schwartz et al., 2012) e, portanto, não tão somente locais (Hewitt-Dundas, 2013). 
H4: A cooperação com parceiros universidades e institutos de pesquisa de outras localidades está mais associada ao desenvolvimento de inovação de processo, quando comparada à cooperação com parceiros da mesma localidade.

A Figura 4.2 apresenta o modelo conceitual proposto no artigo.

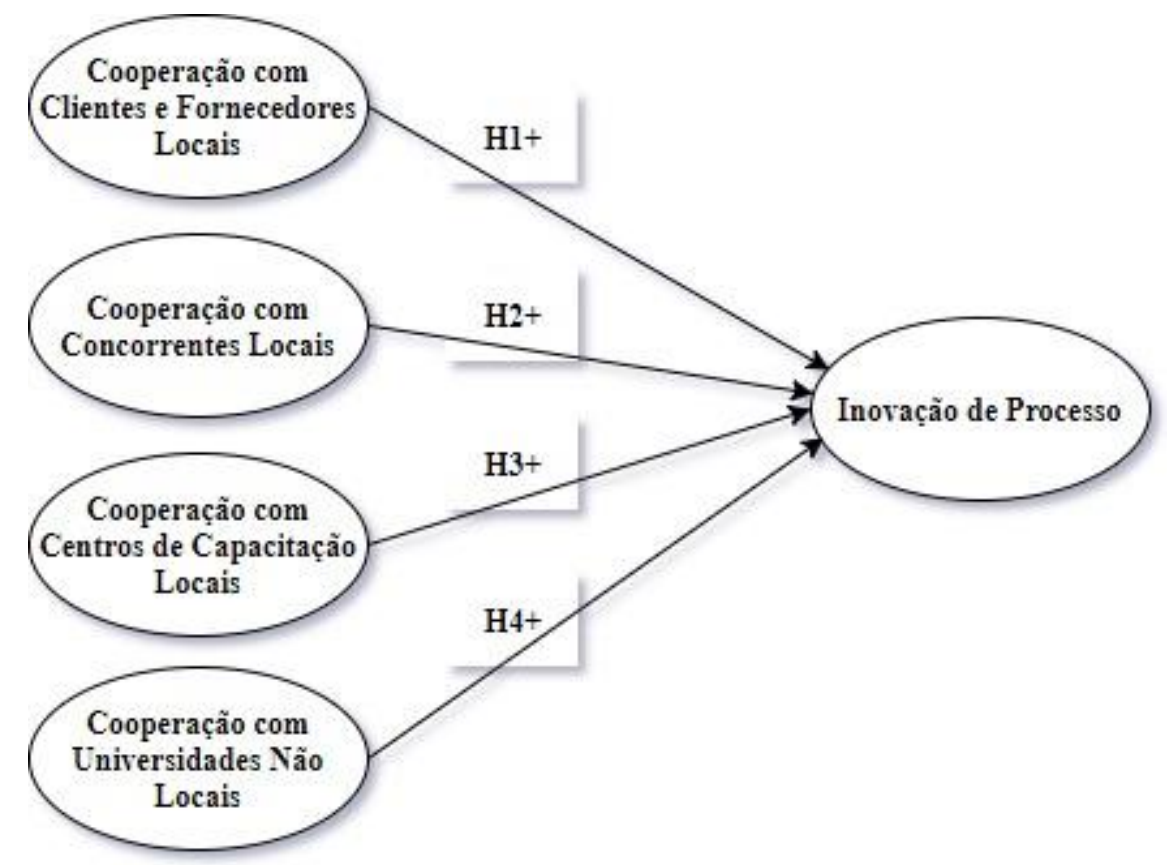

Figura 4.2. Modelo conceitual proposto.

Fonte: Elaborado pelo Autor.

\subsection{METODOLOGIA}

\subsubsection{Base de Dados}

A abordagem adotada no artigo foi de cunho quantitativo, com a utilização do método de pesquisa levantamento de dados secundários. A base de dados foi a Pesquisa de Inovação (PINTEC) desenvolvida pelo Instituto Brasileiro de Geografia e Estatística (IBGE), a partir do Manual de Oslo, que tem como objetivo oferecer diretrizes para a coleta e a interpretação de dados sobre inovação (OECD, 2005), base referencial também para a Community Innovation Survey (CIS) da Comunidade Europeia, adotada em diversas pesquisas na área de inovação (Belderbos, Carree, \& Lokshin, 2004; Segarra-Blasco \& Arauzo-Carod, 2008). As unidades de análise foram 28 setores empresariais (Anexo A) segundo a Classificação Nacional de Atividades Econômicas (CNAE 1 e CNAE 2, equivalentes) e compreendeu o período de cinco edições da pesquisa (2003, 2005, 2008, 2011 e 2014), totalizando uma amostra em painel de 140 observações. 


\subsubsection{Variáveis}

As variáveis dependentes mensuram a inovação de processo. Na PINTEC, a inovação de processo é definida como um processo novo ou substancialmente aprimorado, caracterizado pela introdução de tecnologia de produção nova ou significativamente aperfeiçoada, de métodos para oferta de serviços ou para manuseio e entrega de produtos novos ou substancialmente aprimorados, como também de equipamentos e softwares novos ou significativamente aperfeiçoados em atividades de suporte à produção. De modo que o resultado da adoção de processo novo ou substancialmente aprimorado deve ser significativo em termos do aumento da qualidade do produto (bem/serviço) ou da diminuição do custo unitário de produção e entrega. A introdução deste processo pode ter por objetivo a produção ou entrega de produtos novos ou substancialmente aprimorados, que não possam utilizar os processos previamente existentes, ou simplesmente aumentar a eficiência da produção e da entrega de produtos já existentes (IBGE, 2014).

Algumas pesquisas consideram proxies semelhantes para a inovação de processo (Fitjar \& Rodriguez-Pose, 2013; Gonzalez-Pernia et al., 2015; Un \& Asakawa, 2015). Ademais, considera-se também três graus de inovatividade (Dosi, 1982; Nieto \& Santamaria, 2007), gerando as seguintes variáveis dependentes: Inovação de processo com grau de inovatividade para a empresa (IPCE), Inovação de processo com grau de inovatividade para o mercado nacional (IPCMN) e Inovação de processo com grau de inovatividade para o mercado mundial (IPCMM). Foram obtidas, respectivamente, por meios das seguintes questões (1) "Este processo [novo ou substancialmente aperfeiçoado] é Novo para a empresa, mas já existente no setor no Brasil", (2) "Este processo [novo ou substancialmente aperfeiçoado] é Novo para o setor no Brasil, mas já existente em outro(s) país(es)" e (3) "Este processo [novo ou substancialmente aperfeiçoado] é Novo para o setor em termos mundiais". Diante dessas questões, a variável IPCE foi resultante do total de empresas que desenvolveram inovação de processo para a empresa dividido pelo total de empresas entrevistadas de cada setor, multiplicado por cem para obtenção de um valor entre 0 e 100. Enquanto a variável IPCMN foi resultante do total de empresas que desenvolveram inovação de processo para o mercado nacional dividido pelo total de empresas entrevistadas de cada setor, multiplicado por cem para obtenção de um valor entre 0 e 100. Por fim, a variável IPCMM foi resultante do total de empresas que desenvolveram inovação de processo para o mercado nacional dividido pelo total de empresas entrevistadas de cada setor, multiplicado por cem para obtenção de um valor entre 
0 e 100. As variáveis dependentes foram transformadas pelo procedimento de Box Cox, para a aderência à normalidade, e padronizadas (Fávero, 2015).

As variáveis independentes estão associadas aos diferentes parceiros de cooperação que as empresas se relacionam para inovar. Na PINTEC, o IBGE adota a definição de cooperação para inovação como a participação ativa em projetos conjuntos de $\mathrm{P} \& \mathrm{D}$ e outros projetos de inovação com outra organização (empresa ou instituição). Não implicando, necessariamente, que as partes envolvidas obtêm benefícios comerciais imediatos. Ao mesmo tempo que a simples contratação de serviços de outra organização, sem a sua colaboração ativa, não é considerada cooperação. A questão referência para a composição das variáveis solicitava que as empresas indicassem "a localização de cada categoria de parceiro", tendo como opções de respostas: (1) - Mesmo estado, (2) - Brasil (outros estados), (3) - Mercosul, (4) - Estados Unidos, (5) - Europa e (6) Outros países.

Diante disso, e considerando as classificações STI e DUI (Fitjar \& Rodriguez-Pose, 2013; Gonzalez-Pernia et al., 2015; Jensen et al., 2007), foram definidas as variáveis independentes. Para a delimitação dessas variáveis, delimitou-se índices organizados em dois grupos relacionados aos diferentes níveis de localidade: a) Índice de Dimensão Nacional: compara a cooperação com parceiros de outros estados brasileiros com parceiros de mesmo estado, portanto foi obtido a partir da divisão de cada tipo de parceiro localizado em outros estados sobre os parceiros do mesmo estado, gerando um índice que foi padronizado de 0 a 1 . Portanto, valores próximos a 1 indicam uma maior cooperação com parceiros de outros estados em relação à cooperação com parceiros de mesmo estado e valores próximos a 0 indicam o contrário. b) Índice de Dimensão Estrangeira: compara a cooperação com parceiros de outros países com parceiros nacionais, portanto foi obtido a partir da divisão de cada tipo de parceiro localizado no exterior sobre os parceiros nacionais, gerando um índice que foi padronizado de 0 a 1. Portanto, valores próximos a 1 indicam uma maior cooperação com parceiros estrangeiros em relação à cooperação com parceiros nacionais e valores próximos a 0 indicam o contrário. A Figura 4.3 sintetiza as variáveis independentes: 


\begin{tabular}{|c|c|c|c|}
\hline $\begin{array}{l}\text { Dimensão da } \\
\text { Localização }\end{array}$ & $\begin{array}{c}\text { Classificação } \\
\text { dos } \\
\text { Parceiros } \\
\end{array}$ & Parceiros & Código \\
\hline \multirow{5}{*}{$\begin{array}{l}\text { Nacional (Outros estados } \\
\text { versus mesmo estado) }\end{array}$} & \multirow{3}{*}{$D U I$} & Clientes & Cli_nac \\
\hline & & Fornecedores & Forn_nac \\
\hline & & Concorrentes & Conc_nac \\
\hline & \multirow[b]{2}{*}{ STI } & Universidades e Institutos de Pesquisa & Univ_nac \\
\hline & & $\begin{array}{l}\text { Centros de Capacitação Profissional e Assistência } \\
\text { Técnica }\end{array}$ & Cent_nac \\
\hline \multirow{5}{*}{$\begin{array}{l}\text { Estrangeira (Estrangeiros } \\
\text { versus Nacionais) }\end{array}$} & \multirow{3}{*}{$D U I$} & Clientes & Cli_est \\
\hline & & Fornecedores & Forn_est \\
\hline & & Concorrentes & Conc_est \\
\hline & \multirow[b]{2}{*}{ STI } & Universidades e Institutos de Pesquisa & Univ_est \\
\hline & & $\begin{array}{l}\text { Centros de Capacitação Profissional e Assistência } \\
\text { Técnica }\end{array}$ & Cent_est \\
\hline
\end{tabular}

Figura 4.3. Variáveis Independentes.

Fonte: Elaborado pelo Autor.

Para o teste das hipóteses também foram consideradas algumas variáveis de controle. A primeira foi a inovação de produto com os seus três graus de inovatividade, Inovação de produto com grau de inovatividade para a empresa (IPDE), Inovação de produto com grau de inovatividade para o mercado nacional (IPDMN) e Inovação de produto com grau de inovatividade para o mercado mundial (IPDMM). A variável IPDE consiste no total de empresas que desenvolveram inovação de produto para a empresa dividido pelo total de empresas entrevistadas de cada setor, multiplicado por cem para obtenção de um valor entre 0 e 100, a variável IPDMN consiste na divisão do total de empresas que desenvolveram inovação de produto para o mercado nacional pelo total de empresas entrevistadas de cada setor, multiplicado por cem para obtenção de um valor entre 0 e 100 e a variável IPDMM consiste na divisão do total de empresas que desenvolveram inovação de produto para o mercado mundial pelo total de empresas entrevistadas de cada setor, multiplicado por cem para obtenção de um valor entre 0 e 100 . Ressalta-se que no desenvolvimento dos modelos foi mantida a equivalência dos graus de inovatividade, portanto a inovação de produto para a empresa foi utilizada como variável de controle somente nos modelos cuja variável dependente foi a inovação de processo a nível empresa, sendo o mesmo aplicado para os mercados nacional e mundial. Espera-se que essas variáveis de inovação de produto se associem positivamente com as respectivas inovações de processo em seus graus de inovatividade, dado que o planejamento e desenvolvimento de novos produtos devem ser integrados ao projeto de processo e às tecnologias de fabricação (Utterback \& Abernathy, 1975; Wagner \& Bode, 2014).

Outro grupo de variáveis considerado como controle nos modelos foi a realização de atividades inovativas pelas empresas. A definição de atividades inovativas na PINTEC refere-se às atividades representativas dos esforços da empresa voltados para a melhoria do seu acervo 
tecnológico e, consequentemente, para o desenvolvimento e implementação de produtos (bens ou serviços) ou processos novos ou significativamente aperfeiçoados. As atividades inovativas consideradas foram o desenvolvimento de atividades internas de Pesquisa \& Desenvolvimento, a aquisição de máquinas e equipamentos e a realização de treinamento orientado ao desenvolvimento de produtos e processos (IBGE, 2014). Essas atividades inovativas representam os esforços empreendidos pelas empresas com vistas ao desenvolvimento de inovações, portanto também refletem a capacidade de absorção das mesmas (Tsai, 2009; Un \& Asakawa, 2015), desse modo espera-se uma relação positiva com a inovação de processo em seus três graus de inovatividade. Essas variáveis foram mensuradas a partir do total de empresas que desenvolveram cada umas dessas atividades inovativas dividido pelo total de empresas entrevistadas de cada setor multiplicado por cem para obtenção de um valor entre 0 e 100.

A Receita Líquida de Vendas (RLV) foi outra variável selecionada como controle, para representar uma variável de produtividade do setor (Su et al., 2009; Un \& Asakawa, 2015), de modo que setores mais produtivos devem apresentam um maior número de empresas que desenvolvem inovação de processos em seus três graus de inovatividade. A RLV consiste no logaritmo natural $(\mathrm{ln})$ da receita líquida de vendas de cada setor dividida pelo total de empresas entrevistadas de cada setor. Por fim, com o objetivo de verificar a influência temporal, foram consideradas as variáveis dummies 2005, 2008, 2011 e 2014, referentes às edições da PINTEC.

\subsubsection{Análise dos Dados}

Para a análise dos dados, considerando que as observações se constituem em um conjunto de indivíduos (setores) ao longo do tempo (edições da PINTEC), foi adotada a técnica de regressão com dados em painel. Para tanto foram estimadas três regressões para cada variável dependente, IPCE, IPCMN e IPCMM, referentes às técnicas (a) Regressão em painel longitudinal (Pooled $O L S)$, (b) Regressão em painel longitudinal com efeitos fixos e (c) Regressão em painel longitudinal com efeitos aleatórios (Fávero, 2015; Gujarati \& Porter, 2011).

Para fins de decisão de qual o melhor modelo de ajuste de dados em painel, foram considerados dois testes: primeiramente, o Teste de Hausman e, quando necessário, o Teste do multiplicador de Lagrange de Breusch-Pagan. A hipótese nula subjacente ao Teste de Hausman é a de que os estimadores dos modelos de efeitos fixos e de modelos aleatórios não diferem substancialmente ( $\mathrm{H} 0=$ efeitos aleatórios é preferível). Se a hipótese nula for rejeitada, a um dado nível de significância, a conclusão é que o modelo de efeitos aleatórios não é adequado, 
sendo preferível o modelo de efeitos fixos. Já o Teste do multiplicador de Lagrange de BreuschPagan permite comparar os estimadores obtidos por efeitos aleatórios e por Pooled OLS. Este teste analisa se a variância entre indivíduos é igual a zero, ou seja, se não existem diferenças significativas entre os indivíduos ( $\mathrm{H} 0=$ Pooled $O L S$ é preferível), ou por outro lado, se ocorrem diferenças estatisticamente diferentes entre os indivíduos (H1 = efeitos aleatórios é preferível), a um determinado nível de significância (Fávero, 2015; Gujarati \& Porter, 2011).

\subsection{RESULTADOS}

A matriz de correlação (Tabela 4.1) apresenta a maioria das correlações como não significativas e quando significativas de fraca intensidade, afastando possíveis indícios de multicolinearidade. 


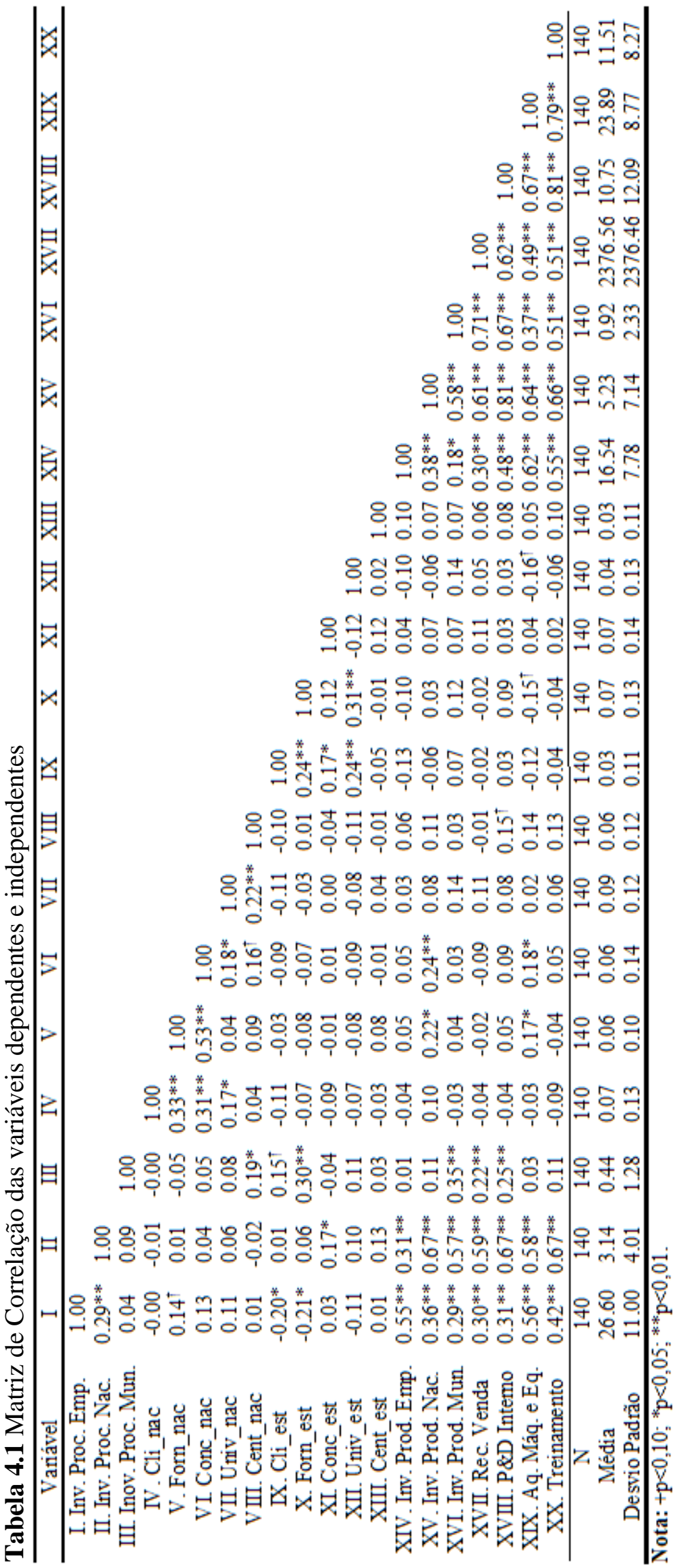


Na Tabela 4.2 são apresentados os resultados dos modelos relacionados as variáveis dependentes Inovação de Processo para a Empresa (IPCE), Inovação de Processo para o Mercado Nacional (IPCMN) e Inovação de Processo para o Mercado Mundial (IPCMM).

Tabela 4.2 Resultados dos modelos.

\begin{tabular}{|c|c|c|c|c|c|c|c|}
\hline \multirow[t]{2}{*}{ Parceiros } & \multirow[t]{2}{*}{ Variável } & \multicolumn{2}{|c|}{$\begin{array}{c}\text { Inov. Proc. } \\
\text { Empresa }\end{array}$} & \multicolumn{2}{|c|}{$\begin{array}{c}\text { Inov. Proc. Merc. } \\
\text { Nacional }\end{array}$} & \multicolumn{2}{|c|}{$\begin{array}{c}\text { Inov. Proc. Merc. } \\
\text { Mundial }\end{array}$} \\
\hline & & Modelo 1 & Modelo 2 & Modelo 3 & Modelo 4 & Modelo 5 & Modelo 6 \\
\hline \multirow{10}{*}{$\begin{array}{c}\text { Outros } \\
\text { Estados } \\
\text { versus } \\
\text { Mesmo } \\
\text { Estado }\end{array}$} & Cli_nac & & 0.026 & & 0.071 & & 0.032 \\
\hline & & & $(0.059)$ & & $(0.060)$ & & $(0.080)$ \\
\hline & Forn_nac & & -0.008 & & 0.101 & & 0.046 \\
\hline & & & $(0.065)$ & & $(0.069)$ & & $(0.099)$ \\
\hline & Conc_nac & & -0.050 & & -0.017 & & 0.025 \\
\hline & & & $(0.064)$ & & $(0.067)$ & & $(0.097)$ \\
\hline & Univ_nac & & -0.004 & & 0.042 & & 0.080 \\
\hline & & & $(0.057)$ & & $(0.058$ & & $(0.081)$ \\
\hline & Cent_nac & & $-0.118 *$ & & -0.020 & & 0.026 \\
\hline & & & $(0.056)$ & & $(0.058)$ & & $(0.085)$ \\
\hline \multirow{10}{*}{$\begin{array}{c}\text { Estrangeiros } \\
\text { versus } \\
\text { Nacionais }\end{array}$} & Cli_est & & 0.006 & & -0.061 & & 0.018 \\
\hline & & & $(0.060)$ & & $(0.061)$ & & $(0.085)$ \\
\hline & Forn_est & & $-0.183^{* *}$ & & -0.077 & & $0.231^{\dagger}$ \\
\hline & & & $(0.060)$ & & $(0.063)$ & & $(0.120)$ \\
\hline & Conc_est & & 0.052 & & $0.126^{*}$ & & 0.055 \\
\hline & & & $(0.058)$ & & $(0.058)$ & & $(0.082)$ \\
\hline & Univ_est & & 0.097 & & $0.129 *$ & & -0.029 \\
\hline & & & $(0.060)$ & & $(0.062)$ & & $(0.084)$ \\
\hline & Cent_est & & -0.032 & & -0.053 & & 0.011 \\
\hline & & & $(0.059)$ & & $(0.058)$ & & $(0.075)$ \\
\hline \multirow{10}{*}{$\begin{array}{l}\text { Variáveis de } \\
\text { Controle }\end{array}$} & Inv. Prod. Emp. & $0.191 * *$ & $0.179 *$ & -0.062 & -0.182 & $0.637 * *$ & 0.272 \\
\hline & & $(0.084)$ & $(0.086)$ & $(0.125)$ & $(0.142)$ & $(0.244)$ & $(0.285)$ \\
\hline & Rec. Venda & $0.436 * *$ & $0.431 * *$ & -0.194 & $-0.254^{\dagger}$ & -0.082 & 0.051 \\
\hline & & $(0.136)$ & $(0.141)$ & $(0.139)$ & $(0.145)$ & $(0.163)$ & $(0.155)$ \\
\hline & P\&D Interno & 0.200 & $0.322 *$ & 0.306 & $0.481 *$ & 0.110 & 0.287 \\
\hline & & $(0.163)$ & $(0.162)$ & $(0.189)$ & $(0.198)$ & $(0.214)$ & $(0.239)$ \\
\hline & Aq. Máq. e Eq. & $0.454 * *$ & $0.462 * *$ & 0.099 & 0.046 & 0.139 & 0.049 \\
\hline & & $(0.103)$ & $(0.108)$ & $(0.103)$ & $(0.110)$ & $(0.136)$ & $(0.152)$ \\
\hline & Treinamento & -0.017 & -0.055 & 0.120 & 0.139 & -0.024 & 0.072 \\
\hline & & $(0.125)$ & $(0.127)$ & $(0.128)$ & $(0.129)$ & $(0.172)$ & $(0.194)$ \\
\hline \multirow{13}{*}{ Fator Tempo } & Dummy 2005 & $1.207 * *$ & $1.207 * *$ & $0.859 * *$ & $0.769 * *$ & -0.089 & -0.155 \\
\hline & & $(0.161)$ & $(0.169)$ & $(0.164)$ & $(0.176)$ & $(0.245)$ & $(0.304)$ \\
\hline & Dummy 2008 & $1.146^{* * *}$ & $1.138 * *$ & $0.702 * *$ & $0.774 * *$ & -0.278 & -0.192 \\
\hline & & $(0.179)$ & $(0.183)$ & $(0.200)$ & $(0.223)$ & $(0.258)$ & $(0.324)$ \\
\hline & Dummy 2011 & $1.343 * *$ & $1.399 * *$ & $0.773 * *$ & $0.729 * *$ & -0.005 & 0.065 \\
\hline & & $(0.155)$ & $(0.164)$ & $(0.161)$ & $(0.173)$ & $(0.253)$ & $(0.328)$ \\
\hline & Dummy 2014 & $1.349 * *$ & $1.373 * *$ & $1.099 * *$ & $1.072 * *$ & 0.053 & 0.102 \\
\hline & & $(0.163)$ & $(0.174)$ & $(0.185)$ & $(0.199)$ & $(0.251)$ & $(0.318)$ \\
\hline & Constante & $-1.009 * *$ & $-1.023^{* *}$ & $-0.704 * *$ & $-0.683^{* *} *$ & 0.156 & 0.122 \\
\hline & & $(0.114)$ & $(0.118)$ & $(0.128)$ & $(0.138)$ & $(0.240)$ & $(0.270)$ \\
\hline & $\mathbf{N}$ & 140 & 140 & 135 & 135 & 102 & 102 \\
\hline & $\mathbf{R}^{2}$ & 0.523 & 0.516 & 0.404 & 0.395 & 0.342 & 0.437 \\
\hline & $\mathbf{F}$ & $27.12 * *$ & $14.91 * *$ & $7.65 * *$ & $4.54 * *$ & $30.71 * *$ & $46.66 * *$ \\
\hline
\end{tabular}

Nota: ${ }^{\dagger} \mathrm{p}<0,10 ;{ }^{*} \mathrm{p}<0,05 ;{ }^{*} \mathrm{p}<0,01$. Erro-Padrão nos parênteses. 
Ademais, os Modelos 1 e 2, representam os modelos de regressão de dados em painel com efeitos fixos para a variável dependente IPCE, considerado o mais adequado em relação às regressões Pooled OLS e com efeitos aleatórios, após a realização do Teste de Hausman ao nível de significância de 5\% (Prob>chi2 $=0.0000$ ). Os Modelos 3 e 4 representam os modelos de regressão com efeitos fixos para a variável dependente IPCMN, considerado o mais adequado, ao nível de significância de $5 \%$ pelo Teste de Hausman (Prob>chi $=0.0000)$. Por fim, os modelos 5 e 6 representam os modelos de regressão com efeitos aleatórios para a variável dependente IPCMM, considerado o mais adequado, ao nível de significância de 5\% pelo Teste do Multiplicador de Lagrange de Breusch-Pagan (Prob>chibar2 = 0.0259).

Considerando o modelo completo para a variável dependente IPCE (Modelo 2), verificou-se um ajuste geral com um F significativo ao nível de significância de $1 \%$ e um $\mathrm{R}^{2}$ de $51,6 \%$. Na comparação da localização na dimensão nacional (outras unidades da federação versus mesma unidade da federação), considerando os parceiros modo de inovação DUI, não constatou-se nenhuma relação significativa. Já em relação aos parceiros de inovação $S T I$, uma relação significativa e negativa dos Centros de Capacitação e Assistência Técnica $(\beta=-0.118, p<0.05)$ foi identificada, ou seja, a localização próxima desses parceiros (mesma unidade da federação) é mais vantajosa quando se pretende desenvolver inovação de processo a nível empresa, logo esse achado demonstra evidências para suportar a hipótese H3.

$\mathrm{Na}$ análise da localização na dimensão estrangeira (estrangeiros versus nacionais), a relação com fornecedores (parceiros DUI) é significativa e negativa com a variável dependente $(\beta=-$ $0.183, \mathrm{p}<0.01)$. Tal fato representa que o parceiro fornecedor dentro do âmbito nacional é preferível em relação aos estrangeiros quando a empresa pretende desenvolver inovação de processo com grau de inovatividade menor, ou seja, para a empresa. Desse modo, a hipótese H1 foi suportada parcialmente, visto que os fornecedores nacionais são relevantes, mas não constatou-se relações significantes para os clientes. Em relação aos parceiros $S T I$, na dimensão estrangeira versus nacional não foi identificada nenhuma relação significativa no modelo completo. Em relação às variáveis de controle, com exceção da variável treinamento, todas foram consideradas significativas e positivamente relacionadas com a inovação de processo para empresa, conforme esperado. Por fim, numa análise longitudinal no tempo, verificou-se uma associação positiva e significativa em todas as variáveis dummies.

Para a variável dependente IPCMN, o modelo completo (Modelo 4 na Tabela 4.2) teve um ajuste geral com um F significativo ao nível de significância de $1 \%$ e com um $\mathrm{R}^{2}$ de 39,5\%. Na dimensão localização nacional (outras unidades da federação versus mesma unidade da 
federação) não foram encontradas relações significativas em nenhum dos dois grupos de parceiros. Por outro lado, na dimensão estrangeira (estrangeiros versus nacionais), tanto os concorrentes, parceiros DUI, quanto as universidades e institutos de pesquisa, parceiros STI, apresentaram uma relação positiva e significativa com o desenvolvimento de inovação de processo para o mercado nacional, apresentado os seguintes coeficientes $\beta=0.126(p<0.05)$ e $\beta=0.129$ ( $\mathrm{p}<0.05)$, respectivamente. Esses resultados demostraram que, considerando a análise da localização dos concorrentes, a hipótese H2 foi suportada negativamente, pois foi proposto que estes parceiros deveriam ser locais. Por outro lado, uma maior importância das universidades e institutos de pesquisa estrangeiros, em relação aos locais, foi evidenciada, suportando a hipótese H4. No que tange às variáveis de controle, as variáveis receita de vendas e desenvolvimento de $P \& D$ interno apresentaram uma relação significativa com a inovação de processo para o mercado nacional, sendo a primeira uma associação negativa $(\beta=-0.254$, $\mathrm{p}<0.10)$ e a segunda uma associação positiva $(\beta=0.481, \mathrm{p}<0.05)$. Por fim, na análise longitudinal do tempo, uma associação positiva e significativa em todas as variáveis dummies foi verificada.

O modelo completo para a variável dependente IPCMM (Modelo 6 na Tabela 4.2) demonstrou um ajuste geral com um valor de $\mathrm{F}$ significativo ao nível de significância de $1 \%$ e um $\mathrm{R}^{2}$ de 43,7\%. Na dimensão localização nacional (outras unidades da federação versus mesma unidade da federação), assim como para a inovação de processo nível mercado nacional, não foram encontradas relações significativas em nenhum dos dois grupos de parceiros com a inovação de processo para o mercado mundial. Em contrapartida, na dimensão estrangeira (estrangeiros versus nacionais), os fornecedores, parceiros DUI, foram os únicos que apresentaram uma relação positiva e significativa com o desenvolvimento de inovação de processo para o mercado mundial $(\beta=0.231, \mathrm{p}<0.05)$. Ou seja, para a inovação de processo com maior grau de inovatividade a cooperação com fornecedores estrangeiros é preferível, em detrimento dos fornecedores nacionais, contrariando a perspectiva proposta. $\mathrm{Na}$ análise das variáveis de controle, apesar da variável desenvolvimento de inovação de produto para o mercado nacional apresentar relação positiva e significativa em modelos intermediários (Modelos 9 e 10), quando se considera o modelo completo ela não se apresenta significativa, assim como ocorre com as demais variáveis de controle e variáveis de fator tempo.

Por fim, em relação às variáveis de controle utilizados, foi constatada a associação entre inovação de produto e inovação de processo a nível de empresa, reforçando a característica de complementariedade existente na literatura sobre esses dois tipos de inovação (Utterback, 
1994), de modo que um não deve ser privilegiado em detrimento da outro (Robertson et al., 2012). Em termos de receita de vendas, proxy para produtividade dos setores (Su et al., 2009), verificou-se uma associação positiva ao nível de empresa da inovação de processo, porém negativa ao nível de inovação de processo para o mercado mundial. Essa constatação revela que setores mais produtivos no que diz respeito ao volume de vendas têm sua inovação de processo a nível micro potencializada, efeito este não verificado na inovação de processo a nível de mercado nacional. Quanto às atividades inovativas, os efeitos do desenvolvimento de P\&D interno são mais relevantes, seguidos pela aquisição de máquinas e equipamentos, para o desenvolvimento de inovação de processo, enquanto os efeitos de treinamento de pessoal são nulos. Essa conjectura demonstra mais uma diferenciação no que diz respeito aos impactos dos esforços das empresas para o desenvolvimento de inovação, revelando, por exemplo, o papel importante de fontes internas de $\mathrm{P} \& \mathrm{D}$, além das externas, fruto de cooperações (Belderbos et al., 2006).

\subsubsection{Análise Complementar: Parceiros Estrangeiros oriundos de países Desenvolvidos}

Haja vista que na análise foi considerado um agrupamento de todas as localidades estrangeiras possíveis de cada parceiro para mensurar a dimensão estrangeiros versus nacionais, procedeuse com uma análise complementar, visando discriminar a relação parceiros estrangeiros de regiões desenvolvidas versus parceiros nacionais. Desse modo, o propósito foi verificar se os resultados encontrados, sobretudo, das relações significativas entre parceiros estrangeiros (frente a nacionais) e o desenvolvimento de inovação de processos em seus diferentes graus de inovatividade, são decorrentes somente da localização estrangeira dos parceiros ou também da localização estrangeira em países ou regiões desenvolvidas.

Para tanto, foi desenvolvido o índice de dimensão estrangeira desenvolvida para cada parceiro, o qual compara a cooperação com parceiros de países desenvolvidos com parceiros nacionais, portanto foi obtido a partir da divisão de cada tipo de parceiro localizado no exterior em regiões desenvolvidas ((4) - Estados Unidos e (5) - Europa) sobre os parceiros nacionais, gerando um índice que foi padronizado de 0 a 1 . Portanto, valores próximos a 1 indicam uma maior cooperação com parceiros estrangeiros desenvolvidos em relação à cooperação com parceiros nacionais e valores próximos a 0 indicam o contrário.

Na Tabela 4.3 são apresentados os resultados dos modelos completos relacionados às três variáveis dependentes: Inovação de Processo para a Empresa (IPCE), para o Mercado Nacional 
(IPCMN) e para o Mercado Mundial (IPCMM), nos modelos de regressão adequados, considerados o Teste de Hausman e o Teste do multiplicador de Lagrange de Breusch-Pagan.

Tabela 4.3 Parceiros estrangeiros de regiões desenvolvidas.

\begin{tabular}{|c|c|c|c|c|c|c|c|}
\hline \multirow[t]{2}{*}{ Parceiros } & \multirow[t]{2}{*}{ Variável } & \multicolumn{2}{|c|}{$\begin{array}{c}{\text { Modelo } 7^{(a)}}^{\text {Inv. Processo Nível }} \\
\text { Empresa } \\
\end{array}$} & \multicolumn{2}{|c|}{$\begin{array}{c}\text { Modelo 8 }^{(\mathbf{b})} \\
\text { Inv. Processo Nível } \\
\text { Nacional } \\
\end{array}$} & \multicolumn{2}{|c|}{$\begin{array}{c}\text { Modelo } 9 \text { (c) } \\
\text { Inv. Processo Nível } \\
\text { Mundial } \\
\end{array}$} \\
\hline & & Coef. & Erro-Padrão & Coef. & Erro-Padrão & Coef. & Erro-Padrão \\
\hline \multirow{5}{*}{$\begin{array}{c}\text { Estrangeiros } \\
\text { Desenvolvidos } \\
\text { versus } \\
\text { Nacionais }\end{array}$} & Cli_des & 0.029 & 0.058 & $-0.100^{\dagger}$ & 0.060 & -0.017 & 0.087 \\
\hline & Forn_des & $-0.244 * *$ & 0.063 & -0.012 & 0.067 & $0.375^{*}$ & 0.162 \\
\hline & Conc_des & 0.067 & 0.055 & $0.117^{*}$ & 0.056 & 0.117 & 0.079 \\
\hline & Univ_des & $0.148^{*}$ & 0.065 & $0.218 * *$ & 0.069 & 0.040 & 0.113 \\
\hline & Cent_des & -0.019 & 0.055 & 0.031 & 0.055 & 0.043 & 0.084 \\
\hline \multirow{5}{*}{$\begin{array}{l}\text { Variáveis de } \\
\text { Controle }\end{array}$} & $\begin{array}{l}\text { Inv. Prod. Emp. } \\
\text { Inv. Prod. Nac. }\end{array}$ & $0.201 *$ & 0.081 & 0.022 & 0.110 & & \\
\hline & Inv. Prod. Mun. & $0425 * *$ & 0137 & 0015 & 0085 & $\begin{array}{l}-0.099 \\
0.152\end{array}$ & $\begin{array}{l}0.297 \\
0.130\end{array}$ \\
\hline & P\&D Interno & $0.347^{*}$ & $\begin{array}{l}0.151 \\
0.161\end{array}$ & $0.323 *$ & $\begin{array}{l}0.085 \\
0.161\end{array}$ & $0.485^{*}$ & 0.239 \\
\hline & Aq. Máq. e Eq. & $0.450 * *$ & 0.100 & 0.040 & 0.098 & 0.017 & 0.148 \\
\hline & Treinamento & -0.094 & 0.122 & $0.236^{\dagger}$ & 0.124 & 0.140 & 0.188 \\
\hline \multirow{5}{*}{ Fator Tempo } & Dummy 2005 & $1.168 * *$ & 0.163 & $0.740 * *$ & 0.179 & -0.139 & 0.333 \\
\hline & Dummy 2008 & $1.133 * *$ & 0.177 & $0.600 * *$ & 0.201 & -0.030 & 0.347 \\
\hline & Dummy 2011 & $1.373 * *$ & 0.153 & $0.708 * *$ & 0.170 & 0.192 & 0.346 \\
\hline & Dummy 2014 & $1.342 * *$ & 0.163 & $0.905 * *$ & 0.183 & 0.222 & 0.338 \\
\hline & Constante & $-1.003 * *$ & 0.113 & $-0.598 * *$ & 0.145 & 0.043 & 0.275 \\
\hline \multicolumn{2}{|c|}{$\mathbf{N}$} & \multicolumn{2}{|r|}{140} & \multicolumn{2}{|r|}{135} & \multicolumn{2}{|r|}{102} \\
\hline \multicolumn{2}{|c|}{$\mathbf{R}^{2}$} & \multicolumn{2}{|c|}{0.519} & \multicolumn{2}{|r|}{0.606} & \multicolumn{2}{|r|}{0.455} \\
\hline \multicolumn{2}{|c|}{$\mathbf{F}$} & \multirow{2}{*}{\multicolumn{2}{|c|}{$20.64 * *$}} & & & \multirow{2}{*}{\multicolumn{2}{|c|}{$5.18 * *$}} \\
\hline $\mathbf{W}$ & $\operatorname{ldd} \chi^{2}$ & & & & $8.00 * *$ & & \\
\hline
\end{tabular}

Nota: (a) Modelo de regressão em painel longitudinal com efeitos fixos. (b) Modelo de regressão em painel longitudinal com efeitos aleatórios. (c) Modelo de regressão em painel longitudinal (Pooled OLS).

${ }^{\dagger} \mathrm{p}<0,10 ; * \mathrm{p}<0,05 ; * * \mathrm{p}<0,01$.

Considerando os três graus de inovatividade, foi verificado que no nível de inovação de processo para a empresa, a cooperação com fornecedores estrangeiros desenvolvidos é significativa e negativa $(\beta=-0.244$, $p<0.01)$ e a cooperação com universidades e institutos de pesquisa é significativa e positiva $(\beta=0.148, \mathrm{p}<0.05)$. No grau de inovatidade de processo para o mercado nacional, constatou-se uma relação significativa e negativa com a cooperação com clientes estrangeiros desenvolvidos $(\beta=-0.100, p<0.10)$ e uma relação significativa e positiva tanto na cooperação com concorrentes $(\beta=0.117, \mathrm{p}<0.05)$ quanto com universidades e institutos de pesquisa de regiões desenvolvidas $(\beta=0.218, \mathrm{p}<0.01)$. Por fim, concernente ao nível de inovação de processo para o mercado mundial, foi identificada uma relação significativa e positiva com a cooperação com fornecedores estrangeiros de regiões desenvolvidas $(\beta=0.375$, p <0.01). Na análise das variáveis de controle, verificou-se uma associação significante e positiva do desenvolvimento de $\mathrm{P} \& \mathrm{D}$ interno com os três graus de inovatidade de processo. No nível empresa, também foram constatadas associações estatisticamente significantes e positivas 
das variáveis inovação de produto nível empresa, receita de vendas e aquisição de máquinas e equipamentos. E no nível inovação de processo para o mercado nacional foi identificada uma relação positiva com as atividades de treinamento. Quanto ao fator tempo, verificamos uma associação positiva e significativa das variáveis dummies para os graus de inovatividade empresa e mercado nacional.

Ademais, ao delinear a perspectiva estrangeira de regiões desenvolvidas, verificou-se novamente uma relação significativa das universidades e institutos de pesquisa com a inovação de processo a nível mercado nacional, mas também a nível empresa. Nesse contexto, mesmo que o potencial da relação com esses parceiros esteja alinhado a inovações com maior grau de inovatidade, os efeitos podem ser encontrados também no nível mais micro, quando se considera origem do parceiro de uma região desenvolvida. Esse fato corrobora a crescente literatura da interação universidade e empresa (Bishop et al., 2011; Perkmann \& Walsh, 2007), que mesmo se apresentando como um corpo teórico em vias de consolidação, encontra-se aberta para novas ilações que delineiem diferentes aspectos, tal como o efeito localização.

\subsection{DISCUSSÃO DOS RESULTADOS}

Diante da proposta de analisar a relação entre a cooperação com parceiros estrangeiros e nacionais e o desenvolvimento de inovação de processo, diferentes contribuições foram reveladas nos resultados. Os achados demonstram que a parceria com centros de capacitação da mesma unidade da federal é importante para o desenvolvimento de inovações de processo com grau de inovatividade para a empresa. Ainda, inovações de processo para a empresa podem ser desenvolvidas a partir da cooperação com fornecedores do mesmo país e com universidades estrangeiras de regiões desenvolvidas. A cooperação com universidades do exterior de países desenvolvidos, juntamente com a cooperação com concorrentes, também deve ser privilegiada quando se objetiva o desenvolvimento de inovações de processo para o mercado nacional. Por fim, se o objetivo é a inovação de processo com inovatividade para o mercado mundial, as parcerias com fornecedores do exterior, localizados em países desenvolvidos, são as mais relevantes. A Figura 4.4 apresenta uma síntese dos nossos resultados. 


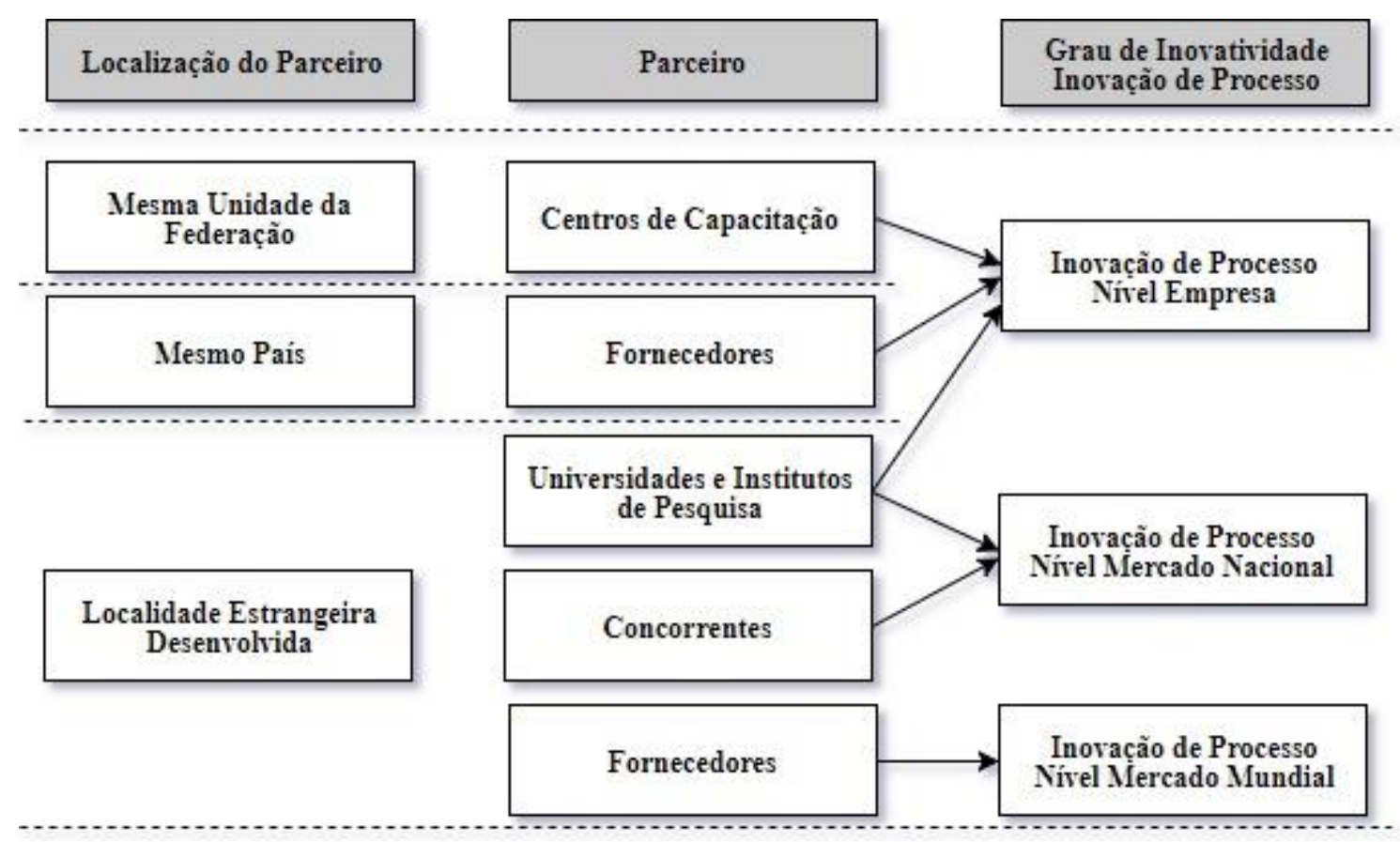

Figura 4.4. Visão Geral dos resultados.

Fonte: Elaborado pelo Autor.

Um primeiro aspecto, relacionado aos parceiros $S T I$, revelou que a cooperação nacional da mesma unidade da federal com centros de capacitação profissional e assistência técnica tem associação positiva com o desenvolvimento de inovação de processo, com grau de inovatividade para a empresa. Desse modo, ressaltamos o papel concernente aos centros de capacitação de atender à demanda, principalmente, de qualificação em pessoal para as atividades de ciência, tecnologia e inovação nas empresas (Fitjar \& Rodriguez-Pose, 2013). Portanto, esses atores representados pelo Sistema S no Brasil (Brasil, 2015) estão associados aos resultados incrementais de inovação, logo a associação consequente com a inovação de processo para a empresa. Nesse sentido, corrobora-se a importância dos agentes STI de mesma localidade (Barge-Gil et al., 2011) para o desenvolvimento de inovação de processo com caráter incremental.

O desenvolvimento de inovação a nível micro também se beneficia da cooperação com fornecedores localizados no mesmo país. Desse modo, reitera-se que a proximidade geográfica com os parceiros de cooperação modo DUI, sobretudo, que se estabelecem de forma vertical, como é caso dos fornecedores, é fundamental para o estabelecimento de relações interorganizacionais, como evidenciado na literatura (Su et al., 2009; Wagner \& Bode, 2014). Haja vista a necessidade de interação face a face e a recorrente transferência de conhecimento tácito, estar perto desses parceiros favorecem os resultados de inovação, inclusive de processo (Fitjar \& Rodriguez-Pose, 2013). Logo, fornecedores próximos geograficamente, em especifico 
no mesmo âmbito nacional é o que importa para inovação de processo com grau de novidade para a empresa.

As universidades e institutos de pesquisa, atores $S T I$, quando localizados no exterior em países desenvolvidos, assumem um duplo papel no desenvolvimento de inovação de processo, pois influenciam a inovação de processo tanto a nível empresa quanto a nível de mercado nacional. No entanto, a cooperação com esses parceiros é associada mais fortemente com a inovação de processo com grau de inovatividade para o mercado nacional (Tabela 4.2). Desse modo, esses achados contrapõem a perspectiva de que a proximidade geográfica é sempre necessária para a obtenção de resultados de inovação oriundos da cooperação orientada à ciência e à pesquisa (Bishop et al., 2011; D'Este et al., 2013; Ponds et al., 2007) e ao mesmo tempo reforça a importância da qualidade e reputação do parceiro que antecede à decisão de cooperar (Dornbusch \& Neuhausler, 2015). Desse modo, reitera-se que a natureza da cooperação com universidades e institutos de pesquisa tem como foco as pesquisas de fronteira em determinados campos da ciência, disso a associação com a inovação de processo com maior grau de inovatividade (D'Este \& Iammarino, 2010). Nessa perspectiva, os achados vão ao encontro da visão de Nishimura e Okamuro (2011), de que quanto mais parceiros universitários forem "buscados", inclusive internacionalmente (Hoekman, Frenken, \& Tijssen, 2010), maior será a probabilidade de encontrar um parceiro ideal, pois nem sempre um parceiro de pesquisa "de ponta" ideal está próximo geograficamente, quando se vislumbra índices elevados na inovatividade em processos.

Ainda no âmbito da inovação para o mercado nacional, os resultados demonstraram a associação positiva entre a parceria com concorrentes estrangeiros e a inovação de processo com esse grau de inovatividade. É reconhecido que os contextos institucionais dos países se diferem e impactam nos resultados de inovação (Gonzalez-Pernia et al., 2015; Su et al., 2009), logo, um ambiente institucional deficitário, que é realidade das economias emergentes, campo empírico do estudo (Frank, Cortimiglia, Ribeiro, \& Oliveira, 2016), reforça ainda mais a insegurança nas relações horizontais com concorrentes locais (Giovannetti \& Piga, 2017; Un \& Asakawa, 2015). Logo, eis aqui uma provável resposta para a associação positiva entre a localização estrangeira do parceiro concorrente e a inovação de processo para o mercado nacional. Pois, diante de um contexto institucional e regulatório ineficientes a busca por parcerias horizontais no exterior se mostra como uma oportunidade para aquelas empresas que buscam incrementar o seu processo produtivo, tendo acesso a recursos e tecnologias 
estrangeiros com concorrentes (Wang \& Li-Ying, 2015), dado o risco associado à cooperação com concorrentes nacionais.

Por fim, enquanto os fornecedores nacionais são importantes para a inovação de processo nível empresa, os fornecedores estrangeiros localizados em países desenvolvidos assumem outro papel para o desenvolvimento de inovação de processo. Afinal, esse tipo de parceria estrangeira potencializa o desenvolvimento de inovação de processo com grau de inovatividade para o mercado mundial. Nesse contexto, a idealização de que as relações com parceiros estrangeiros promovem acessos a melhores recursos e, consequentemente, a melhores resultados de inovação ou com maiores graus de inovatividade (Fitjar \& Rodriguez-Pose, 2013; van Beers \& Zand, 2014) se concretiza diante desses resultados, no que tange aos parceiros da cadeia de valor, especificamente fornecedores. Assim, ao passo que inovações de processos com maior grau de inovatividade demandam parcerias internacionais, o papel fundamental dos fornecedores no desenvolvimento de inovação de processo (Un \& Asakawa, 2015) é potencializado para níveis maiores de inovatividade quando se associa a uma parceria estrangeira e não tão somente nacional.

\subsection{CONSIDERAÇÕES FINAIS}

Diante do problema de pesquisa que se propôs avaliar se a localização do parceiro interorganizacional importa para a inovação de processo, os resultados demonstraram que a cooperação tanto com parceiros nacionais quanto estrangeiros é relevante, contudo com efeitos diferenciados sobre os diferentes graus de inovatividade da inovação de processo. Foi confirmado que a inovação de processo nível empresa é beneficiada pela cooperação com centros de capacitação localizados na mesma unidade da federação, com fornecedores do mesmo país e com universidades e institutos de pesquisa localizados no exterior em regiões desenvolvidas. Ainda, constatou-se que as parcerias internacionais com concorrentes estrangeiros, de países desenvolvidos, são relevantes para o desenvolvimento de inovação de processo com grau de inovatividade para o mercado nacional. Por fim, diante da busca por conhecimento e técnicas de produção de ponta, a cooperação com fornecedores estrangeiros é determinante para a inovação de processo com maior grau de inovatividade, revelando um duplo papel da localização de um mesmo parceiro (fornecedor).

Desse modo, esses resultados evidenciam contribuições para a literatura em diferentes dimensões. Primeiro, destaca-se o fato de adotar a classificação dos parceiros DUI e STI, 
individualizando o papel da localização de cada parceiro nacional e estrangeiro, portanto fora da dimensão geográfica somente nacional de pesquisas realizadas (Fitjar \& Rodriguez-Pose, 2013; Gonzalez-Pernia et al., 2015). Ademais, foi considerado como campo empírico um país emergente numa dinâmica longitudinal, diferente de estudos anteriores (Ponds et al., 2010; Su et al., 2009). Ademais, a principal contribuição do estudo consiste em evidenciar que a localização (próxima ou distante) dos parceiros é relevante para os resultados de inovação de processo das empresas, porém é determinada de forma heterogênea em função de cada tipo de parceiro e considerando diferentes graus de inovatividade (Un \& Asakawa, 2015). Portanto, o agrupamento indiscriminado dos atores na literatura (Chen, Chen, \& Vanhaverbeke, 2011) deve ser realizado com cautela, dado os distintos efeitos percebidos dos parceiros sobre os resultados de inovação de processo que se diferem da inovação de produto, quando se considera o fator localização. Por fim, em termos de contribuições para o contexto gerencial e de políticas públicas, o estudo apresenta como diferentes parceiros estão relacionados aos resultados de inovação de processos, permitindo a escolha de melhores parceiros de acordo com os objetivos de inovação; e para os governantes os resultados demonstram a importância do fortalecimento do ambiente institucional do sistema nacional de inovação, evidenciando a necessidade de ações públicas de incentivo à inovação que fomentem relações mais produtivas e mais seguras, fortalecendo os centros de capacitação profissional e assistência técnica.

Por fim, haja vista que nenhum esforço científico está livre de limitações, destaca-se principalmente o recorte adotado de analisar principalmente os efeitos da cooperação externa à organização sobre os resultados de inovação, no caso inovação de processo, e não um alinhamento com a capacidade interna de inovação das empresas. Ademais, como forma de amenizar tal de limitação foram consideradas como variáveis de controle atividades inovativas (P\&D interno, aquisição de máquinas e equipamentos e treinamento), que representam os esforços da empresa para a inovação em uma perspectiva interna. Como sugestões para futuras pesquisas, propõe-se a replicação da proposta aqui empreendida em outros contextos de países emergentes, a fim de validar os resultados encontrados e ao mesmo tempo consolidar um panorama consistente passível de comparação entre os efeitos da cooperação tanto em países emergentes quanto em países desenvolvidos. 


\section{CONCLUSÃO GERAL}

Diante da questão de pesquisa, Qual a associação entre as relações interorganizacionais com diferentes parceiros e os resultados de inovação?, os resultados dos três artigos desenvolvidos comprovaram a tese defendida nesta dissertação. De modo que foi evidenciado como a associação entre as relações interorganizacionais com diferentes parceiros e os resultados de inovação é heterogênea. No primeiro artigo, após a realização de um levantamento da literatura sobre a associação entre as relações interorganizacionais e os diferentes resultados de inovação, considerando campos de estudo subjacentes, tipos, objetos, parceiros e características das relações, foram evidenciadas diferentes constatações. Como exemplos, a cooperação com fornecedores tende a ser considerada a mais profícua dentre os parceiros de mercado (Du et al., 2014; Fitjar \& Rodriguez-Pose, 2013; Nieto \& Santamaria, 2007; Tomlinson \& Fai, 2013), enquanto alguns estudos evidenciaram a associação positiva da cooperação com clientes somente com a inovação de produto (Gesing et al., 2015) e, quanto aos concorrentes, foram identificados resultados positivos, negativos e nulos sobre os diferentes resultados de inovação (Bougrain \& Haudeville, 2002; Gonzalez-Pernia et al., 2015; Un \& Asakawa, 2015), demonstrando que há um campo que necessita de mais constatações empíricas. Por outro lado, o efeito da associação com universidades e institutos de pesquisa sobre os resultados de inovação é mais relevante dentre todos os parceiros identificados (Baba et al., 2009; Belderbos et al., 2006), o que se justifica, sobretudo, no suporte em uma literatura própria que tem sido desenvolvida e aprimorada (Geuna \& Muscio, 2009). Nesse intento, pesquisas futuras que analisem os diferentes intervenientes no processo de colaboração universidade e empresa também são bem-vindas (Perkmann \& Walsh, 2007).

Em relação à análise da relação entre os parceiros de cooperação e o desenvolvimento de imitação de produtos e de processos, foco do segundo artigo, a distinção entre a importância da cooperação com diferentes parceiros para os dois resultados de inovação considerados (produto e processo ao nível empresa) foi revelada. Considerando a imitação com passo inicial para a atualização tecnológica de empresas em economias emergentes (Kim, 1997), reiterou-se a tese de heterogeneidade, visto que que os parceiros de pesquisa e mercado tiveram uma importância diferenciada em relação à imitação de produto e de processo. Para os parceiros DUI, a cooperação com os fornecedores se apresentou negativa para a imitação de processo, a importância dos concorrentes teve relação negativa para a imitação de produto e a cooperação com clientes apresentou alta importância para a imitação de produto. Ou seja, dentro do próprio grupo de parceiros DUI foram identificadas relações diferentes com os tipos de imitação 
considerados. Já para os parceiros de STI, o destaque é dado aos centros de capacitação para o desenvolvimento da imitação de processo, o que não ocorre para a relação da cooperação com universidade e institutos de pesquisa para a imitação de produto. Nesse contex to, o alinhamento dos parceiros STI com inovações de menor grau de inovatividade, ou seja, imitação, está amparada pelas relações com centros de capacitação e não com universidades e institutos de pesquisa.

Por fim, ao analisar a relação entre a localização do parceiro e o desenvolvimento de inovação de processos, mais uma vez foi reforçada a tese de heterogeneidade proposta, visto que constatou-se que a localização distante (ou próxima) dos parceiros é relevante para os resultados de inovação de processos das empresas, porém é determinada de forma heterogênea em função de cada tipo de parceiro. Pois, foi confirmado que a cooperação com fornecedores assume distintas influências quando se considera diferentes dimensões de localização e diferentes graus de inovatividade, ampliando a perspectiva de estudos da área (Fitjar \& Rodriguez-Pose, 2013; Wagner \& Bode, 2014). Ao passo que os concorrentes estrangeiros, também parceiros DUI, apresentaram uma relação positiva não proposta com a inovação de processo ao nível mercado nacional, fato este que se justifica pela busca de segurança em ambientes externos, dada à fragilidade do contexto institucional de país emergente (Un \& Asakawa, 2015). Por outro lado, na análise do fator localização dos parceiros modo STI (universidades, institutos de pesquisa, centros de capacitação e assistência técnica) associada aos resultados de inovação de processo, mesmo com as especificidades da natureza dos atores desse grupo, foi reforçada a necessidade de localização próxima dos centros de capacitação e importância da qualidade do parceiro de pesquisa em detrimento exclusivamente da proximidade geográfica na relação com universidades e institutos de pesquisa (Dornbusch \& Neuhausler, 2015).

\subsection{LIMITAÇÕES E SUGESTÕES PARA FUTURAS PESQUISAS}

Como limitações do estudo desenvolvido destaca-se alguns aspectos. A unidade de análise dos artigos teórico-empíricos, setores empresariais brasileiros, pode ser considerada uma limitação, haja vista que permite uma análise agregada e não particular de um conjunto de empresas. Desse modo, o acesso aos microdados das empresas da PINTEC pode contextualizar novas características dos setores analisados, ao considerar o nível micro de empresa. Além disso, adotou-se somente cinco parceiros, classificados em dois grupos (DUI e STI), para a análise da importância da cooperação e do fator localização e não uma variedade maior apresentada na literatura. Esse fato se justifica em função da limitação da base de dados secundária utilizada, 
contudo, não diminui os achados encontrados, visto o suporte teórico e relevância dos parceiros selecionados identificados a partir da literatura. Por fim, o campo para pesquisas que busquem analisar a importância da cooperação com diferentes parceiros para os diferentes resultados de inovação encontra-se em aberto para novas constatações. Desse modo, novas análises podem vir a complementar a proposta deste estudo a partir de perspectivas comparativas em outras localidades, preferencialmente, economias emergentes. Além disso, outros intervenientes da associação entre relações interorganizacionais e inovação, com por exemplo o objeto da cooperação estabelecida e os efeitos dos resultados de inovação, oriundos de cooperação, sobre o desempenho organizacional, são perspectivas promissoras para pesquisas futuras. 


\section{REFERÊNCIAS}

Abernathy, W. J., \& Utterback, J. M. (1978). Patterns of industrial innovation. Technology Review, 80(7), 40-47.

Abramo, G., D'Angelo, C. A., Di Costa, F., \& Solazzi, M. (2011). The role of information asymmetry in the market for university-industry research collaboration. Journal of Technology Transfer, 36(1), 84-100. doi: 10.1007/s10961-009-9131-5

Alnuaimi, T., Opsahl, T., \& George, G. (2012). Innovating in the periphery: The impact of local and foreign inventor mobility on the value of Indian patents. Research Policy, 41(9), 1534-1543. doi: 10.1016/j.respol.2012.06.001

Arranz, N., \& de Arroyabe, J. C. F. (2012). Can innovation network projects result in efficient performance? Technological Forecasting and Social Change, 79(3), 485-497. doi: 10.1016/j.techfore.2011.09.003

Baba, Y., Shichijo, N., \& Sedita, S. R. (2009). How do collaborations with universities affect firms' innovative performance? The role of "Pasteur scientists" in the advanced materials field. Research Policy, 38(5), 756-764. doi: http://dx.doi.org/10.1016/j.respol.2009.01.006

Barajas, A., Huergo, E., \& Moreno, L. (2012). Measuring the economic impact of research joint ventures supported by the EU Framework Programme. Journal of Technology Transfer, 37(6), 917-942. doi: 10.1007/s10961-011-9222-y

Barge-Gil, A., Santamaría, L., \& Modrego, A. (2011). Complementarities Between Universities and Technology Institutes: New Empirical Lessons and Perspectives. European Planning Studies, 19(2), 195-215. doi: 10.1080/09654313.2011.532665

Becker, W., \& Dietz, J. (2004). R\&D cooperation and innovation activities of firms - Evidence for the German manufacturing industry. Research Policy, 33(2), 209-223. doi: 10.1016/j.respol.2003.07.003

Belderbos, R., Carree, M., Diederen, B., Lokshin, B., \& Veugelers, R. (2004). Heterogeneity in R\&D cooperation strategies. International Journal of Industrial Organization, 22(89), 1237-1263. doi: http://dx.doi.org/10.1016/j.ijindorg.2004.08.001

Belderbos, R., Carree, M., \& Lokshin, B. (2004). Cooperative R\&D and firm performance. Research Policy, 33(10), 1477-1492. doi: 10.1016/j.respol.2004.07.003 
Belderbos, R., Carree, M., \& Lokshin, B. (2006). Complementarity in R\&D Cooperation Strategies. Review of Industrial Organization, 28(4), 401-426. doi: 10.1007/s11151006-9102-z

Belderbos, R., Carree, M., Lokshin, B., \& Sastre, J. F. (2015). Inter-temporal patterns of R\&D collaboration and innovative performance. Journal of Technology Transfer, 40(1), 123137. doi: 10.1007/s10961-014-9332-4

Berbegal-Mirabent, J., Sánchez García, J. L., \& Ribeiro-Soriano, D. E. (2015). Universityindustry partnerships for the provision of R\&amp;D services. Journal of Business Research, 68(7), 1407-1413. doi: http://dx.doi.org/10.1016/j.jbusres.2015.01.023

Bishop, K., D'Este, P., \& Neely, A. (2011). Gaining from interactions with universities: Multiple methods for nurturing absorptive capacity. Research Policy, 40(1), 30-40. doi: 10.1016/j.respol.2010.09.009

Borini, F. M., Pereira, R. M., \& Rossetto, D. E. (2016). O Impacto da Cooperação com Parceiros de Mercado e de Pesquisa na Inovação de Produto e Processo das Empresas Brasileiras. Paper presented at the XL Encontro da ANPAD - EnANPAD 2016, Costa do Sauípe, BA.

Botelho, M. D. R. A., Oliveira, O. P. A. d., \& Carrijo, M. D. C. (2013). Cooperação e inovação - uma análise evolutiva para empresas de eletroeletrônicos do arranjo produtivo de Santa Rita do Sapucaí (MG). Revista de Economia e Administração, 12(4). doi: 10.11132/rea.2013.760

Bougrain, F., \& Haudeville, B. (2002). Innovation, collaboration and SMEs internai research capacities. Research Policy, 31(5), 735-747. doi: 10.1016/S0048-7333(01)00144-5

Brasil. (2015). Sistema $S$ é forte aliado do empresário na capacitação de trabalhadores. Brasília, DF: Portal Brasil Retrieved from http://www.brasil.gov.br/educacao/2012/02/sistema-s-e-estrutura-educacionalmantida-pela-industria.

Bruneel, J., D'Este, P., \& Salter, A. (2016). The impact of financial slack on explorative and exploitative knowledge sourcing from universities: evidence from the UK. Industrial and Corporate Change, 25(4), 689-706. doi: 10.1093/icc/dtv045

Buesa, M., Heijs, J., Pellitero, M. M., \& Baumert, T. (2006). Regional systems of innovation and the knowledge production function: the Spanish case. Technovation, 26(4), 463472. doi: http://dx.doi.org/10.1016/j.technovation.2004.11.007 
Bygballe, L. E., \& Ingemansson, M. (2014). The logic of innovation in construction. Industrial Marketing Management, 43(3), 512-524. doi: 10.1016/j.indmarman.2013.12.019

Calia, R. C., Guerrini, F. M., \& Moura, G. L. (2007). Innovation networks: From technological development to business model reconfiguration. Technovation, 27(8), 426-432. doi: http://dx.doi.org/10.1016/j.technovation.2006.08.003

Cappelli, R., Czarnitzki, D., \& Kraft, K. (2014). Sources of spillovers for imitation and innovation. Research Policy, 43(1), 115-120. doi: http://dx.doi.org/10.1016/j.respol.2013.07.016

Cefis, E., \& Marsili, O. (2012). Going, going, gone. Exit forms and the innovative capabilities of firms. Research Policy, 41(5), 795-807. doi: 10.1016/j.respol.2012.01.006

Cerqueti, R., Quaranta, A. G., \& Ventura, M. (2016). Innovation, imitation and policy inaction. Technological Forecasting and Social Change, 111, 22-30. doi: http://dx.doi.org/10.1016/j.techfore.2016.06.001

Cerqueti, R., Tramontana, F., \& Ventura, M. (2015). On the coexistence of innovators and imitators. Technological Forecasting and Social Change, 90, 487-496. doi: http://dx.doi.org/10.1016/j.techfore.2014.03.011

Chen, J., Chen, Y. F., \& Vanhaverbeke, W. (2011). The influence of scope, depth, and orientation of external technology sources on the innovative performance of Chinese firms. Technovation, 31(8), 362-373. doi: 10.1016/j.technovation.2011.03.002

Chen, Y. F., Vanhaverbeke, W., \& Du, J. S. (2016). The interaction between internal R\&D and different types of external knowledge sourcing: an empirical study of Chinese innovative firms. $R \& D$ Management, 46, 1006-1023. doi: 10.1111/radm.12162

Chesbrough, H. W. (2003). The Era of Open Innovation. MIT Sloan Management Review, $44(3), 34-41$.

Christensen, C. M. (1997). The Innovator's Dilemma: When New Technologies Cause Great Firms to Fail. Boston, Massachusetts: Harvard Business School Press.

Chung, S., \& Kim, G. M. (2003). Performance effects of partnership between manufacturers and suppliers for new product development: the supplier's standpoint. Research Policy, 32(4), 587-603. doi: http://dx.doi.org/10.1016/S0048-7333(02)00047-1 
Cohen, W. M., \& Levinthal, D. A. (1990). Absorptive Capacity: A New Perspective on Learning and Innovation. Administrative Science Quarterly, 35(1), 128-152. doi: $10.2307 / 2393553$

Cowan, R., \& Zinovyeva, N. (2013). University effects on regional innovation. Research Policy, 42(3), 788-800. doi: 10.1016/j.respol.2012.10.001

Cropper, S., Ebers, M., Huxham, C., \& Ring, P. S. (2008). The Oxford Handbook of Interorganizational Relations: Oxford University Press.

Crossan, M. M., \& Apaydin, M. (2010). A Multi-Dimensional Framework of Organizational Innovation: A Systematic Review of the Literature. Journal of Management Studies, 47(6), 1154-1191. doi: 10.1111/j.1467-6486.2009.00880.x

D'Este, P., Guy, F., \& Iammarino, S. (2013). Shaping the formation of university-industry research collaborations: what type of proximity does really matter? Journal of Economic Geography, 13(4), 537-558. doi: 10.1093/jeg/lbs010

D'Este, P., \& Iammarino, S. (2010). The spatial profile of university-business research partnerships. Papers in Regional Science, 89(2), 335-350. doi: 10.1111/j.14355957.2010.00292.x

Dahlander, L., \& Gann, D. M. (2010). How open is innovation? Research Policy, 39(6), 699709. doi: 10.1016/j.respol.2010.01.013

de Brentani, U. (2001). Innovative versus incremental new business services: different keys for achieving success. Journal of Product Innovation Management, 18(3), 169-187. doi: http://dx.doi.org/10.1016/S0737-6782(01)00071-6

Dornbusch, F., \& Neuhausler, P. (2015). Composition of inventor teams and technological progress - The role of collaboration between academia and industry. Research Policy, 44(7), 1360-1375. doi: 10.1016/j.respol.2015.04.003

Dosi, G. (1982). Technological paradigms and technological trajectories. Research Policy, 11(3), 147-162. doi: http://dx.doi.org/10.1016/0048-7333(82)90016-6

Drechsler, W., \& Natter, M. (2012). Understanding a firm's openness decisions in innovation. Journal of Business Research, 65(3), 438-445. doi: http://dx.doi.org/10.1016/j.jbusres.2011.11.003 
Du, J. S., Leten, B., \& Vanhaverbeke, W. (2014). Managing open innovation projects with science-based and market-based partners. Research Policy, 43(5), 828-840. doi: http://dx.doi.org/10.1016/j.respol.2013.12.008

Edquist, C. (1997). Systems of Innovation: Technologies, Institutions and Organizations. London: Pinter/Cassell Academic.

Edquist, C., \& Hommen, L. (1999). Systems of innovation: theory and policy for the demand side1. Technology in Society, 21(1), 63-79. doi: http://dx.doi.org/10.1016/S0160$\underline{791 X(98) 00037-2}$

Ernst, D. (2008). Asia's' Upgrading Through Innovation'Strategies and Global Innovation Networks: An Extension of Sanjaya Lall's Research Agenda.

Ettlie, J. E., \& Reza, E. M. (1992). Organizational Integration and Process Innovation. The Academy of Management Journal, 35(4), 795-827. doi: 10.2307/256316

Etzkowitz, H., \& Leydesdorff, L. (2000). The dynamics of innovation: from National Systems and "Mode 2" to a Triple Helix of university-industry-government relations. Research Policy, 29(2), 109-123. doi: http://dx.doi.org/10.1016/S0048-7333(99)00055-4

Fagerberg, J., Mowery, D., \& Nelson, R. (2004). The Oxford Handbook of Innovation. Oxford: Oxford University Press.

Faria, P. d., Lima, F., \& Santos, R. (2010). Cooperation in innovation activities: The importance of partners. Research Policy, 39(8), 1082-1092. doi: 10.1016/j.respol.2010.05.003

Fastoso, F., \& Whitelock, J. (2010). Regionalization vs. globalization in advertising research: Insights from five decades of academic study. Journal of International Management, 16(1), 32-42. doi: http://dx.doi.org/10.1016/j.intman.2009.02.005

Fávero, L. P. (2015). Análise de dados: modelos de regressão com Excel®, Stata® e SPSS®. Rio de Janeiro: Campus Elsevier.

Fey, C. F., \& Birkinshaw, J. (2005). External Sources of Knowledge, Governance Mode, and R\&D Performance. Journal of Management, 31(4), 597-621. doi: $10.1177 / 0149206304272346$

Fitjar, R. D., \& Rodriguez-Pose, A. (2013). Firm collaboration and modes of innovation in Norway. Research Policy, 42(1), 128-138. doi: 10.1016/j.respol.2012.05.009 
Fossas-Olalla, M., Minguela-Rata, B., López-Sánchez, J.-I., \& Fernández-Menéndez, J. (2015). Product innovation: When should suppliers begin to collaborate? Journal of Business Research, 68(7), 1404-1406. doi: http://dx.doi.org/10.1016/j.jbusres.2015.01.022

Frank, A. G., Cortimiglia, M. N., Ribeiro, J. L. D., \& Oliveira, L. S. d. (2016). The effect of innovation activities on innovation outputs in the Brazilian industry: Market-orientation vs. technology-acquisition strategies. Research Policy, 45(3), 577-592. doi: http://dx.doi.org/10.1016/j.respol.2015.11.011

Freel, M., \& de Jong, J. P. J. (2009). Market novelty, competence-seeking and innovation networking. Technovation, 29(12), 873-884. doi: 10.1016/j.technovation.2009.07.005

Freeman, C. (1987). Technology Policy and Economic Performance: Lessons from Japan. London: Printer.

Freeman, C. (1991). Innovation, Changes of Techno-Economic Paradigm and Biological Analogies in Economics. Revue Économique, 42(2), 211-231. doi: 10.2307/3502005

Fu, X., Pietrobelli, C., \& Soete, L. (2011). The Role of Foreign Technology and Indigenous Innovation in the Emerging Economies: Technological Change and Catching-up. World Development, 39(7), 1204-1212. doi: http://dx.doi.org/10.1016/j.worlddev.2010.05.009

Fukugawa, N. (2013). University spillovers into small technology-based firms: channel, mechanism, and geography. Journal of Technology Transfer, 38(4), 415-431. doi: 10.1007/s10961-012-9247-x

Galanakis, K. (2006). Innovation process. Make sense using systems thinking. Technovation, 26(11), 1222-1232. doi: 10.1016/j.technovation.2005.07.002

Garcia, R., \& Calantone, R. (2002). A critical look at technological innovation typology and innovativeness terminology: a literature review. Journal of Product Innovation Management, 19(2), 110-132. doi: http://dx.doi.org/10.1016/S0737-6782(01)00132-1

Gelsing, L. E. (1992). Innovation and the development of industrial networks. In B.-A. Lundvall (Ed.), National systems of innovations: Towards a theory of innovation and interactive learning. London: Anthem Press.

George, G., Zahra, S. A., \& Wood Jr, D. R. (2002). The effects of business-university alliances on innovative output and financial performance: a study of publicly traded biotechnology companies. Journal of Business Venturing, 17(6), 577-609. doi: http://dx.doi.org/10.1016/S0883-9026(01)00069-6 
Gereffi, G., Humphrey, J., \& Sturgeon, T. (2005). The governance of global value chains. Review of international political economy, 12(1), 78-104.

Gesing, J., Antons, D., Piening, E. P., Rese, M., \& Salge, T. O. (2015). Joining Forces or Going It Alone? On the Interplay among External Collaboration Partner Types, Interfirm Governance Modes, and Internal R\&D. Journal of Product Innovation Management, 32(3), 424-440. doi: 10.1111/jpim.12227

Geuna, A., \& Muscio, A. (2009). The Governance of University Knowledge Transfer: A Critical Review of the Literature. Minerva, 47(1), 93-114. doi: 10.1007/s11024-0099118-2

Giovannetti, E., \& Piga, C. A. (2017). The contrasting effects of active and passive cooperation on innovation and productivity: Evidence from British local innovation networks. International Journal of Production Economics, 187(Supplement C), 102-112. doi: https://doi.org/10.1016/j.ijpe.2017.02.013

Giroud, A., Jindra, B., \& Marek, P. (2012). Heterogeneous FDI in Transition Economies - A Novel Approach to Assess the Developmental Impact of Backward Linkages. World Development, $\quad 40(11), \quad 2206-2220 . \quad$ doi: http://dx.doi.org/10.1016/j.worlddev.2012.03.018

Gnyawali, D. R., \& Park, B.-J. (2011). Co-opetition between giants: Collaboration with competitors for technological innovation. Research Policy, 40(5), 650-663. doi: 10.1016/j.respol.2011.01.009

Gonzalez-Pernia, J. L., Parrilli, M. D., \& Pena-Legazkue, I. (2015). STI-DUI learning modes, firm- university collaboration and innovation. Journal of Technology Transfer, 40(3), 475-492. doi: 10.1007/s10961-014-9352-0

Grabher, G., \& Ibert, O. (2014). Distance as asset? Knowledge collaboration in hybrid virtual communities. Journal of Economic Geography, 14(1), 97-123. doi: 10.1093/jeg/lbt014

Greer, C. R., \& Lei, D. (2012). Collaborative Innovation with Customers: A Review of the Literature and Suggestions for Future Research. International Journal of Management Reviews, 14(1), 63-84. doi: 10.1111/j.1468-2370.2011.00310.x

Guan, J. C., \& Liu, N. (2016). Exploitative and exploratory innovations in knowledge network and collaboration network: A patent analysis in the technological field of nano-energy. Research Policy, 45(1), 97-112. doi: 10.1016/j.respol.2015.08.002 
Guan, J. C., Zuo, K. R., Chen, K. H., \& Yam, R. C. M. (2016). Does country-level R\&D efficiency benefit from the collaboration network structure? Research Policy, 45(4), 770-784. doi: 10.1016/j.respol.2016.01.003

Gujarati, D. N., \& Porter, D. C. (2011). Econometria Básica (5 ed.). São Paulo: AMGH Editora Ltda.

Hagedoorn, J. (1993). Understanding the rationale of strategic technology partnering: Nterorganizational modes of cooperation and sectoral differences. Strategic Management Journal, 14(5), 371-385. doi: 10.1002/smj.4250140505

Hagedoorn, J., Link, A. N., \& Vonortas, N. S. (2000). Research partnerships. Research Policy, 29(4-5), 567-586. doi: 10.1016/s0048-7333(99)00090-6

Hall, B. H., Link, A. N., \& Scott, J. T. (2003). Universities as Research Partners. The Review of Economics and Statistics, 85(2), 485-491.

Hewitt-Dundas, N. (2013). The role of proximity in university-business cooperation for innovation. Journal of Technology Transfer, 38(2), 93-115. doi: 10.1007/s10961-0119229-4

Hobday, M. (1995). East Asian latecomer firms: Learning the technology of electronics. World Development, 23(7), 1171-1193. doi: http://dx.doi.org/10.1016/0305-750X(95)00035$\underline{\mathrm{B}}$

Hoegl, M., \& Wagner, S. M. (2005). Buyer-Supplier Collaboration in Product Development Projects. Journal of Management, 31(4), 530-548. doi: 10.1177/0149206304272291

Hoekman, J., Frenken, K., \& Tijssen, R. J. W. (2010). Research collaboration at a distance: Changing spatial patterns of scientific collaboration within Europe. Research Policy, 39(5), 662-673. doi: http://doi.org/10.1016/j.respol.2010.01.012

Hoekman, J., Frenken, K., \& van Oort, F. (2009). The geography of collaborative knowledge production in Europe. The Annals of Regional Science, 43(3), 721-738. doi: $10.1007 / \mathrm{s} 00168-008-0252-9$

Hofman, E., Halman, J. I. M., \& van Looy, B. (2016). Do design rules facilitate or complicate architectural innovation in innovation alliance networks? Research Policy, 45(7), 14361448. doi: 10.1016/j.respol.2016.04.001 
Huang, K. F., \& Yu, C. M. J. (2011). The effect of competitive and non-competitive R\&D collaboration on firm innovation. Journal of Technology Transfer, 36(4), 383-403. doi: 10.1007/s10961-010-9155-X

Huggins, R. (1998). Local Business Co-operation and Training and Enterprise Councils: The Development of Inter-firm Networks. Regional Studies, 32(9), 813-826. doi: 10.1080/00343409850117979

Huggins, R. (2010). Forms of network resource: Knowledge access and the role of inter-firm networks. International Journal of Management Reviews. doi: 10.1111/j.14682370.2009.00266.x

Ibert, O., \& Muller, F. C. (2015). Network dynamics in constellations of cultural differences: Relational distance in innovation processes in legal services and biotechnology. Research Policy, 44(1), 181-194. doi: 10.1016/j.respol.2014.07.016

IBGE, P. (2014). Pesquisa de Inovação (PINTEC). Rio de Janeiro: IBGE.

IEDI. (2016). A Nova PINTEC: um quadro pouco animador. São Paulo: IEDI - Instituto de Estudos para o Desenvolvimento Industrial.

Jaklič, A., Damijan, J. P., Rojec, M., \& Kunčič, A. (2014). Relevance of innovation cooperation for firms' innovation activity: the case of Slovenia. Economic Research-Ekonomska Istraživanja, 27(1), 645-661. doi: 10.1080/1331677x.2014.975513

Jenkins, M. (2014). Innovate or Imitate? The Role of Collective Beliefs in Competences in Competing Firms. Long Range Planning, 47(4), 173-185. doi: http://dx.doi.org/10.1016/j.lrp.2013.04.001

Jensen, M. B., Johnson, B., Lorenz, E., \& Lundvall, B. Å. (2007). Forms of knowledge and modes of innovation. Research Policy, 36(5), 680-693. doi: https://doi.org/10.1016/j.respol.2007.01.006

Kaufmann, A., \& Tödtling, F. (2001). Science-industry interaction in the process of innovation: The importance of boundary-crossing between systems. Research Policy, 30(5), 791804. doi: http://dx.doi.org/10.1016/S0048-7333(00)00118-9

Kim, L. (1997). Imitação à inovação: a dinâmica da aprendizagem tecnológica da Coréia. Boston: Harvard Business School Press.

Koufteros, X., Vickery, S. K., \& Dröge, C. (2012). The Effects of Strategic Supplier Selection on Buyer Competitive Performance in Matched Domains: Does Supplier Integration 
Mediate the Relationships? Journal of Supply Chain Management, 48(2), 93-115. doi: 10.1111/j.1745-493X.2012.03263.x

Laursen, K., Reichstein, T., \& Salter, A. (2011). Exploring the Effect of Geographical Proximity and University Quality on University-Industry Collaboration in the United Kingdom. Regional Studies, 45(4), 507-523. doi: 10.1080/00343400903401618

Laursen, K., \& Salter, A. (2006). Open for innovation: the role of openness in explaining innovation performance among U.K. manufacturing firms. Strategic Management Journal, 27(2), 131-150. doi: 10.1002/smj.507

Levén, P., Holmström, J., \& Mathiassen, L. (2014). Managing research and innovation networks: Evidence from a government sponsored cross-industry program. Research Policy, 43(1), 156-168. doi: 10.1016/j.respol.2013.08.004

Linton, J. D., \& Thongpapanl, N. (2004). PERSPECTIVE: Ranking the Technology Innovation Management Journals. Journal of Product Innovation Management, 21(2), 123-139. doi: 10.1111/j.0737-6782.2004.00062.x

Lundvall, B.-A. (1988). From user-producer interaction to the national system of innovation. In B.-A. Lundvall (Ed.), Technical Change and Economic Theory. London: Printer.

Lundvall, B.-A. (1992a). National Systems of Innovation. Towards a Theory of Innovation and Interactive Learning. London: Pinter Publishers.

Lundvall, B.-A. (1992b). User-producer relationships, national systems of innovation and internationalisation. In B.-A. Lundvall (Ed.), National Systems of Innovation : Towards a Theory of Innovation and Interactive Learning (pp. 47-70). London: Anthem Press.

Mahroum, S., \& Al-Saleh, Y. (2013). Towards a functional framework for measuring national innovation efficacy. Technovation, 33(10-11), 320-332. doi: http://dx.doi.org/10.1016/j.technovation.2013.03.013

Manfredi, S. M. (2017). Educação profissional no Brasil: Paco Editorial.

Martin, B. R. (2012). The evolution of science policy and innovation studies. Research Policy, 41(7), 1219-1239. doi: https://doi.org/10.1016/j.respol.2012.03.012

Marxt, C., \& Link, P. (2002). Success factors for cooperative ventures in innovation and production systems. International Journal of Production Economics, 77(3), 219-229. doi: https://doi.org/10.1016/S0925-5273(01)00197-9 
Michailova, S., \& Mustaffa, Z. (2012). Subsidiary knowledge flows in multinational corporations: Research accomplishments, gaps, and opportunities. Journal of World Business, 47(3), 383-396. doi: http://dx.doi.org/10.1016/j.jwb.2011.05.006

Miotti, L., \& Sachwald, F. (2003). Co-operative R\&D: why and with whom? Research Policy, 32(8), 1481-1499. doi: 10.1016/s0048-7333(02)00159-2

Nelson, R. R. (1993). National Innovation Systems: A Comparative Study. New York: Oxford University Press.

Nielsen, H. (2010). Universities in Regional Systems of Innovation: Has the Rural Research Center in Höfn Enhanced the Interaction between the University and Local Actors? (Master), Lund University, Suécia.

Nieto, M. J., \& Santamaria, L. (2007). The importance of diverse collaborative networks for the novelty of product innovation. Technovation, 27(6-7), 367-377. doi: http://dx.doi.org/10.1016/j.technovation.2006.10.001

Nishimura, J., \& Okamuro, H. (2011). R\&D productivity and the organization of cluster policy: an empirical evaluation of the Industrial Cluster Project in Japan. Journal of Technology Transfer, 36(2), 117-144. doi: 10.1007/s10961-009-9148-9

Öberg, C., \& Shih, T. T.-Y. (2014). Divergent and convergent logic of firms: Barriers and enablers for development and commercialization of innovations. Industrial Marketing Management, 43(3), 419-428. doi: 10.1016/j.indmarman.2013.12.010

OECD. (1997). National Innovation Systems. Paris: OECD Publications.

OECD. (2005). Organisation for Economic Co-operation and Development. Manual de Oslo Diretrizes para coleta e interpretação de dados sobre inovação (3 ed.): FINEP Financiadora de Estudos e Projetos.

Okamuro, H., \& Nishimura, J. (2013). Impact of university intellectual property policy on the performance of university-industry research collaboration. Journal of Technology Transfer, 38(3), 273-301. doi: 10.1007/s10961-012-9253-z

Owen-Smith, J., \& Powell, W. W. (2004). Knowledge Networks as Channels and Conduits: The Effects of Spillovers in the Boston Biotechnology Community. Organization Science, 15(1), 5-21. doi: 10.1287/orsc.1030.0054 
Pan, X., \& Li, S. (2016). Dynamic optimal control of process-product innovation with learning by doing. European Journal of Operational Research, 248(1), 136-145. doi: http://dx.doi.org/10.1016/j.ejor.2015.07.007

Perkmann, M., \& Walsh, K. (2007). University-industry relationships and open innovation: Towards a research agenda. International Journal of Management Reviews, 9(4), 259280. doi: 10.1111/j.1468-2370.2007.00225.x

Pittaway, L., Robertson, M., Munir, K., Denyer, D., \& Neely, A. (2004). Networking and innovation: a systematic review of the evidence. International Journal of Management Reviews, 56(3 \& 4), 137-168.

Ponds, R., Oort, F. v., \& Frenken, K. (2010). Innovation, spillovers and university-industry collaboration: an extended knowledge production function approach. Journal of Economic Geography, 10(2), 231-255. doi: 10.1093/jeg/lbp036

Ponds, R., Van Oort, F., \& Frenken, K. (2007). The geographical and institutional proximity of research collaboration. Papers in Regional Science, 86(3), 423-443. doi: 10.1111/j.1435-5957.2007.00126.x

Powell, W. W., Koput, K. W., \& Smith-Doerr, L. (1996). Interorganizational Collaboration and the Locus of Innovation: Networks of Learning in Biotechnology. Administrative Science Quarterly, 41(1), 116-145. doi: 10.2307/2393988

Purchase, S., Olaru, D., \& Denize, S. (2014). Innovation network trajectories and changes in resource bundles. Industrial Marketing Management, 43(3), 448-459. doi: 10.1016/j.indmarman.2013.12.013

Quandt, C. O. (2012). Redes de Cooperação e Inovação Localizada: Estudo de Caso de um Arranjo Produtivo Local. Review of Administration and Innovation - RAI, 1(1). doi: 10.5773/rai.v1i1.674

Radosevic, S., \& Yoruk, E. (2016). Why do we need a theory and metrics of technology upgrading? Asian Journal of Technology Innovation, 24(sup1), 8-32. doi: 10.1080/19761597.2016.1207415

Ratinho, T., Harms, R., \& Walsh, S. (2015). Structuring the Technology Entrepreneurship publication landscape: Making sense out of chaos. Technological Forecasting and Social Change, 100, 168-175. doi: http://dx.doi.org/10.1016/j.techfore.2015.05.004

Rawhouser, H., Villanueva, J., \& Newbert, S. L. (2016). Strategies and Tools for Entrepreneurial Resource Access: A Cross-disciplinary Review and Typology. International Journal of Management Reviews, n/a-n/a. doi: 10.1111/ijmr.12105 
Reichstein, T., \& Salter, A. (2006). Investigating the sources of process innovation among UK manufacturing firms. Industrial and Corporate Change, 15(4), 653-682. doi: 10.1093/icc/dt1014

Roberts, D. L., \& Candi, M. (2014). Leveraging Social Network Sites in New Product Development: Opportunity or Hype? Journal of Product Innovation Management, 31, 105-117. doi: 10.1111/jpim.12195

Robertson, P. L., Casali, G. L., \& Jacobson, D. (2012). Managing open incremental process innovation: Absorptive Capacity and distributed learning. Research Policy, 41(5), 822832. doi: https://doi.org/10.1016/j.respol.2012.02.008

Robin, S., \& Schubert, T. (2013). Cooperation with public research institutions and success in innovation: Evidence from France and Germany. Research Policy, 42(1), 149-166. doi: 10.1016/j.respol.2012.06.002

Romijn, H., \& Albaladejo, M. (2002). Determinants of innovation capability in small electronics and software firms in southeast England. Research Policy, 31(7), 10531067. doi: https://doi.org/10.1016/S0048-7333(01)00176-7

Rosenberg, N. (1982). Inside the Black Box. Cambridge, MA: Cambridge University Press.

Rothwell, R. (1994). Towards the Fifth-generation Innovation Process. International Marketing Review, 11(1), 7-31. doi: doi:10.1108/02651339410057491

Scandura, A. (2016). University-industry collaboration and firms' R\&D effort. Research Policy, 45(9), 1907-1922. doi: 10.1016/j.respol.2016.06.009

Schøtt, T., \& Jensen, K. W. (2016). Firms' innovation benefiting from networking and institutional support: A global analysis of national and firm effects. Research Policy, 45(6), 1233-1246. doi: 10.1016/j.respol.2016.03.006

Schumpeter, J. A. (1912). Theorie der Wirtschaftlichen Entwicklung [The Theory of Economic Development]. Cambridge: Harvard University Press.

Schumpeter, J. A. (1982). A Teoria do Desenvolvimento Econômico. São Paulo: Abril Cultural.

Schwartz, M., Peglow, F., Fritsch, M., \& Gunther, J. (2012). What drives innovation output from subsidized R\&D cooperation?-Project-level evidence from Germany. Technovation, 32(6), 358-369. doi: 10.1016/j.technovation.2012.03.004 
Segarra-Blasco, A., \& Arauzo-Carod, J. M. (2008). Sources of innovation and industryuniversity interaction: Evidence from Spanish firms. Research Policy, 37(8), 12831295. doi: 10.1016/j.respol.2008.05.003

Soh, P. H., \& Subramanian, A. M. (2014). When do firms benefit from university-industry R\&D collaborations? The implications of firm R\&D focus on scientific research and technological recombination. Journal of Business Venturing, 29(6), 807-821. doi: 10.1016/j.jbusvent.2013.11.001

Soosay, C. A., Hyland, P. W., \& Ferrer, M. (2008). Supply chain collaboration: Capabilities for continuous innovation. Supply Chain Management: An International Journal, 13(2), 160-169. doi: 10.1108/13598540810860994

Sorenson, O., Rivkin, J. W., \& Fleming, L. (2006). Complexity, networks and knowledge flow. Research Policy, 35(7), 994-1017. doi: 10.1016/j.respol.2006.05.002

Storbacka, K., \& Nenonen, S. (2015). Learning with the market: Facilitating market innovation. Industrial Marketing Management, 44, 73-82. doi: 10.1016/j.indmarman.2014.10.009

Su, Y.-S., Tsang, E. W. K., \& Peng, M. W. (2009). How do internal capabilities and external partnerships affect innovativeness? Asia Pacific Journal of Management, 26(2), 309331. doi: 10.1007/s10490-008-9114-3

Sun, Y., \& Cao, C. (2015). Intra- and inter-regional research collaboration across organizational boundaries: Evolving patterns in China. Technological Forecasting and Social Change, 96, 215-231. doi: http://dx.doi.org/10.1016/j.techfore.2015.03.013

Tether, B. S. (2002). Who co-operates for innovation, and why: An empirical analysis. Research Policy, 31(6), 947-967. doi: http://dx.doi.org/10.1016/S0048-7333(01)00172$\underline{X}$

Thongpapanl, N. (2012). The changing landscape of technology and innovation management: An updated ranking of journals in the field. Technovation, 32(5), 257-271. doi: http://dx.doi.org/10.1016/j.technovation.2012.01.001

Thorgren, S., Wincent, J., \& Ortqvist, D. (2009). Designing interorganizational networks for innovation: An empirical examination of network configuration, formation and governance. Journal of Engineering and Technology Management, 26(3), 148-166. doi: 10.1016/j.jengtecman.2009.06.006

Tidd, B., Bessant, J., \& Pavitt, K. (2008). Gestão da Inovação (3 ed. ed.). Porto Alegre: Bookman,. 
Tödtling, F., \& Trippl, M. (2005). One size fits all?: Towards a differentiated regional innovation policy approach. Research Policy, 34(8), 1203-1219. doi: https://doi.org/10.1016/j.respol.2005.01.018

Tomlinson, P. R., \& Fai, F. M. (2013). The nature of SME co-operation and innovation: A multi-scalar and multi-dimensional analysis. International Journal of Production Economics, 141(1), 316-326. doi: http://dx.doi.org/10.1016/j.ijpe.2012.08.012

Tranfield, D., Denyer, D., \& Smart, P. (2003). Towards a Methodology for Developing Evidence-Informed Management Knowledge by Means of Systematic Review. British Journal of Management, 14(3), 207-222. doi: 10.1111/1467-8551.00375

Tsai, K. H. (2009). Collaborative networks and product innovation performance: Toward a contingency perspective. Research Policy, 38(5), 765-778. doi: 10.1016/j.respol.2008.12.012

Un, C. A., \& Asakawa, K. (2015). Types of R\&D Collaborations and Process Innovation: The Benefit of Collaborating Upstream in the Knowledge Chain. Journal of Product Innovation Management, 32(1), 138-153. doi: 10.1111/jpim.12229

Un, C. A., Cuervo-Cazurra, A., \& Asakawa, K. (2010). R\&D Collaborations and Product Innovation. Journal of Product Innovation Management, 27(5), 673-689. doi: 10.1111/j.1540-5885.2010.00744.x

Utterback, J. M. (1994). Mastering The Dynamics Of Innovation. Boston: Harvard Business School Press.

Utterback, J. M., \& Abernathy, W. J. (1975). A dynamic model of process and product innovation. Omega, 3(6), 639-656. doi: https://doi.org/10.1016/0305-0483(75)90068-7

van Beers, C., \& Zand, F. (2014). R\&D Cooperation, Partner Diversity, and Innovation Performance: An Empirical Analysis. Journal of Product Innovation Management, 31(2), 292-312. doi: 10.1111/jpim.12096

Van de Ven, A. H. (1986). Central problems in the management of innovation. Management Science, 32(5), 590.

Van Echtelt, F. E. A., Wynstra, F., Van Weele, A. J., \& Duysters, G. (2008). Managing Supplier Involvement in New Product Development: A Multiple-Case Study*. Journal of Product Innovation Management, 25(2), 180-201. doi: 10.1111/j.15405885.2008.00293.x 
Von Hippel, E. (2005). Democratizing innovation: MIT press.

Wagner, S. M., \& Bode, C. (2014). Supplier relationship-specific investments and the role of safeguards for supplier innovation sharing. Journal of Operations Management, 32(3), 65-78. doi: http://dx.doi.org/10.1016/j.jom.2013.11.001

Wang, F., Fu, X., \& Chen, J. I. N. (2013). DIFFERENTIAL FORMS OF TECHNOLOGICAL CHANGE AND CATCH-UP: EVIDENCE FROM CHINA. International Journal of Innovation and Technology Management, 11(02), 1450013. doi: $10.1142 / \mathrm{S} 0219877014500138$

Wang, Y., \& Li-Ying, J. (2015). Licensing Foreign Technology and the Moderating Role of Local R\&D Collaboration: Extending the Relational View. Journal of Product Innovation Management, 32(6), 997-1013. doi: 10.1111/jpim.12246

West, J., \& Bogers, M. (2014). Leveraging External Sources of Innovation: A Review of Research on Open Innovation. Journal of Product Innovation Management, 31(4), 814831. doi: 10.1111/jpim.12125

Wonglimpiyarat, J. (2011). The dynamics of financial innovation system. The Journal of High Technology Management Research, 22(1), 36-46. doi: http://dx.doi.org/10.1016/j.hitech.2011.03.003

Xu, K., \& Li, X. (2014). Technological innovation from imitation in latecomer firms: evidence from China's auto firms. Innovation and Development, 4(1), 161-173. doi: $10.1080 / 2157930 X .2014 .886815$

Yeo, W., Kim, S., Park, H., \& Kang, J. (2015). A bibliometric method for measuring the degree of technological innovation. Technological Forecasting and Social Change, 95(Supplement C), 152-162. doi: https://doi.org/10.1016/j.techfore.2015.01.018

Zeng, S. X., Xie, X. M., \& Tam, C. M. (2010). Relationship between cooperation networks and innovation performance of SMEs. Technovation, 30(3), 181-194. doi: 10.1016/j.technovation.2009.08.003

Zhou, K. Z. (2006). Innovation, imitation, and new product performance: The case of China. Industrial Marketing Management, 35(3), 394-402. doi: http://dx.doi.org/10.1016/j.indmarman.2005.10.006 
ANEXO A - Setores da Classificação Nacional de Atividades Econômicas

\begin{tabular}{|c|c|}
\hline ID & SETOR \\
\hline 1 & B INDÚSTRIAS EXTRATIVAS \\
\hline 2 & 10 FABRICAÇÃO DE PRODUTOS ALIMENTÍCIOS \\
\hline 3 & 11 FABRICAÇÃO DE BEBIDAS \\
\hline 4 & 12 FABRICAÇÃO DE PRODUTOS DO FUMO \\
\hline 5 & 13 FABRICAÇÃO DE PRODUTOS TÊXTEIS \\
\hline 6 & 14 CONFECÇÃO DE ARTIGOS DO VESTUÁRIO E ACESSÓRIOS \\
\hline 7 & $\begin{array}{l}15 \text { PREPARAÇÃO DE COUROS E FABRICAÇÃO DE ARTEFATOS DE COURO, } \\
\text { ARTIGOS PARA VIAGEM E CALÇADOS }\end{array}$ \\
\hline 8 & 16 FABRICAÇÃO DE PRODUTOS DE MADEIRA \\
\hline 9 & $\begin{array}{l}\text { 17.1 FABRICAÇÃO DE CELULOSE E OUTRAS PASTAS PARA A FABRICAÇÃO DE } \\
\text { PAPEL }\end{array}$ \\
\hline 10 & $\begin{array}{l}\text { 17.D FABRICAÇÃO DE PAPEL, EMBALAGENS E ARTEFATOS DE PAPEL (17.2 E } 17.3 \\
\text { E 17.4) }\end{array}$ \\
\hline 11 & $\begin{array}{l}\text { 19.D FABRICAÇÃO DE COQUE E BIOCOMBUSTÍVEIS (ÁLCOOL E OUTROS) (19.1 E } \\
\text { 19.3) }\end{array}$ \\
\hline 12 & 19.2 FABRICAÇÃO DE PRODUTOS DERIVADOS DO PETRÓLEO \\
\hline 13 & 20 FABRICAÇÃO DE PRODUTOS QUÍMICOS \\
\hline 14 & 21 FABRICAÇÃO DE PRODUTOS FARMOQUÍMICOS E FARMACÊUTICOS \\
\hline 15 & 22 FABRICAÇÃO DE PRODUTOS DE BORRACHA E DE MATERIAL PLÁSTICO \\
\hline 16 & 23 FABRICAÇÃO DE PRODUTOS DE MINERAIS NÃO-METÁLICOS \\
\hline 17 & 24.A PRODUTOS SIDERÚRGICOS (24.1 E 24.2 E 24.3) \\
\hline 18 & 24.D METALURGIA DE METAIS NÃO-FERROSOS E FUNDIÇÃO (24.4 E 24.5) \\
\hline 19 & $\begin{array}{l}\text { 25 FABRICAÇÃO DE PRODUTOS DE METAL, EXCETO MÁQUINAS E } \\
\text { EQUIPAMENTOS }\end{array}$ \\
\hline 20 & 26.1 FABRICAÇÃO DE COMPONENTES ELETRÔNICOS \\
\hline 21 & 26.A FABRICAÇÃO DE EQUIPAMENTOS DE COMUNICAÇÃO (26.3 E 26.4) \\
\hline 22 & 28 FABRICAÇÃO DE MÁQUINAS E EQUIPAMENTOS \\
\hline 23 & $\begin{array}{l}\text { 29.A FABRICAÇÃO DE AUTOMÓVEIS, CAMINHONETAS E UTILITÁRIOS, } \\
\text { CAMINHÔES E ÔNIBUS (29.1 E 29.2) }\end{array}$ \\
\hline 24 & 29.4 FABRICAÇÃO DE PEÇAS E ACESSÓRIOS PARA VEÍCULOS AUTOMOTORES \\
\hline 25 & $\begin{array}{l}\text { 29.D FABRICAÇÃO DE CABINES, CARROCERIAS, REBOQUES E } \\
\text { RECONDICIONAMENTO DE MOTORES (29.3 E 29.5) }\end{array}$ \\
\hline 26 & $\begin{array}{l}\text { 30 FABRICAÇÃO DE OUTROS EQUIPAMENTOS DE TRANSPORTE, EXCETO } \\
\text { VEÍCULOS AUTOMOTORES }\end{array}$ \\
\hline 27 & 31 FABRICAÇÃO DE MÓVEIS \\
\hline 28 & 32 FABRICAÇÃO DE PRODUTOS DIVERSOS \\
\hline
\end{tabular}

